\title{
"How can you love a work, if you don't know it?": \\ Critical Code and Design toward Participatory Digital Editions
}

Dissertation whitepaper by Amanda Visconti for dissertation.AmandaVisconti.com

\section{Section 1: Introduction}

1.1 Thinking through design and code

1.2 The humanities, public and participatory

1.3 Hypertextual and digital approaches to Ulysses

1.4 An introduction to the Infinite Ulysses digital edition

Section 2: Public participation in digital editions

2.1 What is critical public engagement?

2.2 Should participatory digital editions always aim for critical public engagement?

2.3 Non-critical but useful public engagement paths

2.4 Non-academic online community precedents

2.5 Ulysses under hypertextualization and hyperannotation

Section 3: Digital editions and the design process

3.1 Humanities design thinking

3.2 User testing in the digital humanities

3.3 Why does the digital edition design process matter?

3.4 Scholarly values

3.5 Usability heuristic

3.6 Technical platform and major code decisions

3.7 Site appearance

3.8 Specific design challenges

3.9 User experience data results and discussion

3.9.2 Crowdflower survey

3.9.3 Open beta user survey

3.9.4 Google Analytics

3.9.5 Results from Inspectlet

3.9.6 Annotation statistics

3.10 Future data collection

Section 4: Reimagining editions

4.1 A brief history of edition values

4.2 Values and value embodiments

4.3 Is Infinite Ulysses a scholarly edition?

4.4. Infinite Ulysses as an edition

4.5 Diversifying embodiments of textual scholarship values 
4.6 What does the label "edition" help us know?

4.7 Edition literacies

Section 5: Next Steps

Sources built on the text of Ulysses

Bibliography

Appendix A: Crowdflower user survey

Appendix B: Open beta user survey

Appendix C: On this dissertation's format and methodology

Appendix D: Wireframes and screenshots 


\begin{abstract}
This whitepaper offers an analytic discussion of the process and product for Amanda Visconti's dissertation "How can you love a work, if you don't know it?": Critical Code and Design toward Participatory Digital Editions (dissertation.AmandaVisconti.com). The introductory section proposes a speculative experiment to test digital edition design theories: "What if we build a digital edition and invite everyone? What if millions of scholars, first-time readers, book clubs, teachers and their students show up and annotate a text with their infinite interpretations, questions, and contextualizations?". Approaching digital editions as Morris Eaves' "problem-solving mechanism"s, the project designed, built, and user-tested a digital edition of James Joyce's Ulysses with various experimental interface features: InfiniteUlysses.com. Three areas of research advanced through the project are presented: designing public and participatory edition projects, and whether critical participation is necessary to such projects; designing digital edition functionalities and appearance to serve a participatory audience, and what we learn about such an endeavor through Infinite Ulysses' user experience data; and separating the values of textual scholarship from their embodiments to imagine new types of edition. A review of theoretical and built precedents from textual scholarship, scholarly design and code projects, public and participatory humanities endeavors, and theories around a digital Ulysses grounds the report, followed by an overview of the features of the Infinite Ulysses participatory digital edition.
\end{abstract}

Section 2 discusses existing examples of public participation in digital humanities (DH) projects, and publicly annotatable digital editions in particular. "Critical public engagement" is defined to mean public interaction with the scholarly community marked by the learning and use of scholarly rhetoric and approaches. Whether participatory digital editions should always aim for critical public engagement is explored through a list of possible scholarly gains from non-critical public engagement, including gains from user testing and the application of scholarly textual analysis tools to users' comments on the texts usually analyzed by such tools. Useful lessons for participatory DH projects from non-academic online communities such as Reddit and StackExchange are discussed. Existing approaches to thinking about a digital (hypertextualized and hyperannotated) Ulysses are considered, laying groundwork for testing these theories through realized digital edition design.

Section 3 focuses on digital editions and the design process, beginning with an overview of humanities design thinking, DH user testing, and the history of the graphic and iconic in textual scholarship. The section turns to the specific example of Infinite Ulysses, defining the scholarly values that went into the project and demonstrating how these values were reified through code and design. The site's design development over the course of the project is charted through wireframes and screenshots, and three specific design challenges are treated in depth. Preliminary data collected about the digital edition 
user experience (including results of informal feedback, formal user surveys, and site analytics) are presented and discussed in the context of understanding participatory use of the digital edition. Because this data only represents an early piece of the predicted life of the digital edition, this section concludes by speculating on how such data might look after further months of site use, and identifying what new questions longer site use would let us address.

Section 4 reimagines the digital edition by separating textual scholarship values from the common embodiments of these values. We begin with a brief history of textual scholarship values and their accompanying manifestations in edition form, followed by a discussion of current guidelines for editions from the MLA and RIDE digital edition review journal. These sources are distilled into 1) the current common embodiments of textual scholarship values and 2) the current state of textual scholarship values. Using these guidelines, whether Infinite Ulysses is a scholarly edition (no; "scholarly edition" is most useful as a specific term of art) and whether Infinite Ulysses is an edition (yes; meets textual scholarship values, advances disciplinary knowledge) are discussed. Issues faced by digital editions striving to meet values that have largely been developed around print editions are considered, and paths to bring Infinite Ulysses even closer to textual scholarship values (and therefore recognizable "edition-ness") are discussed. Other embodiments of textual scholarship values that don't look like the most common manifestations of these values are examined towards an expanded edition typology arranged via edition values and values performance. Against the argument that expanding the bounds of what is considered a digital edition is healthy for the discipline, what isn't an edition is discussed through the examples of a commercial reading app, an audio text, a literary museum exhibit, and an editorial experiment. The section ends by building on Jerome McGann's review of Gabler's synoptic Ulysses to imagine editions as providing new literacies for textual engagement.

The conclusion sums up the interventions of this project and lists next steps for continuing this research. A bibliography and appendices (full texts of user surveys, explanation of project's dissertational format, wireframes and screenshot from throughout the design process) conclude the report. 


\title{
"How can you love a work, if you don't know it?": Critical Code and Design toward Participatory Digital Editions
}

\author{
How can you love a work, if you don't know it? How can you know it, if you can't \\ get near it? How can you get near it, without editors? — Gary Taylor, "The \\ Renaissance and the End of Editing"1
}

Scholarly editors are integral to the continuum that keeps the stories of the past available to and understood by the present — but in Taylor's formulation, the "you" is just as important: that public of readers beyond the academy whose interest keeps the humanities alive and relevant. What if we build a digital edition and invite everyone? What if millions of scholars, first-time readers, book clubs, teachers and their students show up and annotate a text with their "infinite" interpretations, questions, and contextualizations? My dissertation pursues this speculative experiment through the creation of the Infinite Ulysses digital edition. I've studied how to improve the design and functionality of a key artifact of the digital humanities - the digital edition - through both this unlikely hypothetical and through feedback from an actual, modestly sized community of edition participants.

Textual scholar Morris Eaves conceives of editions not just as vessels for textual content, but also as "problem-solving mechanisms"2. I've addressed the problem of designing participatory digital editions through three project phases. First, I designed, coded, and publicly released an actual digital edition of James Joyce's Ulysses with various experimental interface features. Second, I conducted user testing and analyzed site analytic data with real readers and researchers. Third, I used the results of the experiment to build on knowledge from fields with a stake in digital social reading: literary studies, textual scholarship, information science, and visual design rhetoric. I'm using this speculative experiment and its pragmatic realization to dream big about the public humanities, produce a useful tool for a realistically sized audience, and capture data to better model the challenges of a public digital humanities. The entire dissertational project can be explored at dissertation.AmandaVisconti.com.

Throughout the project, I've foregrounded three research areas that align with the three phases of the project.

1. How can we design digital editions that are not just public, but invite and assist participation in the scholarly love for the nuances of a text's materiality, history,

1Taylor, Gary. “The Renaissance and the End of Editing”, in Palimpsest: Textual Theory and the Humanities, ed. George Bornstein and Ralph G. Williams (1993), 121-50.

2Eaves, Morris. “Electronic Textual Editing: Multimedia Body Plans: A Self-Assessment”. Text Encoding Initiative website.

http://www.tei-c.org/About/Archive new/ETE/Preview/eaves.xml 
and meaning? Are there ways to design for meaningful participation that don't necessarily scaffold critical participation?

2. How can we design participatory digital editions to handle an influx of readers and annotations? What might we learn about digital editions and their texts from the accompanying influx of site use data?

3. Can we separate the values of textual scholarship from the common embodiments of these values? How might this clarification help us imagine new types of digital edition that hold true to those values?

This whitepaper will explore how the dissertation's process and product developed these research questions, produced some preliminary answers, and pointed to further necessary work in the fields of textual scholarship and the digital humanities. ${ }^{3}$

\subsection{Thinking through design and code}

Textual studies concerns itself with the history, forms, and whole content of texts (including the linguistic, iconic, and material). Digital textual scholarship, as a narrower discipline, focuses on the preparation of such texts for use in a digital space. To push the current research, reading, and teaching abilities of the digital edition further, we need to not just theorize how we should change editions, but also manifest theorized changes to digital editions through web design and code work, and then assess what our interventions teach us about the texts of these digital editions; the form of digital editions in general; and literary research, reading, and teaching in digital spaces.

Textual scholarship has always intertwined theory and embodied practice. Arguments about which document (or eclectic patchwork of documents) best represents the ideal of a text, for example, were practically realized through editions of specific texts. My Infinite Ulysses project falls more on the "digital editions" than the "digital editing" side of textual scholarship ${ }^{4}$, but it builds on the same intellectual values of digital editing: communication of a methodology, and the reification of theory in the end product of an edition. Scholarly editing concerns itself with questions such as which text an edition represents and what set of words best communicates that text to the edition's user. This project's concerns instead align with Bethany Nowviskie's idea of "interfacing" scholarly editions: focusing on critical work at the "point of contact between a user and a set of embodied information" ${ }^{5}$, with the design of the edition the user experiences — visual, architectural, and methodological — an important facet of the edition's creation. These concerns, studied through activities such as coding, designing, and modeling, are my focus.

3Portions of this paper were previously published in draft form as posts on LiteratureGeek.com and reposted on the $\underline{\text { MITH }}$ and HASTAC blogs.

4Similar product, different process; see Section 4 for more on whether Infinite Ulysses should be considered an edition. 5Nowviskie, Bethany. "Interfacing the Edition". Conference talk text (2000). http://www2.iath.virginia.edu/bpn2f/1866/interface.html 
Experimentation in textual scholarship most often takes the form of small side experiments on larger, more traditional digital edition projects (e.g. the Whitman Archive's TokenX intervention tool, the Romantic Circles' Villa Diodati MOO), rather than as innovations manifested by the entire edition. Many editors conceive editions as textual theory reified as an edition (e.g. the Rossetti Archive), but such theories are often specific to the texts in question rather than to applying text-agnostic questions about digital editions as a form. Such questions - for example, the place of crowdsourced curation and annotation in textual scholarship — often play out in conference talks, articles, and books rather than through actual digital editions.

Despite their pervasive presence in textual scholars' methodology, practice and embodied experimentation have not always been treated as parts of a textual scholar's critical work. This hasn't kept design experiments from becoming a traditional tactic of textual scholarship. The typographic and spatial innovations of scholarly editor Teena Rochfort Smith's 1883 Four-Text 'Hamlet' in Parallel Columns ${ }^{6}$ offer one example of a scholar's experimentation focused on editions as a form. Smith intended this prototype to provide diplomatic transcriptions of Hamlet's first and second quartos (Q1, Q2), first folio (F1), plus her own old-spelling edition based on Q2 but also pulling from $\mathrm{F} 1^{78}$. The texts occupy four columns across each pair of the book's landscape-oriented open pages, two columns per page. The edition employed six varieties of typeface, four inks, three kinds of underlining, and daggers, asterisks, and other symbols call out variants and the extent of variance.

This prototype would have been nearly impossible to set and print given contemporary technology, and Smith agreed, after her prototype's initial circulation, to work toward a simpler final version of the edition ${ }^{9}$. This approach suggests Smith's focus was on an experiment with the form of a prototyped edition, rather than a fully realized edition with a focus on its text.

Alan Galey's Visualizing Variation coding project is another example of critical textual building work that focuses on edition form over any one text. The Visualizing Variation code set is a scholarly response to the early modern experience of reading, when spellings varied wildly and a reader was accustomed to holding multiple possible

6Visconti, Amanda. "Recovering Teena Rochfort-Smith: Complex Edition Prototype, Female Victorian Editor". (2012). http://www.literaturegeek.com/2012/11/12/recovering-teena-rochfort-smith-complex-edition-prototype-female-victorian-editor/. 7Murphy, Andrew. "Electric Shakespeares, The Arden Shakespeare CD ROM”. Computers and the Humanities. 32(5). 1998. 411-420. 8Thompson, Ann. "Teena Rochfort Smith, Frederick Furnivall, and the New Shakspere Society's Four-Text Edition of Hamlet". Shakespeare Quarterly. 49(2). Summer 1998. 128. http://www.jstor.org/stable/2902297.

9Ibid., 131. 


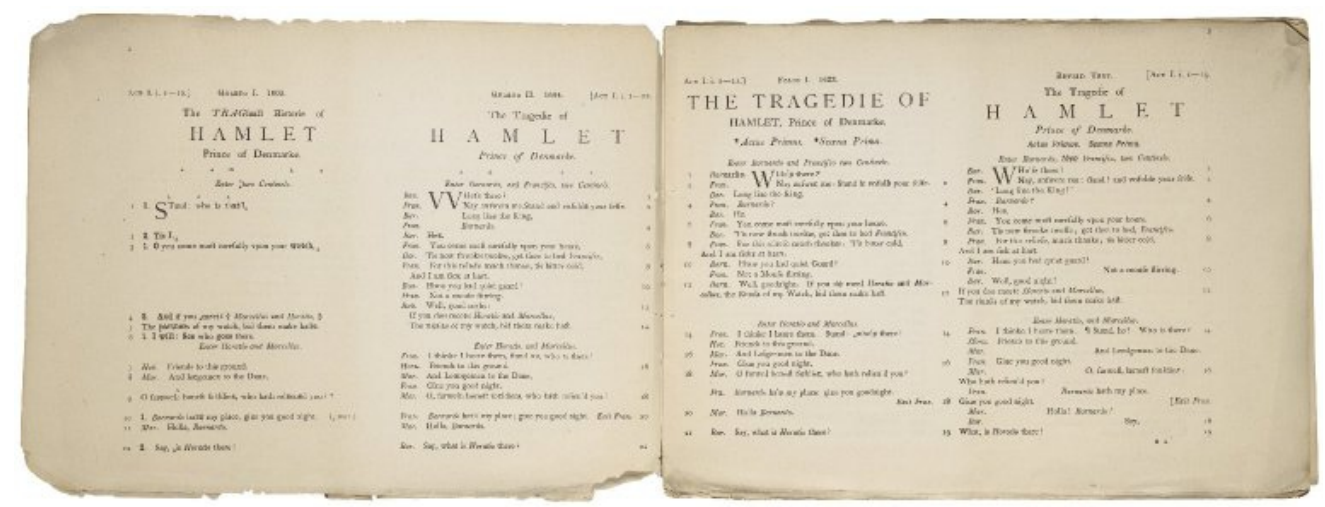

Image courtesy of the Folger Shakespeare Library Digital Image Collection (CC BY-SA 4.0).

meanings for badly printed or ambiguously spelled words in their mind at the same time. For example, his "Animated Variants" code cycles which word to display in the reading text for contended words such as Hamlet's sallied/solid/sullied, so that the reader isn't biased by a word's placement in the main text rather than in the footnotes. By experimenting with digital means of approximating this historical experience, Galey moves theorists past discussing that this different experience of texts occurred. Instead, scholars can now respond to an actual participation in that historical experience.

Galey's experiments with animating textual variants, layering scans of marginalia from different copies of the same book, and other approaches embodied as code libraries are themselves critical arguments:

Just as an edition of a book can be a means of reifying a theory about how books should be edited, so can the creation of an experimental digital prototype be understood as conveying an argument about designing interfaces. - Alan Galey and Stan Ruecker ${ }^{10}$

The arguments made by digital prototypes and other code and design work are most often about meta-textual questions such as how we read and research, and how interfaces aid and shape our readings and interpretations. The digital object itself can perform such arguments (practice-based research). When more text-centric arguments are made, these do often need to be drawn out from the tool and provided with a written analytic discussion (practice-led research). With Visualizing Variation, Galey's examples of the code in use on sample texts perform an argument about the function of editions, while what Galey discovered about the effect of the realities of early modern reading on the reception of a Middleton play would best be performed through written analysis. Likewise, with my project I've performed some of the possibilities for a more public

10Galey, Alan and Stan Ruecker. “How a Prototype Argues.” Literary and Linguistic Computing. 25(4). 2010. 405-424. 
humanities through my Infinite Ulysses edition, but the implications of the larger project around that digital edition need this whitepaper for a thorough exploration ${ }^{11}$.

\subsection{The humanities, public and participatory}

Public History is a thriving field, with support from groups like the National Council on Public History and engaged communities transcribing and commenting on documentary texts and other collection items (e.g. Papers of the War Department, Histories of the National Mall, and the Scripto plugin for Omeka that allows site visitors to aid in moderated transcription of historical documents). "Public Literature" is a seldom-used phrase, despite the similarity in objects of study and activities between the two fields. "Public humanities" is a phrase encompassing both fields that's been around for a while (e.g. the Brown Center for Public Humanities and Cultural Heritage, founded in 1979) but is beginning to see more traction in recent years (e.g. the NEH's Division of Public Programs and its recent Public Scholar Program). Much of digital humanities work has been on some level publicly available ${ }^{12}$.

But does placing content online without a paywall truly make it an engagement with the public? Lindsey Thomas notes that making something freely available online does not necessarily guarantee that thing is public, or that it will be used as a public resource... "Openness", as we tend to understand the term in the Digital Humanities, might not necessarily involve "making public" as we are used to thinking about it. ${ }^{13}$

Thomas suggests it isn't enough to make something theoretically publicly accessible to advance a public humanities. We need to prioritize accessibility, inclusion, and education if we want to create a real conversation among academics and the public. But what does that level of public engagement look like in practice? How do we design to invite public engagement, and how do we support it once we've achieved public interest?

The template provided by public history projects suggests public humanities scholars need to explicitly decide for what type of engagement they are designing. Site visitors can be passive consumers, or they can interact with the scholars who created a project. Digital humanities designers can also choose whether they value any level of engagement with their project, or whether they want to scaffold critical engagement by teaching a site's users the terminology and rhetoric required to interact with academics on a critical level.

11"Practice-based" work results in a creative artifact as the knowledge contribution, while "practice-led" work results primarily in changes to theories about the practice.

12With the exception of media-bounded projects like those available only on CD-ROM, and of paywalled or password-protected online archives (though these are fast fading from use).

13Thomas, Lindsey. "Open Access and the Digital Humanities". 12/16/2013 post on the Postcolonial Digital Humanities blog. http://dhpoco.org/blog/2013/12/16/open-access-and-the-digital-humanities 
Both the call for a more public digital humanities, and the increasingly popular idea that we should make use of all this lovingly marked-up edition text, connect in the development of multiple options for a given edition's interfacing, each focused on a particular interpretation of a text. Textual interfaces offering differing uses of marked-up text are an increasingly theorized topic (Nowviskie "Interfacing", Saklofske, Fraistat and Flanders). The proliferation of different digital edition forms inclines some scholars to shift their focus from markup and traditional editing (scholarly digital editions) to related concerns such as curation (thematic research collections), images and cross-collection knowledge discovery (digital archives), and broader encounters with digitized texts (digital engagements or interventions ${ }^{14}$ ), a diversifying of textual roles that could help resituate edition interface design as a critical activity.

Besides diversifying the kinds of textual projects available to readers, we can actively work toward designing for broader audience participation. "Participatory design" in a DH project is a tactic resituating academics and non-academics as co-participants in shaping a digital project's development. Some DH sites and projects are designed "primarily with scholars in mind" 15 , and these are necessary and important contributions to the academy and human knowledge - but they serve only one of many possible audiences. In a formal usability study ${ }^{16}$ of public use of several key digital archives, I found that it was often the simplest interface changes that non-academic users required to understand and use a digital humanities edition or archive (e.g. the addition of a short tour of what the site can do). When we bring the public into our critical conversations, everyone can benefit. As I designed my digital edition, I kept in mind projected needs for a variety of users in the shared space of the public humanities, such as first-time readers, teachers preparing to read the novel with their class, and scholars assembling textual evidence for a journal article. I'll discuss what my findings were with these user groups in Section 3.9.

Precedents for participatory work in the humanities include efforts to engage the public at cultural museums online and off, such as the approaches in Nina Simon's Participatory Museum or the Rosenbach Museum's participatory approach to their Joyce manuscript ${ }^{17}$. The University of Virginia's IATH and Scholars' Lab have a history of participatory building, including the original and rebooted Ivanhoe games ("enabling collaborative criticism through roleplay - for scholars, students, and cultural enthusiasts") and the Scholars' Lab Prism tool for collaborative interpretation of texts. In the world of textual scholarship, the Shelley-Godwin Archive has worked toward public participation, envisioning an eventual "work-site for scholars, students, and the general public, whose contributions in the form of transcriptions, corrections, annotations, and TEI encoding

14Price, Ken. “Edition, Project, Database, Archive, Thematic Research Collection: What's in a Name?”. The Walt Whitman Archive. 15http://www.blakearchive.org/blake/public/about/plan

16Visconti, Amanda. "Songs of Innocence and of Experience:" Amateur Users and Digital Texts. Master's thesis; University of Michigan School of Information (2010). deepblue.lib.umich.edu/handle/2027.42/71380

17 Utell, Janine. "The Archivist, the Archaeologist, and the Amateur: Reading Joyce at the Rosenbach".

http://www.jstor.org/stable/30053268 
will create a commons through which various discourse networks related to its texts intersect and interact"18.

In the digital humanities, designing with users in mind does not always include usertesting or audience feedback integrated into a project. Developer-users - key members of the main intended audience for a tool — conceive and manage many digital editions and archives. Because of limited budgets, lack of exposure to user-centered design approaches, and in particular the lack of study into performing user research and tool evaluation for the digital humanities, testing the efficacy of these projects for an audience beyond these stakeholders is rare (e.g. Edwards; Harley et al.; Karlsson and Malm; Visconti "Songs"; Warwick, Terras, Huntington, and Pappa). Projects that aim to serve an audience broader than the small team developing them - or perhaps even a secondary, more public audience of self-motivated learners - need to consider metrics for exploring various areas of project efficacy such as:

- Demographics: Who is using your project, and what are their specific needs and obstacles to success? How does the reception of a text in a given country influence digital edition readers' needs?

- Use: How are people using your tool--as expected, or otherwise? Do you want to cater to those unexpected uses?

- Usability: Does your site support visitors doing what they want to do? For example, if you give them a simple research task, how many steps should it take them to complete it using your project — and how many does it actually take?

- Usefulness: Is this tool making a difference in its scholarly field? Is it better than other similar digital or print tools?

Digital humanities websites are increasingly sites of wider participation in textual interpretation, with how to evoke and harness meaningful crowdsourcing an increasingly urgent question for public humanists. As we use the Web to open the texts we study to a wider community of annotation and discussion, we bring in diverse knowledges and interpretive biases. How can we best architect the overabundance of information proceeding from public annotation of literary texts? When we combine this quantity of voices with an unusually complex text such as James Joyce's Ulysses, the critical experience we create needs to adeptly handle not only issues of information quantity, but also quality. If we invite everyone into our critical conversation around a text, how might we automate the curation of multiple best ways to interface with annotations and interpretations of that text? My project has helped me think through — and test—possible answers to these questions.

\subsection{Hypertextual and digital approaches to Ulysses}

18The Shelley-Godwin Archive: About 
To use Ulysses as its example text, my project builds on previous Joycean contextualizing work: on the print side, Blamires' New Bloomsday Book and Gifford's Ulysses Annotated, and online, the James Joyce Online Notes and Michael Groden's notes and prototypes. In addition to the online glimpses of Groden's work and the James Joyce Text Machine, my 2008 prototype UlyssesUlysses.com explored not only Ulysses' annotation, but also how to best display annotations for reading and research — the digital form around the text of a novel. Key print precedents for this project are variorum and similar editions that deal with a large quantity of variants, marginalia, or other annotation, such as the ShelleyGodwin manuscript notebooks and Hans Walter Gabler's synoptic Ulysses. These last two examples have convenient digital counterparts in the developing Shelley-Godwin Archive and Michael Groden's Ulysses in Hypermedia prototypes.

Each of these resources aims at a specific audience and annotates the text at a certain depth; the New Bloomsday Book walks the reader through the plots and the basics of the novel's incredibly rich allusions, while Gifford's book tracks down references to smaller details like street addresses and song lyrics. A goal of Infinite Ulysses is demonstrating how a participatory edition might handle the discovery and display of various granularities of contextualization and interpretation. Understanding how a social ranking system for annotations might assist in identifying quality contributions to the editionand might also might reinstate or veer from the currently canonical opinions on aspects of the text - is another edition goal. I'm exploring both by bringing diverse sets of interpretation together in one place and seeing how they overlap or contend.

While there isn't a completed scholarly digital edition of Ulysses yet published, Joycean scholars have anticipated issues that might arise with the eventual migration to digital space. Where the limitations of print space have in the past kept annotations of the notoriously complex text in check, what will happen when a digital platform allows the addition and navigation of crowd-sourced annotations? Can we migrate complex print hypertexts such as Ulysses to a digital space and garland it with socially multiplied annotations, without also "diminish[ing] the force of the book"19 ${ }^{19}$ "normaliz[ing]"20 it?

\subsection{An introduction to the Infinite Ulysses digital edition}

Infinite Ulysses (www.InfiniteUlysses.com) is the digital edition I created to explore my research questions. I'll delve into whether Infinite Ulysses is a scholarly edition and other questions related to textual scholarship terminology in Section 4 of this whitepaper. For now, it may help to have a general sense of what I'm talking about when I say "digital edition". Digital editions are texts (literary or otherwise) prepared for online reading and research according to some critical ideal for presentation, methodology, and content. There are further values (attention to versioning history) and features (use of facsimile)

19Derek Attridge as cited in Marino, Mark C. "Ulysses on Web 2.0: Towards a Hypermedia Parallax Engine". http://www.jstor.org/stable/25571051.

20Marino, Mark C. "Ulysses on Web 2.0: Towards a Hypermedia Parallax Engine". http://www.jstor.org/stable/25571051. 
that vary in importance according to what text is at issue and who is editing it. Don't picture just any scan or digital transcription of a document you might find online; digital editions guarantee carefully justified methodologies and meticulous attention to the text that reaches the reader. Think The Social Edition of the Devonshire Manuscript or archives containing multiple editions like The Walt Whitman Archive, not Google Books or Project Gutenberg ${ }^{21}$.

This project combines its speculative design approach with the scholarly primitive of curation: dealing with information abundance and quality and bias. I've imagined scholarly digital editions as popular sites of interpretation and conversation around a text. Infinite Ulysses hinges on the ability of readers to annotate the text as they read it, plus use a variety of other features dependent on the presence of socially authored annotations. When a reader "annotates" my digital edition, they highlight a section of the literary text, then type in a comment about that highlighted text. This annotation can then be displayed in the margins of the text, dependent on how a reader has used the filter and sort tools for annotation display personalization. By drawing from examples of how people actually interact with text on thriving websites, such as the social community Reddit and the Q\&A StackExchange sites, I've created a digital edition interface that allows site visitors to interact usefully with a potentially overwhelming number of annotations and interpretations of the text.

So that readers on the beta site were not working from a blank slate, I seeded the site with over 200 annotations on the book first two chapters, plus 30 broadly useful tags that mark annotation topics such as advanced vocabulary, foreign languages, and references to Joyce's biography. On top of a platform for adding annotations to edited texts, readers of the digital edition are currently able to:

\section{Tag the annotations}

For Stephen's description of Haines' raving nightmare about a black panther, a reader might add the annotation 'Haines' dream foreshadows the arrival of main character Leopold Bloom in the story; Bloom, a Jewish Dubliner, social misfit, and outcast from his own home, is often described as a sort of 'dark horse'". This annotation's writer (or any subsequent reader) can augment the comment with tags such as "biography" (to mark allusions to Joyce's own experience in a similar tower), "darkhorse" (to help track the "outsider" imagery applied to Bloom throughout the novel), and "dreams".

\section{Filter annotations both by tags and by annotation author}

21Patrick Sahle compiles a list of particularly interesting scholarly digital editions here: http://www.digitaleedition.de/vlet interesting.html 
Readers can hide annotations they don't need to see (e.g. if you know Medieval Latin, hide all annotations translating it) or filter to only display annotations dealing with areas of interest (e.g. if you're interested in references to Shakespeare's plays). Readers can hide annotations added by certain user accounts (e.g. if you disagree with someone's interpretations), or filter to only display annotations authored by certain users (e.g. if you only want to see annotations by other users that are also first-time readers of the book).

\section{Assign weights to individual annotations and their authors via voting}

As with Reddit, each annotation on the text can receive either one upvote or one downvote from each reader, letting the community collectively measure an annotation's usefulness ${ }^{22}$. Annotation votes will also accrue to the user who authored those annotations, so that helpfulness and credibility of annotators can also be roughly assessed. These votes allow readers to prioritize what annotations they are shown when a word or phrase has multiple annotations; for example, a reader can choose to see the top-rated annotations first, or the newest annotations.

\section{Cycle through less-seen and lower-ranked editorial contributions}

To prevent certain annotations from never being read - a real issue unless every site visitor wishes to sit and rank every annotation - the initial display of annotations for the page, and for any clicked highlight, is a random sampling of all available annotations for that page or highlight.

\section{Favorite annotations}

Readers can click on a star icon next to any annotation to add it to a list of favorites viewable on their user profile page.

\section{Bookmarks pages}

Readers can click on a bookmark logo on any page to have their bookmark moved there. The expandable table of contents menu contains a link to this bookmark so that it's accessible anywhere on the site.

\section{Flag annotations for moderation}

Readers can click on an icon to alert the moderator that an annotation needs to be checked for abuse, spam, or for some other reason. This immediately removes the annotation from public display until a moderator can review it (read more about how the site moderation system prevents bad-faith annotations in Section 3.8).

Multiple additional features are currently under development, including:

\section{- Track contentious annotations}

22Voting systems on sites carry similar issues to other systems that hinge on "meritocracy"; for example, early voters opinions may carry more weight by disappearing an annotation from later readers' consideration. Infinite Ulysses will follow how readers are using voting to determine whether "usefulness" or some other measure is being voted on, and work to supplement this feature to give a diversity of interpretations adequate exposure. 
Users will be able to prioritize viewing annotations with the widest spread of up- and down-votes to identify material that is most contentious. If users employ downvotes to disagree or agree with an interpretation (rather than use voting to indicate whether an annotation was a useful contribution to the site), this filter will help me analyze at what points in the book reader interpretations most differ.

\section{- Save private and public sets of annotations}

Tying into the existing annotation favoriting feature ( $\# 5$, above), users can curate specific sets of annotations from the entire pool of annotations for either personal use or public sharing. The goal is to eventually generate a custom URL for each user that will display the novel with only their favorited annotations visible, creating a "custom edition" of the text. For example, a reader might curate a set of annotations that provide clues to Ulysses' mysteries, track how religion is handled in the book, support arguments made in their scholarly journal article (which can link to the site), or represent the combined work of the students in an undergraduate course where Ulysses was an assigned text.

The site also includes pages discussing the provenance of the text, a data plan for the site's maintenance and preservation, user-friendly discussion of how copyright and intellectual property are used on the site, a glossary of what core annotation tags mean, instructions on citing content on and from the site, explanation of user rights and the moderation policy, terms of use, an explanation of the research project underlying the digital edition, and a statement on accessibility and inclusion. 


\section{Section 2: Public participation in digital editions}

The easiest thing about creating educational technology is creating the educational technology. Once that is done, the hard work begins: creating the pedagogical support necessary to make the technology comprehensible and easy for educators and students to use.

-Donald Brinkman, The Chronozoom Project

What better thing to do than to sit in a nice cozy office at home, with your computer, and find out what the guys from 200 years ago were saying about this or that?" Ms. Cardinal says. "Some would say that's an awfully lonely life. But I'm a grandmother of four. ... It isn't like I'm a recluse or anything. It's just I'm very excited about history and the fact that you can access all this stuff that you couldn't before.

- "Historians Ask the Public to Help Organize the Past" by Marc Parry, The Chronicle of Higher Education

Participatory projects, as defined in Section 1.3, are a means for the humanities to preserve the relevance of culture past and present by engaging more members of the public in the subjects of our studies. In addition to work from digital and non-digital museums toward increasing meaningful visitor participation in cultural collections, the field of human-computer interaction (HCI) offers precedents for designing public engagement. HCI, a field focused on interfaces between user and computer (including interfaces of reading and research), provides a useful approach to a humanities that benefits both the public and scholars: "participatory design" centers not just on the scholar or on the public, but finesses a "third space" of discussion, shared design, and shared learning that exists when the two groups come into conversation. Michael Muller found that results of participatory design can include

challenging assumptions, learning reciprocally, and creating new ideas, which emerge through negotiation and co-creation of identities, working languages, understandings, and relationships, and polyvocal dialogues across and through differences ${ }^{23}$

All these results indicate public engagement beyond passive consumption.

Besides these benefits to knowledge development, design for participation can target specific barriers to public engagement. Nina Simon's The Participatory Museum ${ }^{24}$ lists "commonly-expressed forms of public dissatisfaction" that museums can address through

23Muller, Michael J. . "Participatory Design: The Third Space in HCI”. In The Human-Computer Interaction Handbook. 1051-1068. 24The Participatory Museum by Nina Simon. Preface. http://www.participatorymuseum.org/preface 
participatory techniques. These areas where the public feels a lack of relevance or involvement carry over well to digital projects, which need to

- establish relevance to the public user

- make the project seem active, and the public user's returning to the project seem worthwhile, through frequently updated or developing content

- include the public user by acknowledging and incorporating diversity

- offer clear modes for active rather than passive participation

- provide a safe and welcoming environment for exploring ideas and interpretations Public users of participatory humanities projects aren't the relatively small circle of creators and colleagues at the center of a digital project's realization, but the nebulous audience just beyond that inner circle: "amateurs" in the old sense of people whose pursuits aren't undertaken in a professional role. These participants are also called "citizen scholars" or simply "members of the public".

Martin Mueller argues (in the context of crowdsourcing) that this audience encompasses anyone motivated by "duty, fame, and love: the amateur scholar, the citizen scholar, and everybody else who would like to be recognized for something useful or splendid they have done" ${ }^{" 25}$. Whether we're seeking public assistance, or making our scholarly efforts meaningful beyond those who already have advanced knowledge in our field, the digital placement of our work means that it's more easily accessible to more people than thirty years ago - but virtual access doesn't mean much if new site visitors are bouncing off your site without using it. How do we create digital humanities projects that see real public use?

Some digital editions and textual archives have achieved participation by allowing site visitors to annotate texts. The New York Public Library's Candide 2.0 offered public annotation alongside the novel: "the margin is a public space where readers can congregate, discuss and debate the book together, in intimate proximity to the text"26. Participation privileges developed in stages: commissioned annotators such as scholars and playwrights seeded the edition with expert commentary, after which the edition was opened to public annotation for a trial period. London Lives similarly used a graded approach to participation, with tagging open to all on a separate wiki and "welldocumented" user-created biographies eligible for republication on the main London Lives archive. Alyssa Arbuckle et al. have assembled an extensive annotated bibliography of more existing projects and studies related to humanities social knowledge creation; the sections on "Social knowledge creation in electronic scholarly editions and e-books" and "Collaborative annotation" in particular provide examples of textual experiments that offer models for engaging the public.

25Mueller, Martin. “Collaboratively Curating Early Modern Texts”. August 9, 2011. Essay drafted for Project Bamboo. https://wikihub.berkeley.edu/display/pbamboo/Essay-+Collaboratively+Curating+Early+Modern+English+Texts 26 "How to read this book". Candide 2.0, NYPL. 


\subsection{What is critical public engagement?}

To be able to talk about "critical engagement", I'll use "critical" somewhat synonymously with "what academics do": researching an idea, marshaling proofs for an interpretation, making your exploration of theories accessible to others in the intellectual community by adhering to certain standards and conventions of scholarly rhetoric. When I contrast critical and "non-critical" activity, I'm referring to the use or nonuse of the types of rhetorical moves and vocabulary valued when engaging in discussion in academia for their history of successfully increasing scholarly knowledge.

Crowdsourcing ${ }^{27}$ for cultural projects has seen success with tasks such as tagging, geolocating ${ }^{28}$, transcription ${ }^{29}$, and answering simple questions about images ${ }^{30}$, activities some scholars regard as non-critical (and thus failing to teach critical thought processes). Critical engagement is often contrasted with passive engagement, without acknowledgement of a possible space between the two extremes. This isn't a terrible state of affairs: designing projects to enfranchise the public with the tools to take part in academic conversations is an excellent goal that can't be embraced by too many projects. But when designing for critical engagement isn't on the cards - whether through lack of expertise, funding, or time - some scholars look askance at inviting any other type of public engagement. Museum professionals in particular seem weary of institutional attempts to "do social media" through under-designed "have your say" projects that garner little in the way of substantive feedback for a museum's exhibits.

The fault with such projects is not fully considering what kind of engagement is wanted, how to design scaffolding for that engagement, and how to moderate participation to subtly indicate the tone of feedback desired. Participatory digital humanities efforts seeking critical feedback need to teach the skills of conversing within a scholarly community - teach being critical: not designing for the public to "have your say", but "here's how to have your say, if you want to take part in the conversation with experts, if you want a response, if you want to build on what's been said and have someone build off your thoughts in turn" ${ }^{13}$. Scaffolding for serious literary discussion by teaching public visitors how to marshal proofs, explore ideas, defend hypotheses, and converse amid cadences of logic familiar to the literary studies community is a worthy goal that even projects primarily aimed at scholars can begin to address. There are ways of serving a wider audience that don't take too much time or effort; these tactics also serve the scholars at the core of your user audience by accelerating attainment of site use expertise

27This report only treats non-digital-edition participatory work ("crowdsourcing") shallowly. A good place to get started reading more is this post by Trevor Owens or the recent Crowdsourcing Our Cultural Heritage collection edited by Mia Ridge.

28E.g. Brooklyn Museum and HistoryPin: "Help us pin Brooklyn to the map!"

29E.g. Smithsonian Digital Volunteers: Transcription Center (transcription), National Archive's Citizen Archivist Dashboard

(transcription, tagging, editing, and more)

30Madison: Help preserve history with just one click. The New York Times.

31 If these references to museum as models for digital editions have piqued your interest, Incluseum, Nina Simon's blog Museum 2.0, and the Center for the Future of Museums all discuss participatory design, crowdsourcing culture, and pertinent issues like opening authority and addressing diversity. 
and augmenting expert knowledge through pedagogical modeling. A formal user study I conducted with public visitors to the Blake and Whitman archives recommended use of three types of site feature ${ }^{32}$ :

- tours and introductions to the site's structure and content (e.g. the Blake Archive offers a site tour),

- intuitive interfaces guiding browsing as well as searching (e.g. Uncle Tom's Cabin and America provides labeled paths for search, browse, and interpret modes), and

- teaching tools and exercises that help the reader learn to think like a scholar in your field (e.g. the Dickinson Electronic Archive's "Emily Dickinson Writing a Poem: Manuscript Ordering Exercise".

Small design changes that can inflect a scholarly digital project toward a broader audience are one path to a more participatory humanities; another path is purposefully designing projects as participatory from the start, but with the understanding that many types of meaningful participation do not appear "critical" in the sense of participating in scholarly rhetoric or methodology.

\subsection{Should participatory digital editions always aim for critical public engagement?}

Infinite Ulysses followed the model of Candide 2.0 (and many other community sites, such as the early Reddit) in seeding the edition with well-written and accessible annotations before the first visitors arrived, a tactic that sets a tone for the type of participation desired. Infinite Ulysses' main concern was not to teach each reader critical engagement to the point where they could comfortably converse with other attendees at the MLA conference or a Joyce symposium. As a result, I can't offer design advice towards scaffolding for that level of critical public engagement. Instead, my goals for Infinite Ulysses' were:

1. discovering what happens when we reimagine digital editions as participatory spaces where readers of all backgrounds interact

2. exploring whether we can design an edition to help the public become comfortable with reading an extremely challenging text

3. understanding how people read and use such an edition

These are big enough steps on their own, and they are steps that must be taken before we can effectively design scaffolding to help the public participate in a fully critical manner. So, should participatory digital editions always aim for critical public engagement? My answer is no: there are other worthwhile goals that sit between critical and passive engagement on the spectrum of participation. We need to design for valuing public contributions of all kinds, both as part of the humanities' mandate to maintain the relevancy of past and present culture, but also because failing to do so misses out on a goldmine of what Microsoft Research's Donald Brinkman has called "deep data"- deep, particular knowledge about cultural artifacts, as opposed to the often facile data that gets bundled up into "big data" projects. What does "deep data" about literary texts mean?

32Visconti, Amanda. "Songs of Innocence and of Experience:" Amateur Users and Digital Texts. Master's thesis; University of Michigan School of Information (2010). deepblue.lib.umich.edu/handle/2027.42/71380. 
Does it necessitate critical disputation, or do we need more diverse - perhaps not even yet imagined - types of metadata around texts in order to know them more intimately?

\subsection{Non-critical but useful public engagement paths}

Non-critical engagement can be more than establishing a passive awareness of a cultural artifact. Acknowledging rhetorical norms for a field is an important part of critical humanities engagement, and teaching people how to think and talk about texts so that their participation leverages these norms can be a useful goal for public engagement. Before you can teach rhetorical norms for participating in a community, though, the public needs to be welcomed into the community: made to feel that their voices are useful and desired.

Scholars shouldn't discount the value of seeing someone in your own shoes-for example, someone also reading a book for the first time, asking similar questions, or expressing similar emotions about a text. I don't want readers on Infinite Ulysses to think "no one is interested in my thoughts" or "everyone knows this basic thing about the novel"; I hope to invite their instead annotating (if for no other purpose) for the person they were before they started the book, or five or ten or however many years agobecause just as you were once at that place, some user will be there again and appreciate your help. This design will produce some annotations that a portion of the audience won't want to read, but the personalization options on the site should help readers identify what level of help they want. The "define", "meaning", and "plot" tags in particular are a graded way to mark annotations at the level of "what does this word mean?", "why did he say that? what's happening?", and "what does this have to do with the broader themes of the novel?". I've tried to be careful about language on the site; although some designers have found that emphasizing user "contributions" instead of "comments" leads to a more critical level of conversation, "contribution" might also be a barrier to the participation that helps people learn to take part in critical discussion. A participatory digital edition project shouldn't be about teaching the public the interpretations scholars have created and refined and accepted, but about teaching new readers the methods we used to be able to make those interpretations so that they may join our conversation: teach critical methodology, not content.

For a digital edition allowing public annotation (as with Infinite Ulysses), one might worry that readers annotating without critical thought would produce annotations of little value. Leaving aside that there are other useful types of annotation than critical interpretations - definitions, translations, questions, and contextualizations, for example -I spent some time considering whether a bunch of comments like "<--this guy!!!<3" and "+1", when a favorite minor character appears, would be inappropriate to the site. Are such annotations not helpful to other readers, or do they not advance what we know about the text? Guiding my moderation policy with these questions might cut out useful 
knowledge: I very much $d o$ want to know if readers don't identify with major character Stephen or are delighted when his friendly antagonist Buck Mulligan shows up to lighten the mood, for example. Users choosing to read the novel on this participatory digital edition, whether teachers prepping for a seminar on the novel or first-time readers, will want to know how other readers feel about the text. I considered replacing such noncritical annotations with a comment that "x readers were excited to see Mulligan appear again" (for example); keeping such comments in users' original words lets readers see their contributions are valued, though, and also preserves the mood of each reader's particular reaction to the text. For readers who wouldn't be well served by encountering these annotations, application of a tag (e.g. "emotion", "reading experience", "reader injokes") lets these users filter such annotations from view. Participatory editions need not force every reader interaction into the strictures of a contribution to critical understanding of the novel.

I resisted the urge to label public, non-critical interaction with texts as "comments" because of the now-common caution "don't read the comments". The discussion section of digital newspaper articles have some work to do, although recent research suggests that getting rid of comments isn't the answer, and putting more effort into setting comments sections' tone and etiquette succeeds ${ }^{33}$. Untended community comments can clutter rather than contribute. On the other hand, part of what defines a scholar as a scholar is their mastery of a certain rhetoric for questioning, seeking, arguing, debating; expecting the public to engage in discussion in the same way without giving them the tools to do so is unfair. Many substantive discussions on the internet do work, such as good academic or activist Twitter conversations, and crowdsourced interpretation like the public commenters on items in the Ransom Center Flickr group for manuscript fragments ${ }^{34}$ and image annotations on Britain from Above. ${ }^{35}$ Disputations have played out in textual margins for centuries, and people who remember the experience of reading Ulysses fondly often speak of the interactions outside the novel (a book club, a fantastic literature class) as part of their enjoyment - a communal reading experience that can be approached in digital space.

What "deep" or substantive information, then, can be drawn from public commentary that isn't critical — that doesn't use the rhetoric of scholarly critique or seem to involve deep thought towards producing new knowledge? The options aren't just between serious literary interpretation or adding a tag; below, I've noted some uses to which non-critical annotations and activity on a digital edition can be put:

33E.g. Stroud, N. J., Scacco, J. M., Muddiman, A. and Curry, A. L. "Changing Deliberative Norms on News Organizations' Facebook Sites". Journal of Computer-Mediated Communication. 2014.

34"Thus far, 94 of the 116 identifiable fragments have been identified, and nearly 57 percent of those were identified through crowdsourcing (by date, region, or the text itself)" — Update blog post on the project by Micah Erwin

35More examples on Kaitlin Wainwright's post "Consider the Comments: Why Online Comments are Important for Public Historians" on ActiveHistory.ca. 
Improving the site through knowledge about user experience:

- Use: What pieces of a project were used by the public, when and how were they used, for what purposes were they used? Were tools or content used in unexpected ways or for unexpected purposes? Heatmapping is an option for aggregating information about how many users clicked or scrolled on various page elements.

- Usability: Does the digital edition design intuitively and efficiently allow the user to perform desired actions? Can experts function as experts on the site, and can new readers comfortably read the text?

- Usefulness: Do members of the public in general find the digital edition useful? Do people who tend to be interested in the content of or actions allowed by the digital edition find this digital edition useful? Does user feedback suggest additional features that would better support user needs?

Tools that scholars apply to texts can also be applied to non-critical annotations:

- Sentiment analysis: Determine changes of emotion in readers over the course of a novel as related to textual content. Identify emotions related to reading experience such as pleasure, success, frustration, and confusion and use this knowledge to offer better reading support.

- Topic modeling: Determine recurring themes in user commentary.

- Word/phrase frequency: Determine recurring vocabulary in user commentary.

\section{Public activities not typically identified as "critical":}

- Shallow curation: Tag or assign data to themes or topics.

- Deep curation: Juxtapose random items in a collection, asking users to score and add a comment about the items' relationships (this could be critical work, or it might involve less introspective activity such as pointing out visual similarities and differences).

- Identifying relevance: Ask for feedback indicating the manner of relevance between project content and users' lives to discover areas of overlapping public and scholarly interest. Because Web users tend to tag for their own purposes rather than a project's intended purpose ${ }^{36}$, tags can often provide windows into understandings of personal relevance.

- Surveys on demographic information: User survey answers can aid interpretation of aggregated site analytic data such as average time spent on a website or level of interaction with a website. For example, a digital edition's scholars could consider what translations and editions of the text are readily available in visitors' home countries, and how differences among these versions may impact site use.

36See Nina Simon's "Tagging in Museums \#blowinguppersonal \#notwhatweplanned" and Tim Spalding at LibraryThing's discussion of tagging failure on Amazon.com versus tagging success on LibraryThing. 
- Observe reactions in context. Comments gain important metadata when they're attached to a particular phrase or section of the page, rather than gathered into one giant forum related to a text.

Public use of a project can advance pedagogical research by requiring scholars to model the experience of new readers with a text. Many of the answers to "what do we learn from classroom teaching and teaching preparation?" carry over to what we can gather from public digital edition use. Examples include identifying:

- Misreadings and interpretations based on incorrect assumptions about the author or setting of a text

- Import: How does the public's assessment of a text's importance match to a text's importance in a scholarly field?

- Values: How do new readers gauge the text's relevance to their lives and interests? Do new readers indicate emotions, experiences, or values that suggest textual relevancies that could be illuminated for other new readers?

- Textual connections: Do new readers of a text apply interpretations they may have garnered from popular culture? What is the common knowledge about a text? Do new readers suggest previously unexplored intertextuality between the text and modern media?

- Canonicity: Do new reader theories accord with existing interpretations, or suggest new avenues for interpretation or observe new intertextual ties among literary texts?

- Assumptions and biases: What unexpected ideas do new readers bring to a text?

- Reading behavior: How do readers move through the book - in what order of pages, at what speed, how many pages at a time, how long between reading sessions?

- Failure points: Are there pages where readers leave and don't return to the edition?

When we create digital editions aimed at new readers, we model and test our own scholarly knowledge about a text in a way we might not require of ourselves without this fresh audience ${ }^{37}$.

By exploring uses of non-critical public participation like those above, we can let the public identify what they enjoy and what interests them, rather than anticipating and thus shaping the public's experience with and assessment of the relevance of a text.

\subsection{Non-academic online community precedents}

37Ulysses is a particularly good text to offer to new readers because of the book's complexity; certain understandings or interpretations can only be had on a second reading of the book because crucial information for comprehending early portions of the book isn't offered until later in the text. Margot Norris discusses this phenomenon in Virgin and Veteran Readings of Ulysses (Palgrave Macmillan, 2012). 
Online communities outside academia already are working on engaging thoughtful site use $^{38}$. How can we borrow successful social mechanics from these existing communities -mechanics like upvoting and reputation-based privileges - to create reading and research experiences that adeptly handle not only issues of user-authored text quantity, but also quality? Infinite Ulysses builds on existing exemplars of community content

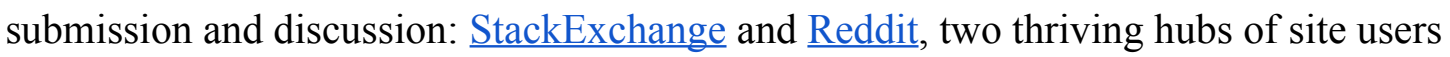
interacting with digital text, each with a variety of subforums dedicated to specific topics for discussion. Readers on these sites aren't interacting with literary editions. The success of the mechanisms supporting their interactions is fairly text-agnostic, though, relying more on an understanding of how people interact online than with what content they're interacting. Besides borrowing specific mechanisms such as upvoting and a queue for unanswered questions, Infinite Ulysses benefits from several broader lessons suggested by these online community platforms:

A tool becomes how its community uses it. The usage of an online community often develops organically - in fits and starts, by word of mouth and by the level of existing user content when a prospective new community member first visits the site. Reddit's unintentional awarding of high-visibility platforms to people who provide highly upvoted content is a particularly useful example for digital editions seeking to highlight quality contributor content. On Reddit, users may edit posts after publishing them; authors of posts that "make the front page" (i.e. get enough upvotes to be seen by a huge number of site visitors landing on Reddit.com) usually make a small addendum on the text of the post to the effect of "wow, I made the front page". There's a sometimes-embraced potential, though, to use that editing power to expose a large number of readers to your thoughts on any subject (e.g. political activism, deeper interpretation of a topic). Providers of "good" content (for some meaning of good) are rewarded with more viewers. As with this example, people will use a site the way that makes sense to them, oftentimes the way that is most convenient in achieving personal goals - whether or not those goals align with a site's mission ${ }^{39}$.

Although I initially anticipated Infinite Ulysses as a place where people would add contextual annotations to the novel, I quickly realized that many readers would use the annotation field to ask questions or simply mark text they didn't understand. To build toward that realistic site usage acknowledges that to read a difficult book is to have questions as well as answers. A future version of the site will borrow a feature from StackExchange: a list of unanswered questions on the site that you can also pull into your RSS feed. Joyce junkies with a few spare minutes over lunch will be able to pull up a

38Another source of design ideas is the Information subdiscipline of "online communities" or "online interaction environments"; "reputation systems" is the term used for studying the mechanics of determining quality online community interaction. A solid introduction to this field can be had in Kraut, R. E., Resnick, P. Building successful online communities: evidence-based social design. Cambridge, MA: MIT Press. 2011.

39Tim Spalding of LibraryThing's discussion of tagging failure on Amazon.com versus tagging success on LibraryThing. 
question or two to answer, and I can identify points in the text in need of thicker annotation. Questions and notes marking non-comprehension can be filtered from view so that they don't overpower annotations containing answers or other substantive content. It might be useful and encouraging to first-time readers, though, to leave a simple icon behind to show that others struggled with the same point in the novel: perhaps a small colored dot at the beginning of a line, or a filter you can turn on to see highlighted text where questions were raised.

\section{The sorting order for displaying multiple annotations on a piece of content matters.} Reddit suffers from a problem where the earliest comments on a post often receive the most upvotes, while later, possibly excellent comments get lost far down the page because users don't read far enough down to assess that writing. Kaj Magnus Lindberg addresses this problem by advocating that sites sort not by upvotes only, but also by upvotes divided by some measure of how much attention a post has received (views or time since the comment was posted $)^{40}$. A similar issue crops up with the question of tagging annotations to allow filtering and toggling: do I define a limited vocabulary that readers can use, or allow users to create new tags? If I choose the latter, how do I deal with similar tags, misspellings, and variants? Even if I put an auto-complete option on the tagging field, the number of possible tags might become so staggering that most tags see little use, and different tagging words are created to basically tag the same thing. With both the questions of sorting comments (i.e. annotations) and wrangling tags, I expect to make changes to the site after I see how real users interact with these options, beginning by designing for the most user flexibility possible.

Reputation is established by your activity on an online community. To reduce the load of work on moderators, StackExchange has tiered ranges of "reputation" points awarded for different activities on the site; new users start with a reduced number of capabilities that expand the more they contribute. This 2009 post on how StackExchange handles moderation emphasizes that abilities and "rep" are gained through active participation and providing content that others deem useful: "Reputation is a (very) rough measurement of how much the Stack Overflow community trusts you. Reputation is never given, it is earned by convincing other Stack Overflow users that you know what you're talking about." With this tiered system plus giving users the ability to flag problematic content for moderator consideration, users are both able to establish credibility and reduce the load of human moderation work. Infinite Ulysses is built to attract diverse Joycean backgrounds, and I worry about creating any bar to participation or a hierarchy of who is "most valuable" to the site. At the same time, rewarding frequent contributions with a weekly top contributors shout-out or a list of top question-answerers on the front page are worth exploring ${ }^{41}$. I'll at least keep private tabs on frequent

40Lindberg, Kaj Magnus. "Solving the problem that the topmost comments get all upvotes".

41One 2013 study found that leaderboards, levels, and points "increased performance, but did not affect perceived autonomy, competence or intrinsic motivation". I'm more interested in perceived autonomy and intrinsic motivation than I am in how prolific 
contributors and try to highlight their work, perhaps by posting curated sets of their annotations on the front of the site.

Any system of comparatively judging user-authored content carries the same issues inherent to meritocracies. Earlier users of the site may accrue more upvotes to their annotations, and usernames that indicate higher credibility (whether through association with a real name, implied gender, or some other metadata producing unconscious bias) may see an unfair percentage of upvotes. Reddit has experimented with various voting algorithms to combat these issues, and Infinite Ulysses defaults the annotation view to a random ordering so no annotation stops being seen (unless it's of such poor quality as to warrant moderation or deletion) and is careful to not visually differentiate annotation authors by their backgrounds.

\section{How can we apply these lessons to participatory digital edition design? "Theory of} Reddit", a Reddit subforum that defines itself as "a mildly navel-gazing space for inquiring into what makes Reddit communities work and what we in a community can do to help make it better", offers the insights of an online community talking about being an online community. Below, I've demonstrated how three example "Theory of Reddit" threads were translated into visual and structural design choices for Infinite Ulysses:

\begin{tabular}{|l|l|}
\hline "Theory of Reddit" discussion & Participatory digital edition application \\
\hline $\begin{array}{l}\text { How upvoting is meant to work (upvote } \\
\text { content that is a positive addition to the site, } \\
\text { downvote things that you don 't want to see as } \\
\text { part of the community thoughtspace) and how } \\
\text { upvoting actually works (people upvote things } \\
\text { they agree with, downvote things with which } \\
\text { they disagree) }\end{array}$ & $\begin{array}{l}\text { Be prepared for unexpected uses of social } \\
\text { mechanics. Don't expect users to read and/or } \\
\text { etiquette. Data on annotation voting may not } \\
\text { represent what you think it represents, as each } \\
\text { user may vote for different reasons at different } \\
\text { times. }\end{array}$ \\
\hline $\begin{array}{l}\text { Changes in the Flesch-Kincaid reading level } \\
\begin{array}{l}\text { of user comments since the beginning of the } \\
\text { site }\end{array}\end{array}$ & $\begin{array}{l}\text { Growth in digital edition user community may } \\
\text { bring with it a diminishment of the level of } \\
\text { "critical" discussion. Design to handle this } \\
\text { (either valuing other types of discourse, or } \\
\text { scaffolding critical discussion). }\end{array}$ \\
\hline $\begin{array}{l}\text { Troubleshooting underprovision (users } \\
\text { relying on other users to create the content } \\
\text { that makes the site useful for everyone })^{42}\end{array}$ & $\begin{array}{l}\text { Although the underpinning hypothetical to } \\
\text { Infinite Ulysses was "what if we build a } \\
\text { digital edition and everyone shows up?", I }\end{array}$ \\
\hline
\end{tabular}

readers are, so leaderboards might not be an appropriate motivator for Infinite Ulysses' site users. From Mekler, Elisa et al. "Do points, levels and leaderboards harm intrinsic motivation?: an empirical analysis of common gamification elements". Proceedings of Gamification '13: Proceedings of the First International Conference on Gameful Design, Research, and Applications. 66-73. 42As with many highly upvoted r/theoryofreddit posts, this thread links to a formal scholarly study: Gilbert, Eric. "Widespread Underprovision on Reddit". CSCW'13. San Antonio, Texas. February 23-27, 2013. 
also thought through "what if no one shows up?" and "what if readers show up, but don't want to create site accounts or add content to the site?". My experience with the earlier UlyssesUlysses site (which did not allow participation) was that a well-designed and moderately annotated digital edition of a difficult text would draw grateful readers regardless of the presence of other authors' annotations ${ }^{43}$.

\subsection{Ulysses under hypertextualization and hyperannotation}

Now that we've established a sense of how the online community for a participatory digital edition might function, let's turn to the particular text of Ulysses and consider the effects of the hypertextualization a digital edition creates and the hyperannotation a participatory edition allows.

While there isn't a complete critical digital edition of Ulysses yet published, that hasn't kept Joycean scholars from anticipating issues that might arise with the eventual migration to digital space. Where the limitations of print space have in the past kept annotations of the text in check, what will happen when a digital platform allows the addition and navigation of crowd-authored annotations? Can we migrate complex print hypertexts such as Ulysses to a digital space with socially multiplied annotations without "diminish[ing] the force of the book" ${ }^{44}$ ? Mark Marino asks, "Would the creation of a system that automatically makes available all the allusions, unravels all the riddles, and translates foreign languages normalize Joyce's text?" Derek Attridge similarly sees a risk to Ulysses through the novel's "cultural supremacy": "[Ulysses has turned] into a text that confirms us in our satisfied certainties instead of one that startles and defies us and thus opens new avenues for thought and pleasure. It now provides a spurious sense of rich complexity by reducing differences and distinctions" ${ }^{\prime 4}$. One imagines this state of diminished power, if true, would only be augmented by hypertextualization and hyperannotation.

Yet Attridge also sees promise in the digital development of the text:

The very magnitude of the encyclopedic Joycean hypertext can itself be unsettling... and it may be possible to produce a hypermedia version of Ulysses that is anything but reassuring - one that revives, in new ways, the provocations and disturbances of the original publication... The best teachers (like the best

43See Section 3.8 for a discussion of Infinite Ulysses' moderation and curation systems, addressing how some readers may prefer only seeing annotations at a certain level of quality. Infinite Ulysses' customization options allow the site to serve readers who prefer to only see content from a limited number of expert annotators.

44Marino, Mark C. "Ulysses on Web 2.0: Towards a Hypermedia Parallax Engine". http://www.jstor.org/stable/25571051.

45Attridge, Derek. Joyce Effects: On Language, Theory, and History. London: Cambridge Univ. Press. 2000. 185. 
critics) are those who find ways to sustain the disruptive force of Ulysses even while they do their necessary work of explaining and demystifying. ${ }^{46}$

I'm hoping that using a particular design metaphor for Infinite Ulysses - the participatory edition as a classroom - we might collectively make Ulysses' chaotic wonder accessible to more readers, without also dampening that wonder.

Despite there being no full digital edition of Ulysses against which to test these fears and assumptions about hypertextualization, we already have some questions about what happens to a complex Modernist text when "everyone shows up". I hoped that by creating a site that experiments with allowing "infinite" contextual annotation of Ulysses, we could capture a picture of what a more realistic, but still distracting amount of crowdauthored annotations actually does to our experience of the text.

Now that we have a digital edition of Ulysses, how can we assess what happens to a text under hyperannotation and hypertextualization? To begin, we review various existing types of digital encounters with Ulysses that preceded a full digital edition.

Critical digital design for the text of Ulysses. Perhaps the most ambitious digital Ulysses project to date (if we don't include Gabler's use of TUstep in creating the print synoptic Ulysses), Michael Groden's James Joyce's Ulysses in Hypermedia was one of the first scholarly attempts to present the novel in a digital hypertextual and hypermedia format. Although copyright issues prevented the project being fully realized, a public outline of the intended presentation is available, as well as an online experiment offering textual prototypes dealing with annotation display in eight different ways. Groden's project included some of the first truly practical discussions of realizing a digital Ulysses, introducing questions about design decisions that remain relevant today such as explorations of audience ("Should information be presented differently for first-time readers than for later ones? If so, how can this be done?") and annotation granularity ("Can there be too much information? Too little? Is there a desirable mean?") ${ }^{47}$. The project also offers a reading list for considering the design and deployment of annotations on Ulysses.

Heyward Ehrlich's James Joyce Text Machine offers twelve experiments on the "computer representation and hypertext architecture of textual annotation and commentary for an imaginary electronic edition of Ulysses". Although much smaller in scale than Groden's project, these demonstrations provide another example of the difficult design decisions for porting Ulysses to the Web and emphasize the critical arguments made by various design decisions for displaying and interacting with the text.

46Ibid., 186-188.

47Michael Groden. "'James Joyce's Ulysses in Hypermedia': Problems of Annotation". 
Contextualization. A number of digital projects have provided ways for readers and scholars to contextualize Ulysses:

- James Joyce Online Notes: "An open-access journal that focuses on the people, the words, and other cultural references in Ulysses and the earlier works. It hopes to contribute to the reader's task of learning to become Joyce's contemporary."

- Robert Craven's Concord project's Ulysses: a digital text ${ }^{48}$ and concordance of the novel allowing users to see all instances of a word across the text, as well as a list of words occurring in the novel sorted by frequency of occurrence.

- Naxos' Joyce's Ulysses: A Guide: Commercial iPad app offering the novel's text ${ }^{48}$ with around 800 annotations, audio of the text being read aloud and some of the text's music, and background material including the text of The Odyssey.

- Ulysses Seen: An iPad app and webcomic thoughtfully interpreting the novel in comics form, adding visual context to the novel.

- An online annotated tex $t^{48}$ that uses non-authorized copyrighted annotations, with color-coding of stylistic techniques and tool-tip annotations.

Public audience. Several projects have used various types of digital media to encourage public interaction with Ulysses:

- Nina Belojevic and Jon Johnson's Hyperlit project for the University of Victoria Maker Lab's exhibit, Long Now of Ulysses: Wireframe and design-fiction video considering "a model for a social reading environment that encourages the deep attention required to read literature while also drawing critical attention to structures and habits generated in the digital economy". The project explores digital means of integrating the significant effort of reading Ulysses into readers' daily lives.

- Another Long Now of Ulysses exhibit, Laura Dosky's Making it New Again: Crowdsourced Readings of James Joyce's Ulysses: A small number of "crowdsourced close readings of algorithmically-selected excerpts of Ulysses" manifested through images and text on a timeline.

- In Ulysses: An under-development virtual reality project, "part virtual game, part next generation ebook, part educational tool", that overlays visuals as if the user were walking along Sandymount Strand with audio of Stephen's thoughts from the Proteus episode.

- He liked thick word soup: An app that lets the user "physically and mentally" struggle with selections from Ulysses through touch manipulation of words.

Public annotation projects. Turning to platforms that allow public annotation of Ulysses, I've located two active projects. Brendan Ward's Wikibooks Ulysses displays facsimile pages from the 1922 Shakespeare \& Co. print edition of Ulysses, annotated with Wikipedia-style footnotes. Many annotations, although properly cited, appear to

48The lack of textual reliability for these projects (they're based on an unknown or Project Gutenberg text) is a key reason for not considering these texts to be digital editions. See Section 4 for more on editions semantics and why textual reliability matters. 
have been taken directly from print resources such as Gifford's Ulysses Annotated without permission. Although participation is invited on the front page, only the page creator seems to have created any content. Key takeaways from this project:

1. Effort needs to be put into publicity for a participatory edition, or the edition won't have any participants.

2. A participatory edition needs to hold a clear stance on content intellectual property rights as well as good faith reuse. Although non-commercial, educational tools have some leeway to interpret fair use, wholesale porting of works that consist only of annotations on a text, with no statement about this reuse or attribution, reduces user trust in a project's reliability.

The Genius annotated version of Ulysses comes closest to my vision of a public conversation around Ulysses: visitors can highlight words or passages in the text and add their interpretations, questions, and comments ${ }^{49}$. Genius grew out of the "Rap Genius" site, a project allowing rap enthusiasts to annotate lyrics with interpretations and contextualizations on the same level as other types of poetry. Some of its design metaphors are more understandable knowing they arose from a music tradition rather than a print text annotation tradition.

Readers can up- or down-vote existing annotations as well as "promote" particular annotations onto the profile pages of users who follow their account. Genius grants locked-down, custom "classroom" versions of any text to a teacher and the users the teacher allows; these versions are stripped of all existing annotations so that a reading group can begin with a fresh slate (e.g. my own, recent classroom version of the first episode of Ulysses). Video, audio, and hyperlinks are all allowed as part of an annotation, which means that users have more ways of helping each other understand what Stephen's hat looks like or the sounds you might hear walking along Sandymount Strand. Account verification and annotation cosigning add levels of moderation and approval to user participation. In contrast to the Wikibooks Ulysses, the Genius Ulysses has attracted adequate attention (48 contributors and over 36,000 views) and relies on strong policies and instructions on what makes a good and ethical annotation.

Where does the Genius Ulysses veer from my goals for Infinite Ulysses? Like many public-aimed digital Ulysses projects, the Genius text was unreliable (pages were unclear as to which text of Ulysses they represented) - an unsurprising trend given that until recently, the Project Gutenberg e-text of Ulysses, created by volunteers without a clear methodology or oversight, was the only freely available digital transcription of the novel. The Modernist Versions Project (MVP) recently solved this problem by providing public, free, reusable Modernist texts as digital facsimiles and digital transcriptions checked by

49Rap Genius was created in 2009, a year after the first version of Infinite Ulysses (UlyssesUlysses.com) had gone up. Rap Genius became Genius in 2014 to support areas beyond rap such as literature. 
scholars. Both the text of the 1922 Shakespeare and Co. edition built on by Infinite Ulysses and Samuel Roth's "pirated" edition of Ulysses (which appeared in the U.S. Two Worlds Monthly magazine in 1926) are available from the MVP, so digital Ulysses projects can now easily start from a reliable text.

My takeaway from the Genius Ulysses for Infinite Ulysses was that features allowing participatory creation of annotations needed to be complemented with personalization features that pull each reader's sound from the noise. The Genius Ulysses deals with this by allowing educators to control their own limited-access versions of a text, and by preventing more than one annotation per piece of highlighted text (readers can reply to that one annotation, but these replies are arranged hierarchically beneath the annotation that got there first). I didn't see the Yellow Block Syndrome on Genius' Ulysses (when most or all of a text is highlighted in yellow for annotation purpose ${ }^{50}$ ), but that seemed due to Genius' only allowing one annotation for any piece of text, moderation by teachers on classroom versions of the text, and a limited number of contributors actually adding annotations. For a platform like Infinite Ulysses that invites a conversation around the text, every user needed the option to add their own annotation to any piece of the text, and readers needed to see annotations displayed not in an arbitrary hierarchy but sorted by preferences like topic and author.

Annotation tagging on Genius' Ulysses is absent. Infinite Ulysses' allows the user to hide or display reader comments depending on their topic. Annotated reading is, by definition, being mentally pulled out of the main text repeatedly; since the earliest incarnations of this project (UlyssesUlysses.com), I've tried to design the reading page so that such distractions are limited to desired information: the definitions, interpretations, and comments a given reader is interested, and nothing else. With the Genius interface, you'd need to weigh whether you were willing to click each highlight, with the chance of the annotation not being worth the interruption to you - or of missing annotations that would benefit you, because you were tired of gambling on whether a distraction was worthwhile.

A related issue on Genius was that a given annotation's author is invisible unless you click on the highlight and then click on a "x contributors" link to toggle a view of the associated authors. The display of contributions on a page via bar charts shows relative amounts of activity, although it is not clear whether this activity compared number of annotations, word count among a user's annotations, percent of the page annotated, or something else. While I sympathize with the drive to keep annotation display minimal and thus reduce reader distraction, a platform relying on user-generated content should keep credits to those authors visible to the casual reader without requiring special action.

50Discussed further in Section 3.8. 
The Genius Ulysses design was text-agnostic: the same design as any other book, poem, or rap song on the site. Visual design always carries an argument and a bias, and interfaces to texts are interpretation. Seeing that people could happily interact with Ulysses without a visual design critically crafted to that particular text reminded me of my experience with an early prototype, UlyssesUlysses.com. The design on that early site was specific to Ulysses, but was created at an early stage of my web design learning and wasn't particularly visually supportive of the text; nevertheless, readers contacted me having used the prototype and wanting to know when additional chapters would be available. Despite strong feelings about visual design rhetoric, these two examples helped me set a reasonable scope for the Infinite Ulysses project: thinking about what I can reasonably add to the digital Ulysses conversation in the course of a dissertation, rather than trying to build everything I wish were available and design the perfect interface to compliment my interpretation of the text.

\section{What does hypertextualization and hyperannotation do to Ulysses? The digital} projects discussed in this section each provide new ways for readers and scholars to interact with Ulysses. If we agree with Tanya Clement's proposal that "the argument of a digital edition like In Transition [(which innovates in form, theory, and content)] is formed as much by the underlying theory of text as it is by its content and the particular application or form it takes"51, then one answer to this question is found in the above exploration of the arguments and goals of digital Ulysses projects: Ulysses has multiplied forms from tactile engagement to augmented reality, with no sign yet of exhausting the forms in which readers eagerly engage the text.

Another way to explore what happens to a text under hypertextualization and hyperannotation is to collect data on a digital edition's users and use experience. For Infinite Ulysses, I've collected written and spoken feedback from a variety of site users, as well as automated the collection of site analytic information such as how long users are spending on a given page of the book. In Section 3.9, I'll analyze this data to help us think about who reads a participatory digital edition.

Whatever the means of exploring the effect of new digital presentation and interaction with a text, the emphasis should be on what we can do with our findings. If we find that Infinite Ulysses indeed diminishes the impact of the text, or changes the experience from a pleasurable struggle to a dull plod - or that readers no longer came away from the book with the same interpretations or experience-or some more nuanced discovery, would we want to do something about it? Would we want to design future editions differently? Ultimately, we need to decide on what we value in a digital edition of a text, and explore whether a given edition reifies those values. In the next section, I'll explore how the goals

51Clement, Tanya. "Knowledge Representation and Digital Scholarly Editions in Theory and Practice". Journal of the Text Encoding Initiative. 1. June 2011. 
of a participatory digital edition might manifest themselves, to what extent I successfully embedded Infinite Ulysses with my scholarly values, and how these goals and values translate to real use and user experience. 


\section{Section 3: Digital editions and the design process}

Section 3 addresses how Infinite Ulysses' participatory goals were met by addressing specific design challenges. The results of data collection on user site experience will also be reported and analyzed.

\subsection{Humanities design thinking}

"Design thinking" is an approach oriented to the process and products of design. To understand what design means in a humanities context, I've parsed the overlapping design approaches used in this project as non-speculative and speculative project design, design of an artifact for theoretical purposes, interface functionality design, interface visual design, user-driven design, and data-driven design. I use "project design" ${ }^{52}$ here to refer to the creation and refining of overarching decisions that will be embodied by the project in its final state, aspects such as broadly construed features, goals, audience, and technology choices that are often the purview of a project development role at a digital humanities center. Speculative project design (as with my speculative experiment, discussed in Section 1.1) applies these concerns to the modeling of a hypothetical artifact. The design of Infinite Ulysses is based on theoretical precedents and also tests its own contribution to digital humanities theories.

Other types of digital design used in this project apply to specific aspects of the website. Interface functionality design concerns a digital artifact's interactive mechanics and behavior (what the user can do with the artifact); "web development" is the term often applied to practitioners who use code to create digital interface functionalities. Interface visual design concerns a digital artifact's visual appearance ("look", e.g. color palettes, typography); "web design" (as opposed to development) is the term often applied to practitioners who use code to create digital interface visual appearance.

This project further uses both user-driven and data-driven design, both on the level of project and interface design. "User-driven" design means use of audience needs, feedback, and data (both qualitative and quantitative survey answers and analysis of those answers, for example) in refining an artifact's design, as well as the use of participatory design techniques (as with my sketching ideal book page layouts with beta-testers; see Section 3.9). "Data-driven" connotes use of quantitative data (e.g. site analytics) in refining project and interface design.

The Design-Based Research Collective describes design research as helping "embody specific theoretical claims about teaching and learning, and help[ing] us understand the

52I use the term academic project design similarly to industrial product design: each concerned with outcomes over individual choices and instantiations of look and behavior. 
relationships among educational theory, designed artifact, and practice" ${ }^{53}$. The approach combines the theoretical activity of abstract modeling with a tangible artifact that could be incrementally inflected to test different hypotheses: "research results that are validated through the consequences of their use, providing consequential evidence or validity." ${ }^{5455}$. You may see digital humanities scholarship through design referred to as critical design ${ }^{56}$, building as scholarship, or making ${ }^{57}$.

\subsection{User testing in the digital humanities}

My master's thesis user study explored how digital humanities archives aimed at a primary audience of scholars could also serve public users. I investigated whether the promise of new learning from digital texts extends beyond scholars to amateurs, or whether the design of purpose-built digital texts - by focusing on more experienced users with direct lines of communication to digital text developers - prevents this extension of benefits. This 2009-2010 study gauged one subgroup of amateur users' perceptions of the value of digital texts in terms of answering self-generated research queries. The participants, graduate students from the University of Michigan's information master's program, worked with a digital archive (either the Blake or Whitman project) and provided narrative and survey data assessing their experience of digital text features and perception of their learning success.

An analysis of the survey data produced an introductory understanding of amateur users' perceptions of their digital text use, their design needs, and their success or failure at learning through digital texts. The study gathered data about amateur-audience digital text use in three areas: general use, nature and success of research queries, and the interplay between experience with digital texts and success at achieving new knowledge. I decided to focus on digital archive use, assessing these resources by whether users were answering their research queries when using that resource; questions pertaining to digital text usefulness (i.e. relevance of the digital text to the amateur audience) and usability (e.g. efficacy of individual features, site structure) were avoided as outside this study's scope.

Infinite Ulysses builds in the opposite direction, looking for shared activities and needs between public readers and scholars. Planned features to better support scholarly users include bulk-editing of your own annotations and bulk-tagging of any annotation; a way

53The Design-Based Research Collective: "Design-Based Research: An Emerging Paradigm for Educational Inquiry"; Educational Researcher. 32(1). Jan/Feb 2003. 5-8.

54Messick, S. "The interplay of evidence and consequences in the validation of performance assessments". Educational Researcher. 23(2). 1992. 13-23. as cited by and with Sasha Barab and Kurt Squire, "Design-Based Research: Putting a Stake in the Ground". The Journal of the Learning Sciences. 13(1). 2.

55Barab, Sasha and Kurt Squire, "Design-Based Research: Putting a Stake in the Ground". The Journal of the Learning Sciences. 13(1). 3.

56Note that a seemingly similar term, "critical code studies", more often applies to exploring arguments and theoretical assumptions underlying pieces of code than it does to the kind of code use for critical building purposes used in this project.

57As with the Maker movement, with or without the complications of the commercial MAKE enterprise. 
to bulk-import annotations and assign them to specific pages and text ranges would also assist readers coming to the site with previous written analytic work on the text. For this beta-testing period, I've focused on the site as a place where new readers are supported through a first encounter with a difficult text, scholars can both model their memory of that encounter for other readers, and teachers can gain a sense of the kinds of questions and needs their students may bring to the text.

Claire Warwick's 2012 piece "Studying users in digital humanities" offers an excellent overview of what's been done towards digital humanities user testing:

Until relatively recently, it was unusual to study users in digital humanities. It was often assumed that the resources created in digital humanities would be used by humanities scholars, who were not technically gifted... there was little point asking them what they needed, because they would not know, or their opinion about how a resource functioned, because they would not care. It was also assumed that technical experts were the people who knew what digital resources should look like, what they should do and how they should work... their opinion was the one that counted, since they understood the details of programming, databases, XML and website building. The plan, then, was to provide good resources for users, tell them what to do and wait for them to adopt digital humanities methods. ${ }^{58}$

Warwick notes that despite perceptions otherwise, we actually do have many user studies about how humanities scholars use information ${ }^{59}$; what we don't have is user studies about humanities scholars using digital humanities information sources ${ }^{60}$. She suggests looking at overlaps between what we know about offline humanities scholarly information use and what we know about online scientific information use to begin filling in the blanks of digital humanities user knowledge, until more practitioners incorporate user studies into the life of their projects ${ }^{61}$.

Interface is argument: a critical act both to create and read. For digital editions, interfacing arguably is the digital edition insofar as it is the thing encountered by its users -what they see and interact with. Intellectual values are embedded in interface design. User testing is a strong way to examine these values and arguments and gather real data on how they're communicated to an edition's users.

\subsection{Why does the digital edition design process matter?}

58Warwick, Claire. "Chapter 1: Studying users in digital humanities". Digital Humanities in Practice. Eds. Claire Warwick, Melissa Terras, and Julianne Nyhan. 2012. 1.

59Ibid., 2.

60A good example of DH user-testing is offered by Hitchcock, Tim et al. "Crime in the Community". (2010-2011). Two-part study exploring use of the Old Bailey Proceedings Online and creating new features and tutorials in response to findings. Products include a "Rapid Impact Analysis Report" and case study.

61If you'd like to read more about digital humanities user-testing, my four-part blog post series pulls user-testing examples from related disciplines that apply well to DH projects, as well as focusing on user-testing public DH project users. 
To be effective, a website has to be designed as a whole. It has to have consistency... in its look and feel. Indeed, the look and feel of a website... are part of its ideology, part of its thesis or argument, and just as we would reject a paper with a jumbled and incoherent thesis, we should reject web materials with a jumbled or inconsistent design.

— Michael O'Malley, "Building Effective Course Sites: Some Thoughts on Design for Academic Work" ${ }^{12}$

Digital edition methodologies, several decades after editors began to use digital platforms for their work, still leans too heavily on the affordances of print models rather than digital platforms:

The contours of a truly electronic-sensitive [editing] theory will only become apparent as we shed assumptions (still too prevalent) of how digitization and encoding enhance or betray the operations and purposes of print. Electronic editions on these terms are still in an early stage of design; our theorizing, though vigorous, is still in its infancy.-Kathryn Sutherland ${ }^{63}$

Throughout the history of textual scholarship, scholarly attention to design-visual design in particular-has lagged behind attention to a text's linguistic codes. Bornstein and Tinkle's The Iconic Page in Manuscript, Print, and Digital Culture illustrates our history of ignoring the information carried in the design of the codex page. Medieval illuminated manuscripts provided a sensory feast: colors and symbols; the texture, smell, and taste of parchment in the air or left on a reader's fingertips; the sounds of the typical method of medieval reading - aloud ${ }^{64}$. Despite the first codices carrying this riot of sensory information, it isn't until the twentieth century and the work of the New Bibliographers that we really see scholarly attention really turn to bibliographic code ${ }^{65}$. After the New Bibliographer's systematic attention to the features of the work as an artifact, social editing brought an extra dose of iconic awareness through a new attention to textual collaborators such as printers and illustrators. New Bibliography and social editing involve a heightened awareness of the features and collaborations involved in the latter products of the creation process, but iconic features are important even in our editing of "pre-publication" documents such as manuscript drafts and fair copies.

Drucker and McVarish's Graphic Design History: A Critical Guide makes clear there are no Platonic ideals of design, and no techniques that truly allow transparency of the visual to the "content" of the "textual vessel". We judge design by conformance to contemporary styles of reading and communication that determine how distracting, helpful, or

62In "Essays on History and New Media" from the RRCHNM 20.

63Sutherland, Kathryn. "Anglo-American Editorial Theory". In Cambridge Companion to Textual Scholarship. Eds. Neil Fraistat and Julia Flanders. Advanced copy. 2012. 65.

64Bornstein, George and Theresa Tinkle, eds. The Iconic Page in Manuscript, Print, and Digital Culture. University of Michigan Press, 1998.

65Gary Taylor blames this on Shakespeare in his "The Renaissance and the End of Editing" speculative experiment, but I suspect this trend would have resulted regardless of the texts at the root of the textual scholarship tradition. 
"transparent" visual design appears to us, styles that in turn feed back into the types of graphic design being developed ${ }^{66}$. Much of the "fundamental" features of the codex were developed in that mechanism's early, medieval days - features such as page numbering and chapter headings - in order to help readers access a particular layout of information. In addition to cultural styles of information access, changes in media technology also feed back into how we know; the technology of engraved plates, for example, allowed for a rapid upswing in the dissemination and development of complex scientific knowledge ${ }^{67}$.

Design gets short shrift in the MLA's "Guidelines for Editors of Scholarly Editions". Editors establish reliability in five areas, two of which - the adequacy of the editorial documentation and the appropriateness of those editing decisions - are directly affected by the design of the delivery format. These methods include the visual choices, cues, and codes of the edition's design: "giving the rationale for decisions concerning construction and representation... discussing... where appropriate, the layout, graphical elements, and physical appearance of the source material" ${ }^{168}$. These guidelines do not touch on specific aspects of extra-textual online edition design, such as design beyond the rendering of facsimiles (e.g. a site's color palette, logo design, how features supporting research and discovery look and work, etc.), only broadly suggesting that "the stylesheets (or other rendering instructions) [be] documented as to their intended effect".

As design in all its meanings becomes more acknowledged in the digital humanities, it's useful to examine popular assumptions about design against actual design work. Nondesigners may be quick to think that "designing for multiple audiences is designing for no one", instead of thinking "How do I design for this space where we learn together? How can I reconcile differing priorities while I design?" For example, the Nielsen usability heuristic (explored in more detail below) includes paths suited for both new users and users with expert knowledge and/or more intensive activity as one of its ten key usability concerns:

Flexibility and efficiency of use: Accelerators-unseen by the novice user-may often speed up the interaction for the expert user such that the system can cater to both inexperienced and experienced users. Allow users to tailor frequent actions. ${ }^{69}$

It is good policy to not design too broadly; "readers of all types" or "learners of all ages" are not helpful design personas. DH projects with clearly stated and prioritized values can design for multiple user types, though, as long as it's understood where the needs of these types overlap and how design choices will be prioritized when a project does need to choose which user type to serve first (or at all) with a particular feature. Participatory

66Drucker, Johanna and Emily McVarish. Graphic Design History: A Critical Guide. Pearson, 2008.

67Ibid.

68Modern Language Association. "Guidelines for Editors of Scholarly Editions". From the page last updated June 29, 2011.

69Nielsen, J. (1994). Heuristic evaluation. In Nielsen, J., and Mack, R.L., eds. Usability Inspection Methods. John Wiley \& Sons. New York, NY. 
design works for and takes feedback from multiple overlapping groups, and our focus on the shared space of the public humanities is ripe for this approach.

\subsection{Scholarly values}

As I built Infinite Ulysses, I wanted to regularly check that my work demonstrates the scholarly values important to $\mathrm{me}^{70}$. The Shelley-Godwin Archive offers an effective example of a specific design decision in line with the edition's values: stoplight icons appear on each of the archive's edition pages, using our intuitive understanding of red, green, and yellow lights to quickly signal the authority of the displayed transcription (red means no transcription, yellow means a basic unvetted transcription, and green means a fully vetted and encoded transcription). Below, I describe my scholarly values and identify how my project reifies them:

Accessibility through universal design. As much as possible, design for all readers; build on existing work on usability and accessibility to create better DH-specific accessibility tutorials and standards. My digital edition includes a page addressing accessibility both in terms of inclusivity and in diverse ways of handling computer input and output, identifying what work has been accomplished toward this goal and what work remains. A label in the digital edition's GitHub repository issues queue marks out site bugs and enhancement ideas that are accessibility barriers so that I can prioritize addressing them and others can lend a hand if they wish.

A public humanities through pragmatic dreaming. Teaching is knowing; you should be able to explain your work to a non-specialist audience (without forgetting there's no royal road to geometry ${ }^{71}$ ). While using speculative experiments is a key methodology for at least the Infinite Ulysses portion of my dissertation (what happens if we build a digital edition and everyone shows up?), I also want these experiments to produce deliverables useful here and now: a participatory edition for reading and discussing Ulysses that's already in use by real readers. The first set of annotations I added to the edition were specifically aimed at helping first-time readers handle the first two episodes of the novel.

Building is scholarship... and while I believe that some works of built scholarship do not require replication or analysis in written form to exist as intellectual contributions to the

70The idea to align my scholarly values against produced work was suggested by digital humanist Scott Weingart‘s "pledges” page, which records his definition of being a good scholarly citizen: committing to open access and open source all the time, reducing barriers to participation in and extension of his scholarly work. Publicly recording what's important to you helps regularly check that you're acting in a way that accords with your values, and not just when it's convenient. For example, if accessibility is important to me, I need to make certain that value is reflected in my current work, and I need to educate or reject participation in venues (conferences, projects) that don't care about accessibility.

71"It is too bad that [the language for explaining mathematics] has to be mathematics, and that mathematics is hard for some people. It is reputed - I do not know if it is true - that when one of the kings was trying to learn geometry from Euclid he complained that it was difficult. And Euclid said, 'There is no royal road to geometry'. And there is no royal road. Physicists cannot make a conversion to any other language. If you want to learn about nature, to appreciate nature, it is necessary to understand the language that she speaks in.”

—Richard Feynman, The Character of Physical Law. 58. 
community, some sort of narrative of the methods and experience of creating the work is important to its reception and usage. To reach a wider, non-specialist community, that often means a written narrative. The benefits of reaching a wider audience by replicating your built scholarly work in an article or monograph aren't as important as getting that work done, though - so we need to advocate for student projects and dissertations to be accepted in forms other than the monograph, because the common requirement of doubling one's built scholarship with a monograph spreads a chilling effect on young scholars' interest in trying design, coding, and other digital or non-monograph-form scholarly work. This whitepaper provides an analytic discussion of my overall project, while its comparatively short length (to the usual humanities proto-monograph) meant that I could accomplish the design and code work I desired without the penalty of doubled labor.

Design is not pre-critical. When I consider an edition and what information it's trying to express, I've moved from thinking about the narrative content of a piece of literature to aspects such as its interpretations and reception history - those features the scholarly editor foregrounds in their textual notes and methodology, aspects which a well-designed interface can support or augment. This information-centered approach requires thinking about your audience and your goals for the use of your scholarly product. What we see when we encounter an edition shapes the questions we raise, the biases we inherit, and the things we end up knowing; as Jon Saklofske asks during his reimagining of the Blake Archive interface: what are the interpretive resonances of redesign ${ }^{72}$ As I designed Infinite Ulysses, the foremost goal was that the site be welcoming to readers from the public_-something user surveys suggest was achieved (see Sections 3.9.2 and 3.9.3).

A public humanities is a participatory humanities. The humanities scholar's work is preserving human culture, and preservation means propagation ${ }^{73}$. Communication of our nerdy passions should be a two-way conversation, with the new questions and thoughts from readers outside our field or the academy brought into the great conversation. User testing incorporates audience participation into the design as well as the final use of a project, but the digital humanities has been slow to establish best practices for $\mathrm{DH}$ specific user testing. I hope to help make user testing easier to include in a grant timeline by exploring and consolidating best practices. My overall focus on designing for lowbarrier public participation also addresses this value. I further broke "participation" into five values necessary to achieve that goal:

1. Inclusion. Public users are an acknowledged audience for the site design; site design is made as universal as possible so barriers to various input/output devices used to access the site are limited.

72Saklofske, Jon. “NewRadial: Revisualizing the Blake Archive”. Poetess Archive Journal 2.1 (December 2010). 73See Ernest Cline' novel Ready Player One for a charming parable of cultural preservation through reviving cultural relevance. 
2. Welcome. Public users felt invited to interact with the site; design shouldn't create a visual hierarchy of power or credibility based on educational background.

3. Encouragement. Public users felt not only invited to interact, but that their participation benefitted the community. Keeping information about a user's accrued points hidden for backend use sorting annotation order, and not displayed on the site, tried to keep points gathering from discouraging users or encouraging quantity of annotations over quality.

4. Enfranchisement. Public users' feedback shaped how the site design develops. Multiple mods to reach the site creator with feedback were highly visible.

5. Clarity. Users could easily understand what steps to take to begin participating.

\subsection{Usability heuristic}

An obvious first step toward that value of clarity was to improve the site's usability. In addition to various forms of user testing discussed in Section 3.9, I've used a popular user experience heuristic to assess how the digital edition addresses basic usability values. The characteristics in the first column are taken directly from the Nielsen usability heuristic.

\begin{tabular}{|l|l|l|}
\hline $\begin{array}{l}\text { Nielsen Usability Heuristic } \\
74,75\end{array}$ & $\begin{array}{l}\text { How does Infinite Ulysses meet } \\
\text { this standard? }\end{array}$ & $\begin{array}{l}\text { How could Infinite Ulysses improve } \\
\text { how it addresses this standard? }\end{array}$ \\
\hline $\begin{array}{l}\text { Visibility of system status: The } \\
\text { system should always keep } \\
\text { users informed about what is } \\
\text { going on, through appropriate } \\
\text { feedback within reasonable } \\
\text { time. }\end{array}$ & $\begin{array}{l}\text { When users add annotations to the } \\
\text { site, these annotations and their } \\
\text { associated highlights are } \\
\text { immediately visible to them (even } \\
\text { if they aren't visible to other } \\
\text { readers until moderation). When } \\
\text { an annotation is flagged for } \\
\text { moderation, a message appears } \\
\text { alerting the user that the } \\
\text { annotation will be looked at and } \\
\text { that it will not display to the } \\
\text { public until it is moderated. }\end{array}$ & $\begin{array}{l}\text { Un (n) } \\
\text { number of people from their reading } \\
\text { group or class on the same page, } \\
\text { usernames of readers on the same } \\
\text { page, usernames of people from their } \\
\text { reading group or class on the same } \\
\text { page). Users requested display of } \\
\text { current page number, the bookmark } \\
\text { automatically updating to latest book } \\
\text { page a reader visited, a graphic } \\
\text { displaying their progress and location } \\
\text { through the novel, and a way to go to } \\
\text { any particular page of the book from } \\
\text { anywhere on the site (not just to } \\
\text { episodes' first pages, as in the book } \\
\text { table of contents menu). }\end{array}$ \\
\hline $\begin{array}{l}\text { Match between system and } \\
\text { the real world: The system } \\
\text { should speak the user's language, }\end{array}$ & $\begin{array}{l}\text { Careful situation of "annotation" } \\
\text { next to words like comment, } \\
\text { question, interpretation to make }\end{array}$ & $\begin{array}{l}\text { "Comment" wasn't used to mean } \\
\text { "annotation" because the site is meant } \\
\text { to allow comments on annotations, }\end{array}$ \\
\hline
\end{tabular}

74Nielsen Group.

75Nielsen, J. Heuristic evaluation. In Nielsen, J., and Mack, R.L., eds. Usability Inspection Methods. John Wiley \& Sons. New York, NY. 1994. 


\begin{tabular}{|c|c|c|}
\hline $\begin{array}{l}\text { with words, phrases and } \\
\text { concepts familiar to the user, } \\
\text { rather than system-oriented } \\
\text { terms. Follow real-world } \\
\text { conventions, making } \\
\text { information appear in a natural } \\
\text { and logical order. }\end{array}$ & meaning more clear. & $\begin{array}{l}\text { and "annotations on annotations" } \\
\text { would be too confusing. These terms } \\
\text { will need rethinking to make them } \\
\text { more intuitive, especially when } \\
\text { commenting on annotations is added } \\
\text { back into the site. }\end{array}$ \\
\hline $\begin{array}{l}\text { User control and freedom: } \\
\text { Users often choose system } \\
\text { functions by mistake and will } \\
\text { need a clearly marked } \\
\text { "emergency exit" to leave the } \\
\text { unwanted state without having } \\
\text { to go through an extended } \\
\text { dialogue. Support undo and } \\
\text { redo. }\end{array}$ & $\begin{array}{l}\text { Favorite, moderation, and voting } \\
\text { icons all allow immediate one- } \\
\text { click revision. Tags can be } \\
\text { immediately removed. } \\
\text { Annotations can be edited via a } \\
\text { link to a separate page. }\end{array}$ & $\begin{array}{l}\text { Allow tag and annotation editing from } \\
\text { the book page rather than from a } \\
\text { linked page. }\end{array}$ \\
\hline $\begin{array}{l}\text { Consistency and standards: } \\
\text { Users should not have to } \\
\text { wonder whether different } \\
\text { words, situations, or actions } \\
\text { mean the same thing. Follow } \\
\text { platform conventions. }\end{array}$ & $\begin{array}{l}\text { I attempted to use the same } \\
\text { terminology throughout the site. }\end{array}$ & $\begin{array}{l}\text { I need do further testing with users, } \\
\text { such as describing an action for a user } \\
\text { to perform without using the site } \\
\text { terminology, then see if they use site } \\
\text { terminology when explaining how to } \\
\text { perform the action. }\end{array}$ \\
\hline $\begin{array}{l}\text { Error prevention: Even better } \\
\text { than good error messages is a } \\
\text { careful design which prevents a } \\
\text { problem from occurring in the } \\
\text { first place. Either eliminate } \\
\text { error-prone conditions or check } \\
\text { for them and present users with } \\
\text { a confirmation option before } \\
\text { they commit to the action. }\end{array}$ & $\begin{array}{l}\text { Moderation flags so far have all } \\
\text { been for annotations that don't } \\
\text { need moderation, suggesting users } \\
\text { either don't know what the icon is } \\
\text { for or are hitting it accidentally. } \\
\text { Tooltips on moderation and other } \\
\text { icons assist if noticed. See also } \\
\text { "user control and freedom" above. }\end{array}$ & $\begin{array}{l}\text { Tooltips aren't enough and may not } \\
\text { work for some methods of accessing } \\
\text { the site. We need clearer mechanisms } \\
\text { throughout the book sidebar, possibly } \\
\text { through removing all customization } \\
\text { features to a set-and-forget form on } \\
\text { the user profile page. See also "user } \\
\text { control and freedom" above. }\end{array}$ \\
\hline $\begin{array}{l}\text { Recognition rather than } \\
\text { recall: Minimize the user's } \\
\text { memory load by making } \\
\text { objects, actions, and options } \\
\text { visible. The user should not } \\
\text { have to remember information } \\
\text { from one part of the dialogue to } \\
\text { another. Instructions for use of } \\
\text { the system should be visible or } \\
\text { easily retrievable whenever } \\
\text { appropriate. }\end{array}$ & $\begin{array}{l}\text { Tooltips on moderation and other } \\
\text { icons assist if noticed. }\end{array}$ & $\begin{array}{l}\text { Instructions for use of a book page } \\
\text { (except for a few tooltips on icons like } \\
\text { favorite, voting, and moderation) are } \\
\text { not accessible on the book page. }\end{array}$ \\
\hline
\end{tabular}




\begin{tabular}{|c|c|c|}
\hline $\begin{array}{l}\text { Flexibility and efficiency of } \\
\text { use: Accelerators-unseen by } \\
\text { the novice user-may often } \\
\text { speed up the interaction for the } \\
\text { expert user such that the system } \\
\text { can cater to both inexperienced } \\
\text { and experienced users. Allow } \\
\text { users to tailor frequent actions. }\end{array}$ & No clear acceleration method. & $\begin{array}{l}\text { Need to allow bulk editing of own } \\
\text { annotations, bulk-tagging of all } \\
\text { annotations. Need to allow bulk } \\
\text { addition of annotations from import } \\
\text { source and method of associating } \\
\text { bulk-imported annotations with page } \\
\text { text ranges. Content experts suggested } \\
\text { some additional tools they'd use in } \\
\text { their research if they were available on } \\
\text { the site in the user surveys. }\end{array}$ \\
\hline $\begin{array}{l}\text { Aesthetic and minimalist } \\
\text { design: Dialogues should not } \\
\text { contain information which is } \\
\text { irrelevant or rarely needed. } \\
\text { Every extra unit of information } \\
\text { in a dialogue competes with the } \\
\text { relevant units of information } \\
\text { and diminishes their relative } \\
\text { visibility. }\end{array}$ & $\begin{array}{l}\text { Multiple depths of site feature } \\
\text { tours are available: the three } \\
\text { captioned image steps on front } \\
\text { page, four captioned image steps } \\
\text { on the About page, and nine slides } \\
\text { on the Tour page slideshow. }\end{array}$ & $\begin{array}{l}\text { The tour feature needs to be radically } \\
\text { compacted, displayed on the front } \\
\text { page, and made easily accessible from } \\
\text { any page of the site (not just hidden in } \\
\text { drop-down menu; perhaps a visible } \\
\text { "help" button in the footer of every } \\
\text { page). }\end{array}$ \\
\hline $\begin{array}{l}\text { Help users recognize, } \\
\text { diagnose, and recover from } \\
\text { errors: Error messages should } \\
\text { be expressed in plain language } \\
\text { (no codes), precisely indicate } \\
\text { the problem, and constructively } \\
\text { suggest a solution. }\end{array}$ & $\begin{array}{l}\text { A warning message appears for } \\
\text { anonymous users that many } \\
\text { features are not displayed on book } \\
\text { pages. }\end{array}$ & $\begin{array}{l}\text { Users in some non-trusted roles may } \\
\text { be confused that they can see their } \\
\text { own annotations when logged in, but } \\
\text { not when they are logged out and not } \\
\text { by other logged in users. Need to find } \\
\text { a way to make this clear without } \\
\text { alerting potential spammers how to } \\
\text { evade spam filter. }\end{array}$ \\
\hline $\begin{array}{l}\text { Help and documentation: } \\
\text { Even though it is better if the } \\
\text { system can be used without } \\
\text { documentation, it may be } \\
\text { necessary to provide help and } \\
\text { documentation. Any such } \\
\text { information should be easy to } \\
\text { search, focused on the user's } \\
\text { task, list concrete steps to be } \\
\text { carried out, and not be too large. }\end{array}$ & $\begin{array}{l}\text { A feedback link in the header of } \\
\text { every page and multiple depths of } \\
\text { feature tours assist users. }\end{array}$ & $\begin{array}{l}\text { The site needs a highly visible FAQ. } \\
\text { The site feedback form should be a } \\
\text { modal on the same page, rather than } \\
\text { bringing the user to a different page. } \\
\text { Tour options need improvement (see } \\
\text { "Aesthetic and minimalist design"). }\end{array}$ \\
\hline
\end{tabular}

Particular areas for digital edition project concentration are "match between system and the real world" (don't use academic terms of art when serving a public audience) and "recognition rather than recall" (complimenting availability of clear site tutorials with intuitive interface design for the whole site). 


\subsection{Technical platform and major code decisions}

In addition to these abstract values assessments, I tried to keep the broad goals of the site in mind when choosing the major code sets the project built on. At the highest level, the site needed to

1. Interface with a database to provide dynamically updating content

2. Allow visitors to add annotations to text pages

There are many excellent reasons to work with free and open-source software (FOSS): for example, demonstrating how a new digital humanities tool could be created by combining existing code with my new code, rather than wholly reinventing the involved wheels. Drupal was chosen to handle the site's dynamic content because it is better at handling structured documents and complex taxonomies than other content management systems, and the annotation solution that best fit Infinite Ulysses' needs had Drupal module versions in active development.

I considered many tools for the annotation functionality, searching not just for "annotation" but for related concepts such as commenting and editorial workflows. A close candidate was Editing Modernism in Canada's Modernist Commons platform, an Islandora system that allows editors to annotate a text via the administration pages of the site, among other features ${ }^{76}$. I decided on $\underline{\text { Annotator.js, }}$, a tool that lets you click and drag your cursor to highlight text, then add an annotation. Unlike any of the other options, Annotator.js allowed you to select specific text to highlight rather than a line or paragraph, was under active development with a lively listserv discussion of development issues, and already offered plugins for two features I wanted on my site:(tagging annotations and controlling who can create and read different annotations.

The Drupal modularization ${ }^{77}$ of Annotator.js was not a plug-and-play solution. Annotations weren't treated as the Drupal default "node" unit, so many modules (plugin code) wouldn't act on annotations out of the box; new tags on annotations looked like they were saved successfully, but actually weren't getting sent to the database and disappeared on refreshing the page. Another digital humanities developer, Michael Widner (an Academic Technology Specialist at Stanford's Division of Literatures, Cultures, and Languages) was also working on the Drupal Annotator modules for the Lacuna Stories project. His code not only fixed the existing Drupal Annotator module problems but added useful new features; he allowed me to incorporate his code in my project and build off his work.

Building off Widner's code allowed me to focus my coding time on adding a new feature to annotation, rather than spending valuable weeks of the dissertation getting the Drupal

76Note that Modernist Commons allows certain common textual scholarship activities that you'd want if trying to make a scholarly digital edition (as defined in Section 4): for example, TEI and RDF encoding.

77To use Annotator.js with the Drupal database, you'll need two modules in addition to the Annotator.js library: Annotator and Annotation. 
version of Annotator.js to do something Annotator.js already could do. I was able to add social ranking of annotations via up-/down-voting to the annotation feature set by removing the Annotator.js annotation display and tying client-side interactions with highlighted text into Views output ${ }^{78}$. This meant that any additions to Drupal annotation nodes - for example, moderation flags - could be displayed and interacted with when viewing an annotation in the book page sidebar.

Infinite Ulysses could not exist without the labor and collegiality of many people. You can read more about contributed code, design properties, and other sources of project support on the site credits page, or read specifically about the provenance of included code from this section in the public code repository.

\subsection{Site appearance}

Only the earliest and latest screenshot are shown in this section; all wireframe (static) and prototype (interactive) screenshots can be viewed from this folder in the public code repository or from Appendix D. Each paragraph's title is linked to the screenshot it summarizes.

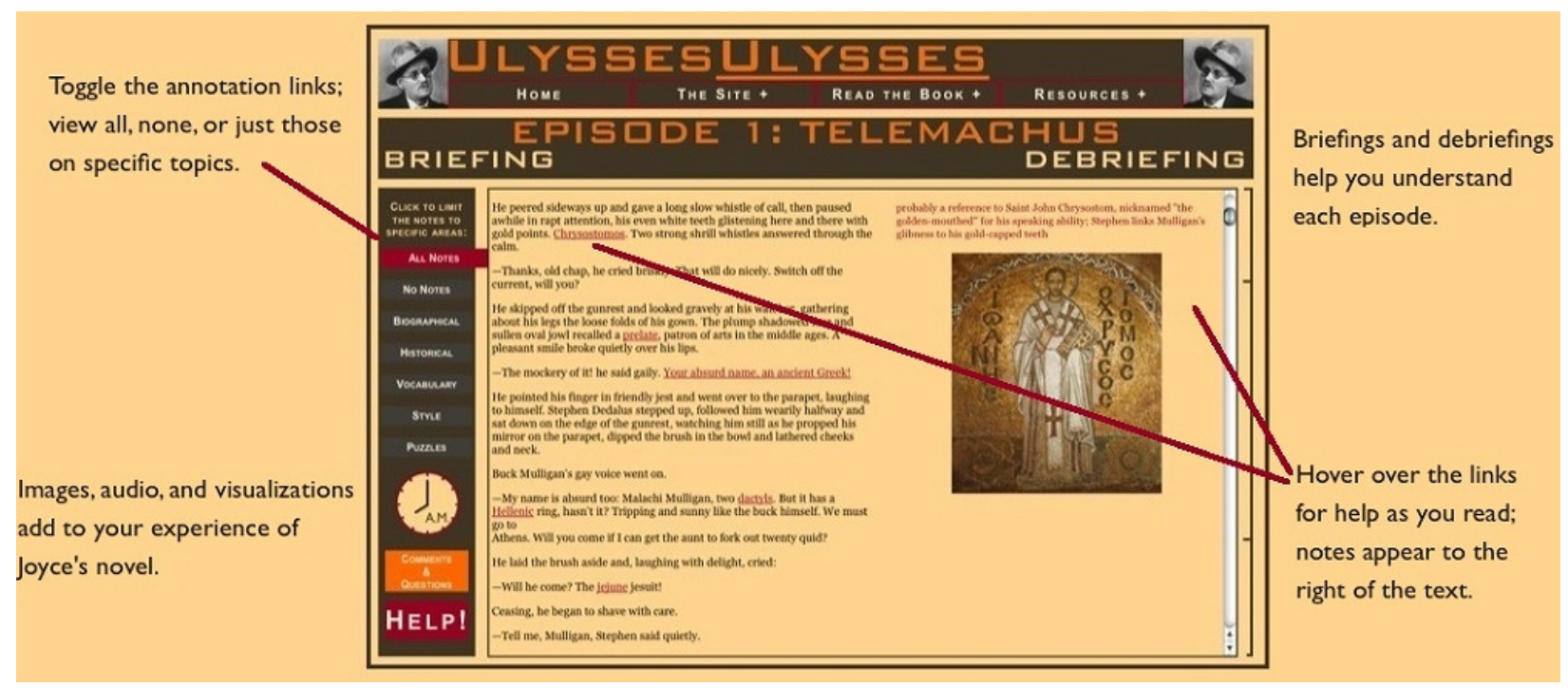

\section{2008-2009: UlyssesUlysses}

Infinite Ulysses builds on HCI and learning technology research conducted during my master's degree, culminating in the 2008-2009 project UlyssesUlysses.com. This early prototype didn't allow reader input; annotations were limited to around 250 definitions and interpretations on the first two episodes of the novel, authored by me. At this point, my main design concern was the personalization of annotations to readers' needs, as a

78The Drupal Views module is basically an interface for displaying results of complex database queries—so I could tell the site commands like "display only those annotations that have been upvoted at least once". 
way to diminish visual distraction and reduce time pulled away from reading the novel to look something up.

UlyssesUlysses allows novel ways of customizing the learning experience (choose which category of annotation you want visibly highlighted) and the reading experience (mouse over difficult words and phrases to see the annotation in the sidebar, instead of reading a text thick with highlightings and footnotes). Problems with the site include use of the non-reliable Project Gutenberg e-text of Ulysses, a complex HTML encrustation to allow the toggling of annotations tied to more than one of the possible filters, and an unpleasant color scheme. I've learned much about web design, textual encoding, and Ulysses since this earliest project, and it's exciting to be able to document these early steps toward a contextualized reading experience with the confidence that this next iteration will be an improvement.

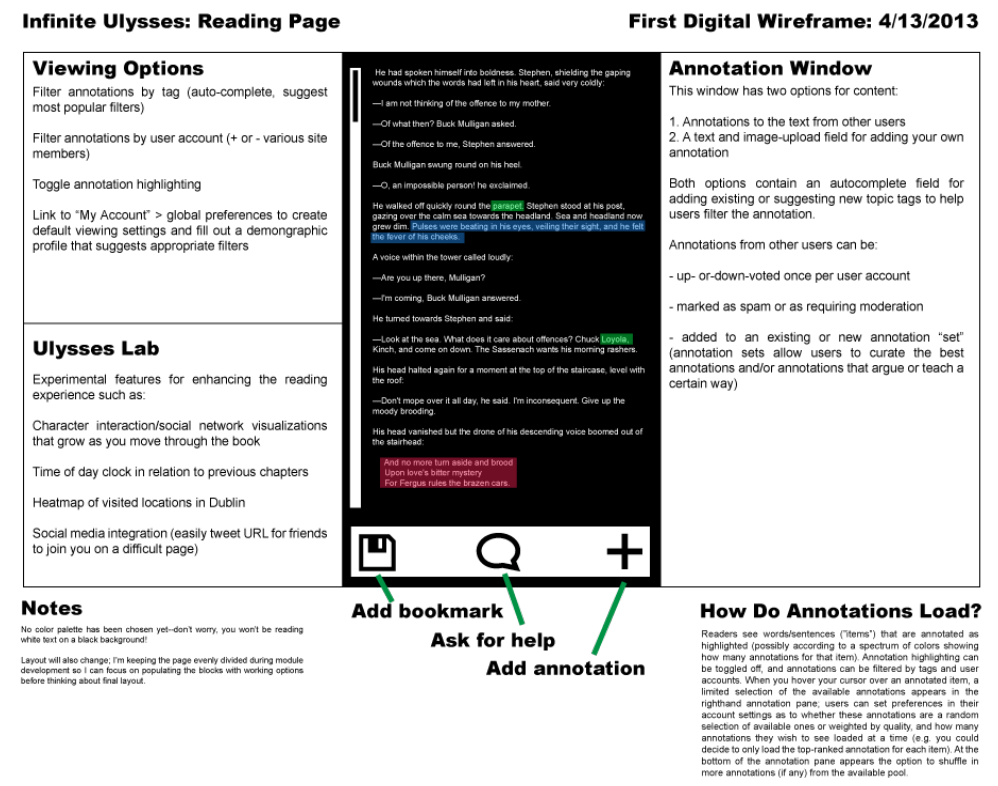

\section{4/13/2013: First Wireframe}

This was a "kitchen sink wireframe"; the point was not to create the final look of the site or to section off correct dimensions for different features, but merely to represent every feature I wanted present in the final design via some mark or symbol. The plan for the final reading page was to offer a central reading pane, a right sidebar where annotations can be authored and voted up or down, and a pullout drawer to the left where readers can fiddle with various settings to customize their reading experience. I already knew at this point that I wanted readers to have the option of setting their default preferences for these features (e.g. that they never want to see annotations defining vocabulary) on their private profile pages. This feature didn't make it into the site during the dissertation process, but 
it's one of my priorities for the site's 1.0 release, as it would cut down the visual noise on reading pages.

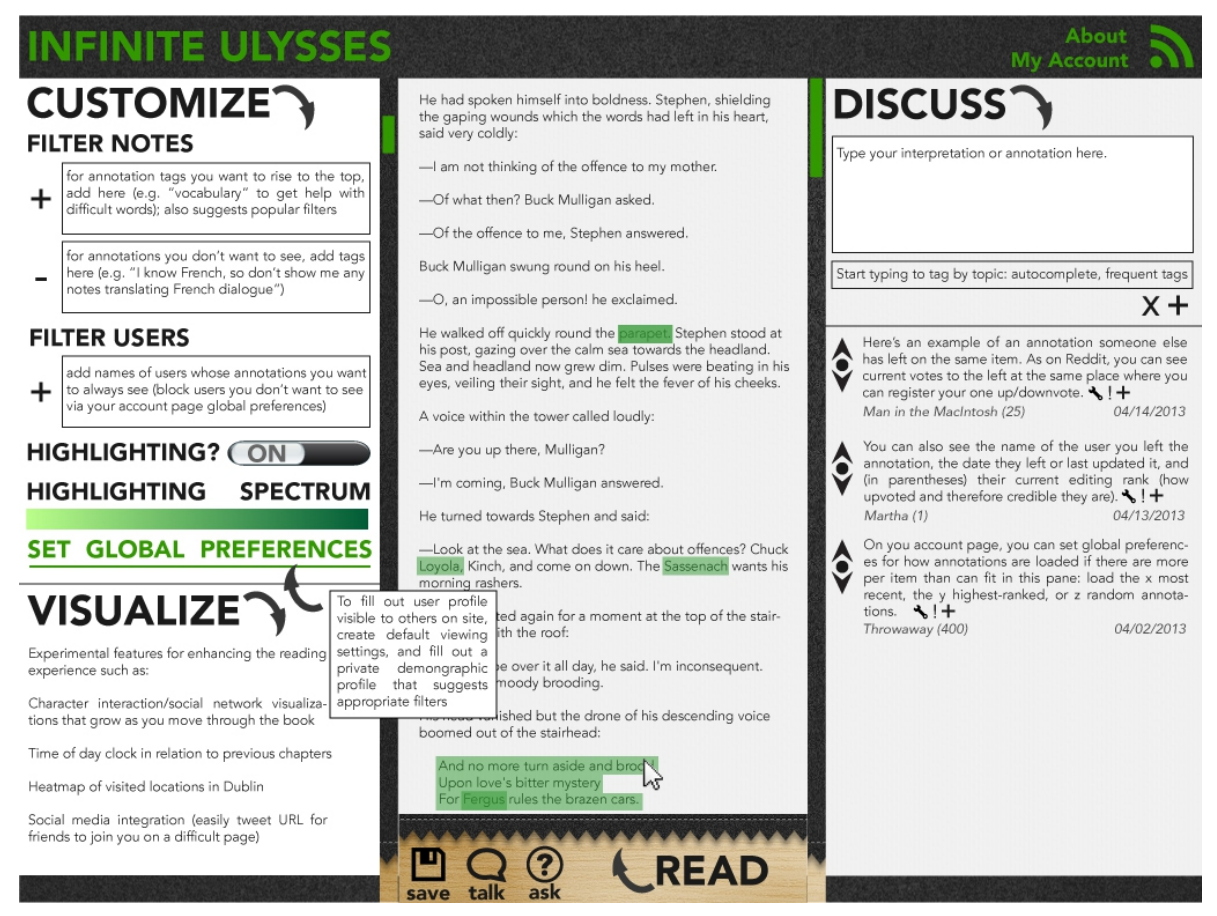

\section{4/13/2014 and 4/20/2014: Wireframes}

At this point I was switching from working with Modernist Commons to Annotator.js, and I was beginning to take public feedback on the design of the site. These wireframes were created around the time of my presentation at the Nebraska Forum on Digital Humanities, when I first opened a form to take in beta-testing volunteer's contact information. The front page shows some of the key ways I wanted readers to be able to interact with the annotations. The book page still has the three-column layout from the previous wireframe; this layout did not make it into the current site because I decided that tablet layout (for which one or both of the sidebars would have collapsed into drawer areas) was out of scope for the dissertation. I like how this separates annotation customization from annotation display, visually chunking them as separate activities.

\section{12/18/2014: Prototype (Front Page and Book Page)}

At this point I was trying to get various conflicting pieces of code working together, with a minimal theme (I believe this was a very mildly customized version of the Zen framework theme).

\section{1/20/2015: Prototype}

This very minimal design was what early talk-aloud and participatory design beta-testers encountered in January 2015. The taskbar along the top was intended to hold drop-down containers with various customization options for the page. 


\section{1/26/2015: Prototype}

This design moved the taskbar into a small right column and added book navigation buttons, which were easier to click than the earlier navigation links. I was still trying to get the interface to look more minimal through use of the taskbar, but the taskbar dimensions weren't right for the items held there.

\section{2/3/2015: Prototype}

More work on the annotation display in the sidebar to condense each annotation's footprint (note the removal of author metadata).

\section{2/4/2015 and 2/5/2015: Prototypes}

Removed the dark color around the book page (meant to house future options like commenting on the whole page and searching inside the book). Still juggling the various annotation fields in the sidebar display.

\section{2/9/2015: Prototype}

Added a tour that stepped through an example book page. The tour was too buggyleaving the tour without clicking the "end the tour" button produced a pop-up that followed you around the site, and clicking outside the tour text box during the tour (e.g. to try the annotation sorting the tour was describing) broke the tour.

\section{2/16/2015: Prototype}

The bookmark icon appears and further small positional shifts are made to the book box and annotation fields in the sidebar.

\section{2/23/2015: Prototype}

Major changes to the look, bringing back the minimal color and cleaner lines. The annotation sidebar is settling into its near-final form here.

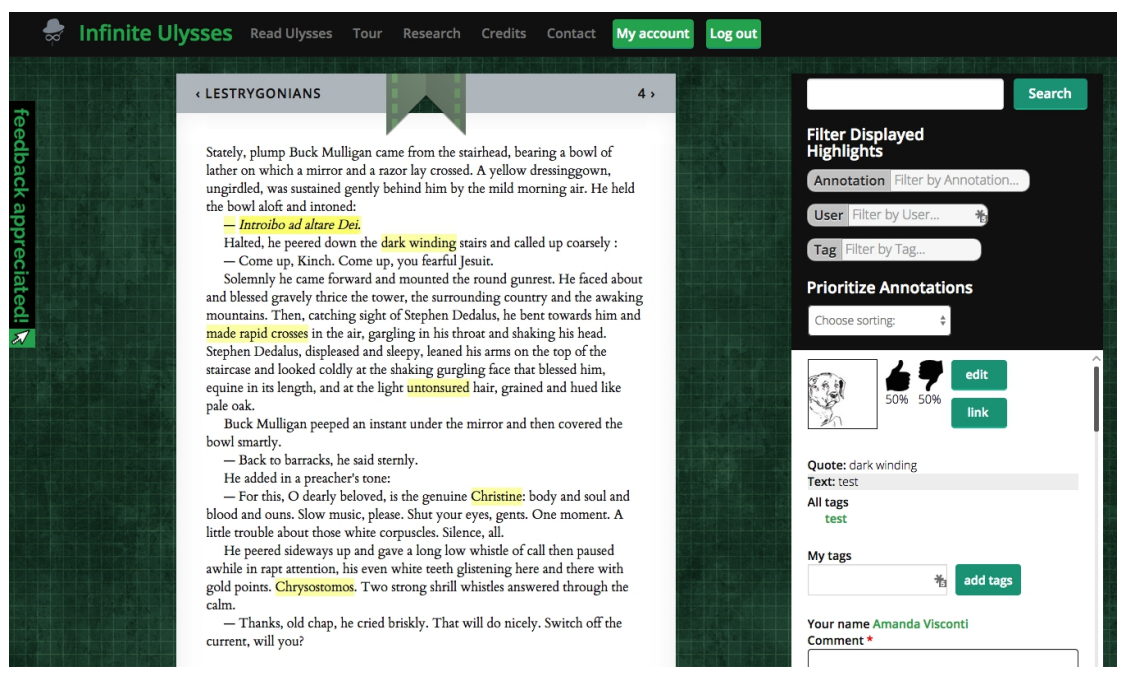




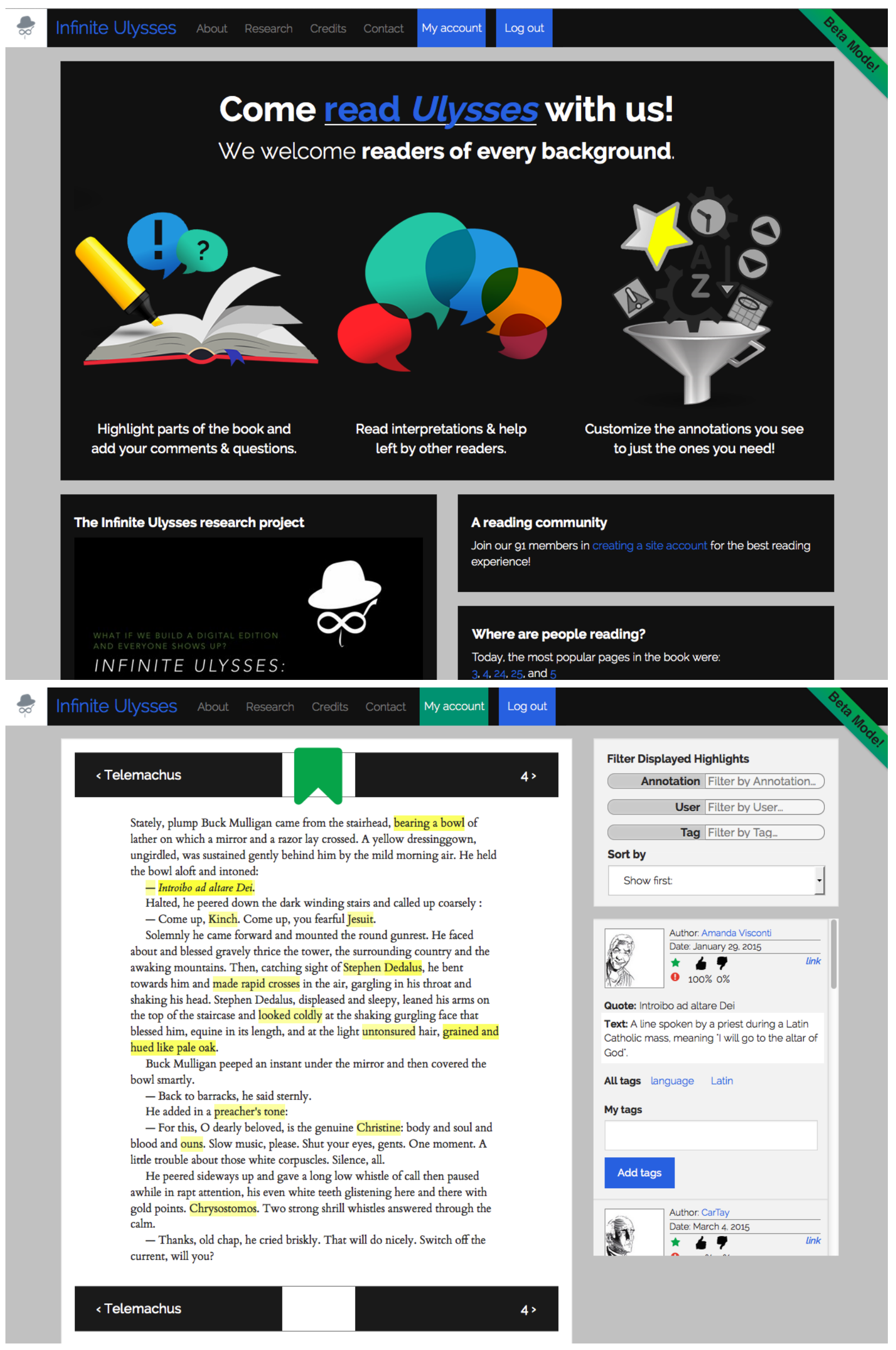




\section{3/7/2015: Final Prototype (Front Page and Book Page)}

These represent the latest design on the site at the time of the dissertation defense. Major changes were a book table of contents menu available on every page, a three-image overview of the site's features on the front page, and a cleaner look for the book page (especially the annotation sidebar). Note that annotation author metadata has been made easily accessible again.

\subsection{Specific design challenges}

Addressing design challenges as they arose was part of the critical work of developing the digital edition. These questions were both practical (How would I implement this? What's the most concise, secure, speedy way to implement this? Can I implement this in a reasonable amount of time with my current technical skills?) and theoretical-the look and behavior of the interface models how users will read the novel on my site (including predicting and scaffolding behavior, and testing how people read digital text, how people read the text with the curation mechanics, how people read complex texts, how people read encyclopedic Modernist novels, and how people read Ulysses). In this section, I'll address three of the design challenges I encountered and how I addressed them.

Automating moderation and curation. If everyone's submitting annotations to a digital edition, how can we automate the massive task of curation and moderation so that it occurs in a timely and unbiased manner? While the success of the curation features (favoriting, voting, and flagging for moderation) remain to be seen with more site use data, the site's moderation system received a thorough testing during the open beta period: hundreds of spam and/or bot accounts were automatically kept off the site, no inappropriate material was ever made public ${ }^{79}$, and anyone who used the site in good faith was promoted to a role allowing the public to also view their annotations within a few hours of their first use of the site ${ }^{80}$.

Previous to the open beta period, I enacted a moderation system that would allow new site visitors to get started using the site immediately, while protecting against public display of annotations that could diminish inclusion or trust in the community.

Annotation candidates for being hidden from public view or removed from the site included spam, trolling, profanity, off-topic comments, and too-lengthy rants (even if civil and on-topic, a chapter-length disquisition is not easy to read within the space of the annotation display and is better suited for another forum such as the author's blog ${ }^{81}$ ). Anyone was allowed to sign up at the site and immediately begin annotating with their

79Surprisingly, the moderation system was never tested in this regard—perhaps because the malicious attempts at creating site accounts were all automated bots that weren't built to highlight text before being presented with a text field to fill. Another option for spam input, the annotation tag field on existing annotations, didn't see any spam either, though.

80Most users probably weren't aware that their annotations were initially not viewable by the public, unless they happened to log out and return to the site without logging back in.

81I want the site to eventually support these, though—no one should be penalized for offering quantity and quality. I might handle this by adding a forum for more in-depth discussions, and/or showing the first $\mathrm{x}$ words of an annotation and a link to a page or modal where you can read the rest of it. 
new account, but a new user would be placed in a probationary role that kept their annotations only visible to them (when logged in).

Once the user demonstrated good-faith use of the site (e.g. through several annotations that were site-appropriate), they were advanced to a role that allowed their annotations to be seen by other accounts and anonymous users. A further advanced user role (also dependent on evidence of good-faith site use) allowed that user's annotations to appear on the "recent activity" feed on the front page of the site. In case this process failed or a site user was made uncomfortable by something that the site moderator didn't experience as problematic, a moderation flag icon appeared on each annotation. Clicking this icon would immediately hide the annotation from public view and alert the moderator that they needed to inspect the annotation before deleting it or returning it to public view.

A secondary system of moderation alerts meant that I didn't need to be constantly checking the site's queue of new accounts and content to prevent malicious use. Using the Drupal module for the Pushover push alert service plus the core Rules module, I was able to receive updates to an app on my smartphone (with sounds, notifications, and a home page badge indicating the number of new notifications) whenever a new user account was created, an annotation was created or edited, or an annotation was flagged for moderation ${ }^{82}$. By

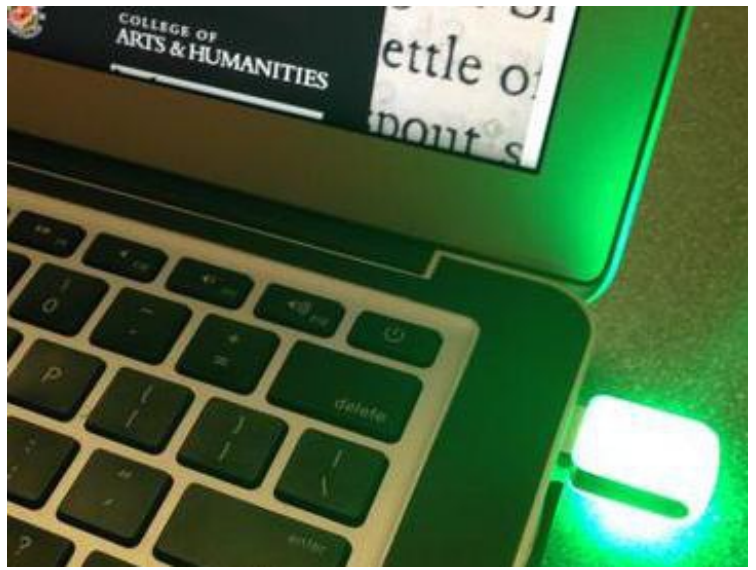
combining the core Rules module and the If This Then That (IFTTT) service, I also received site updates in the form of colored light patterns. I used a blink(1) — essentially a variety of colored LED lights attached to a USB stick - with my laptop so that I'd notice a blinking red light, for example, if something on the digital edition needed moderation. In addition to providing a second line of notification for the site events that triggered phone notifications, I used a gentle pattern of yellow light on the blink(1) to noninvasively make me aware when someone (logged in or not) was visiting a page on the site $^{83}$.

Yellow block syndrome. The moderation system (and hopefully, the curation features as well) helps the digital edition separate the wheat of critical yet diverse annotations from the chaff of repetitions, spam, and under-substantiated suggestions. How do we make the still-plentiful remaining material accessible to the users it would best serve? Even if a

82Further customization options allowed for marking the priority of each type of notification and giving each a particular sound, as well as setting quiet hours delivery preferences. Through the Drupal modules, the information I desired in each update could be customized (e.g. I included an edit link to make changing a new or edited annotation from my phone easy.)

83In addition to the pleasantness of knowing your site is being visited throughout the day, this helped me be aware of anonymous site visits when I was gauging whether the site was empty so that I could make a code update. 
participatorily annotated digital edition doesn't garner annotations in the hundreds or higher, it is likely that at least the very first page of the text (the page everyone visits, whether they decide to read using the site or not) will become heavily annotated. Heavy annotations mean heavy highlighting of the text; the yellow overlay that initially helped to visually call out annotated text becomes a nuisance as the page begins to appear more like a solid yellow block.

How do we separate the signal from the noise of all those highlights and annotations, when the "signal" of pertinent contextual annotations means different things for different reader needs? My first approach was allowing readers to place tags on any annotations (both annotations they author and others readers'). I seeded the site before the open beta with a number of basic tags identifying annotations that were definitions, translations of a specific language, or intertextual references to a specific Shakespearean play (see a list of all the seed tags here). Readers have since used those tagging terms and added new terms such as "acrostic", "debatable", and "German". On a given page, readers can filter what yellow highlights are displayed by these tags, as well as by usernames (authors of annotations) and text within annotations.

The second phase of this approach (not available yet on the site) will provide an improved interface for personalization of annotations. Users will set their preferences as to what annotations are shown by using a form on their user profile page that asks questions such as "Would you like to see annotations by other readers who've identified as first-time readers, or as readers who've taught Ulysses?" and lets the user choose whether to be shown annotations (e.g. annotations tagged as spoilers) or to have certain types of annotation hidden (e.g. translations of a language the reader speaks). These settings will persist throughout a user's their reading. Users will be able to refine these filters on an individual page of the book if desired, or they can visit their user profile and update their filters globally. It is hoped that tagging will provide a way to personalize annotations to different readers, but more data is needed on how frequently readers add tags and what kind of tags are being added before I'll know whether this tactic works. I'll also continue looking for ways to surface alternate viewpoints or annotations that are seldom seen.

User Avatars. Choosing the look of user avatars raised questions of author attribution, diversity, and power hierarchies. I knew I wanted annotation authors to have their names noticeably attached to their annotations (something creators of content on other such sites have complained about), and I wanted readers to feel like there were other readers preceding them on that page - not just by random-sounding usernames, but by some representation of diverse faces. A solution and a problem came in the form of a set of beautiful sketches of the characters in Ulysses created by Ulysses Seen artist Rob Berry and generously shared with the site. Letting the readers use these avatars preserves a 
unity of style on the book page: black-on-white ink drawings, instead of random photos of someone's cat or whatever else someone wants to use as their avatar. The problem with these avatars is actually a problem with Ulysses ${ }^{84}$. Joyce's novel has a lot of characters, but they're all in Dublin at the beginning of the twentieth century, so they're not very diverse (the drawings are in ink, but all appear white and able-bodied and most are male). Berry is currently creating more diverse avatar options for the site.

Another issue raised by the user avatars was whether they should have some marking to show if a reader had particular experience with Ulysses (e.g. a Joyce scholar or college teacher). I considered a different-colored avatar background or an icon like the Twitter verified badge, but decided that — at least for the site in its most experimental stage - I was more worried that readers wouldn't feel qualified enough to contribute annotations, than I was that readers with particularly applicable experience wouldn't be listened to. It's difficult to allow markings for experience (and who gets to say what experience is?) when users can be pseudonymous or anonymous, and it's problematic to invite everyone to a conversation around the novel and then privilege some voices over others. The site will eventually have features supporting groups (teachers and their students, or book club readers and their friends) as well as a space that suggests annotation authors to pay attention to, and I'll want to rethink how experience is displayed on the site with the help of the user community at that point.

\subsection{User experience data results and discussion}

Data collection about user experience of the digital edition took several overlapping phases and forms:

\begin{tabular}{|l|l|l|l|}
\hline$\#$ & Test form & When & Test goals \\
\hline 1 & $\begin{array}{l}\text { Informal opinion solicitation (e.g. } \\
\text { hallway testing, Twitter discussion of } \\
\text { whether "annotation" or "comment" } \\
\text { was a more intuitive term) }\end{array}$ & Throughout project & $\begin{array}{l}\text { Design for people unfamiliar with } \\
\text { digital editions, literary studies } \\
\text { terminology. Check assumptions about } \\
\text { user needs. Consider various existing } \\
\text { technological wheels to build off. }\end{array}$ \\
\hline 2 & $\begin{array}{l}\text { Talk-aloud observation (seven single } \\
\text { or paired testers } \\
\text { process as they navigated the site for } \\
\text { the first time) }\end{array}$ & $\begin{array}{l}\text { December 2014 - } \\
\text { January 2015 }\end{array}$ & $\begin{array}{l}\text { Hear users thoughts as they interact } \\
\text { with the site for the first time: what was } \\
\text { intuitive, what needed better design } \\
\text { and/or explanation. Check new site } \\
\text { visitor expectations for feature } \\
\text { behavior. }\end{array}$ \\
\hline
\end{tabular}

84It's also a problem with web design in general. I had to update the Drupal Rate module (which provides the thumbs-up/-down voting on annotations) with a new image sprite because the image included in the module was of a Caucasian hand. 85Throughout, "testers" means people who explored an early version of the digital edition by signing up for a user account on the site. 


\begin{tabular}{|c|c|c|c|}
\hline 3 & $\begin{array}{l}\text { Participatory design (testers listed } \\
\text { features and layout they'd want in an } \\
\text { ideal digital edition interface, then } \\
\text { responded to wireframes I sketched } \\
\text { from their answers) }\end{array}$ & $\begin{array}{l}\text { December } 2014 \text { - } \\
\text { January } 2015\end{array}$ & $\begin{array}{l}\text { Base design off reader desires rather } \\
\text { than my personal desires or } \\
\text { assumptions. }\end{array}$ \\
\hline 4 & $\begin{array}{l}\text { Email conversations with site visitors } \\
\text { (e.g. requests for features, feedback } \\
\text { on site design, questions about } \\
\text { approaches to design challenges) }\end{array}$ & $\begin{array}{l}\text { January } 2015 \\
\text { onward }\end{array}$ & $\begin{array}{l}\text { Make sure I interpreted bug fixes and } \\
\text { feature requests correctly. }\end{array}$ \\
\hline 5 & $\begin{array}{l}\text { GitHub issues (a site user submitted } \\
\text { bug reports and feature requests via } \\
\text { the site's public code repository issues } \\
\text { tracker) }\end{array}$ & March 2015 onward & $\begin{array}{l}\text { Public display of issues I was already } \\
\text { aware of. }\end{array}$ \\
\hline 6 & Crowdflower survey responses (16) & March 5, 2015 & $\begin{array}{l}\text { Check for issues before open beta } \\
\text { publicity; test with more diverse } \\
\text { audience than invited by publicity to } \\
\text { DH and academic Twitter users. }\end{array}$ \\
\hline 7 & Open beta survey responses (12) & March 9-21, 2015 & $\begin{array}{l}\text { Site user demographics, site } \\
\text { experience, desires for the site, and } \\
\text { whether the site made them more likely } \\
\text { to read Ulysses. }\end{array}$ \\
\hline 8 & $\begin{array}{l}\text { Site analytics (Google Analytics } \\
\text { reports on aggregated visitor data, } \\
\text { e.g. \% of site visitors from each } \\
\text { country, \% of visitors who returned to } \\
\text { the site once or more) }\end{array}$ & $\begin{array}{l}\text { January } 2015 \\
\text { onward }\end{array}$ & $\begin{array}{l}\text { Understand behavior for all users } \\
\text { (including anonymous site visitors and } \\
\text { users who didn't fill out the survey), } \\
\text { discover aggregate results like } \% \text { of } \\
\text { user base from each country or bounce } \\
\text { rates for specific pages. }\end{array}$ \\
\hline 9 & $\begin{array}{l}\text { Anonymous visitor mapping } \\
\text { (Inspectlet and Crazy Egg heatmaps } \\
\text { of digital edition visitor clicking and } \\
\text { scrolling) }\end{array}$ & March 2015 onward & $\begin{array}{l}\text { See where users were clicking and } \\
\text { looking, identify pages where users } \\
\text { weren't scrolling to the bottom (missing } \\
\text { information below the fold). }\end{array}$ \\
\hline 10 & $\begin{array}{l}\text { Drupal statistics on frequency and } \\
\text { authorship of annotations }\end{array}$ & March 2015 onward & $\begin{array}{l}\text { Understand where in the book users } \\
\text { added annotations; understand how } \\
\text { users did or did not use the annotation } \\
\text { feature. }\end{array}$ \\
\hline
\end{tabular}

Data collection forms 1-3 were informal parts of the design process and are not specifically discussed here; forms $4,6,7$, and 10 are reported here as anonymized and/or aggregates. 
Digital edition testers ${ }^{86}$ created site accounts by invitation from December 2014 through early March 2015. A live site with access only allowed for pages describing the site (i.e. no access to the book pages) was first publicized on January 12, 2015. An open betatesting period began with a soft launch on March 4, 2015, followed by heavy publicizing via Twitter and academic listservs on March 9, 2015 and after. During this open beta, anyone could create a site account and access all site features and pages; limited access to the site's features was also available to anonymous visitors (e.g. annotations on book pages could be read, but not favorited, tagged, or voted on, and anonymous visitors could not create annotations).

The site was prepared for two types of visitors: people interested in seeing how the site works but not interested in using it to read Ulysses, and people who return to the site more than once for the purpose of reading Ulysses. Awareness of the site's existence reaching people with the availability and interest to begin regularly reading Ulysses will take time; once those returning readers find the site, they'll likely need a few weeks at minimum to read the entire novel using the site. Because publicity for open site use did not begin until several weeks before the writing of this report, the shape and guidance of results reported here are quite preliminary; months and years of site reading and classroom use are needed to establish any significant trends of reading behavior. Findings from this initial testing period are, however, useful in addressing key design issues for the digital edition, under the usability commonplace that testing with a handful of people will locate $90 \%$ of a website's design issues. These results were gathered and are addressed here for the explicit purpose of site testing and improvement, rather than for highly abstractable knowledge through human subject research, which would require a more formal statistical analysis ${ }^{87}$.

With the earliness of these results in mind, I report below on results from site data collected at specific points in March 2015 (see each section for the exact day of data collection). Also keep in mind that as the site's creator, my interpretation of these results is optimistically biased. Full copies of any data collection that is non-identifiable (e.g. heatmaps of aggregated visitor clicking locations) are available here for independent review. A more thorough statistical analysis of site data will be conducted and submitted for peer review after further site use in December 2015.

\subsubsection{Crowdflower survey}

Using the Crowdflower platform ${ }^{88}$, on March 5, 2015, 16 participant read a page of Ulysses on the site and tested the participatory features before answering a survey on

86These testers were pulled from a form that solicited beta-testers for the site, as well as friends, family, and academic colleagues. 87This is a difference recognized by the University of Maryland's IRB; this dissertation received a waiver from IRB oversight due to its focus on site use and usability over human research. To explore an alternative approach to digital humanities user-testing on a similar project, see my master's dissertation. Its approach included the social science process of stated methodology, results report, and separate results discussion section; use of SPSS and R for data analysis; and statistical approaches and visualizations that help to identify correlations among data types as well as data significance. 
their site use experience (see Appendix A). This survey was taken during the soft launch of the site's open beta (the period between opening the site to anyone who wanted to signup, and publicizing this state of things on March 9, 2015) with the purpose of fixing any major issues before widely publicizing the site and adding any necessary design changes to the final design before pushing it to the live site. This survey was conducted with the site looking like the 2/23/2015 screenshot (except that the background was still the busy photograph seen in this earlier screenshot) while working on the design seen in the $3 / 7 / 2015$ screenshot. The tour in use was the one represented by this screenshot (since replaced).

Asking Crowdflower users for assistance in testing the site was additionally useful in that participants offered more diverse backgrounds than I was usually able to reach through my social networks. Age ranges represented by participants were 19-22 (2), 23-29 (3), 30s (4), 40s (4), 50s (2), and 60s (1). Countries represented by participants were the U.S.A. (5), Canada (5), Great Britain (3), Ireland (1), Greece (1), and Australia (1). These locations weren't as diverse as I would have liked; I've received feedback via email from site users from Korea and Norway, though, that point to work I could do to serve readers coming to the text without English as their first language.

This survey solicited feedback from users who weren't familiar with humanities research or digital editions, nor were they biased from knowing me or about my project $^{89}$; no participants were teachers, and one participant was currently a college student. Participants' highest levels of education were high school graduate (4), non-humanities college degree (6), humanities college degree (2), college degree in an unspecified field (3), and a master's degree (1). 4 of the 16 participants identified as active learners who regularly sought knowledge outside the classroom. These backgrounds were useful, since I wanted to serve readers with curiosity but without formal academic backgrounds supporting reading the difficult novel.

When asked what they liked about the site, 5 participants described liking the general goals of the site: "I liked the whole concept, didn't realize such a site existed". This reminded me that part of my future participatory work is simply to make diverse audiences aware that sites like mine exist. 7 participants described use of the site as intuitive and/or quick; 5 participants described liking the overall appearance of the site. 2

88Crowdflower is a platform for crowdsourcing tasks such as data entry and content categorization, similar to Amazon's Mechanical Turk. Participants in this crowdsourced task were compensated out-of-pocket at $\$ 10 /$ hour for fifteen minutes of work (the task was estimated to require 6-15 minutes, but all participants were paid for a full 15 minutes). Several checks were put in place to require participants to complete the pre-survey activities in good faith (e.g. users who opted into the Crowdflower task and then tried to submit the survey under a very low minimum amount of time were not allowed to complete the task; the task rate was set to $\$ 0.10$ to discourage bad-faith completion of the task, but bonuses to bring participants' compensation up to $\$ 10 /$ hour for 15 minutes were given to every participant). For what it's worth, no one tried to complete the task in bad faith. 89Most of the site's publicity was through academic (particularly digital humanities) individuals on Twitter, making initial site feedback from other sources skewed toward those with a background assisting understanding the hows and whys of this kind of project. 
of those users specifically mentioned finding the font used on the book good for reading, and four of participants who mentioned liking the design used the word "clean" in describing what they liked about the site's appearance. Because the initial site tour feature was buggy, it was reassuring to hear that some readers didn't need additional support to start using the site.

9 participants mentioned liking the possibility of reading other readers' annotations; one described this as the feature that made the site worth sitting at a computer instead of using their Kindle. This comment reminded me that a design that works on tablets could invite in the large audience that would presumably rather read in an armchair than at a desk. 2 participants discussed how the site made the book "less intimidating"; one noted "I am not a student but literature was a passion. This looks like a good way to direct that passion again". Specific features participants mentioned liking were the way annotations could be added to the text (4), bookmarking your page (2), and the personalization options (filters and sorts; 3 ). In the section for extra comments, 4 participants again expressed liking the idea and/or potential of the site, and 4 participants said they would use such a site regularly to read more/other books.

Asked what they disliked about the site, the most common complaint was that the site was too busy in general (5), including that the background was too busy ${ }^{90}$ (4). 4 participants said they hadn't yet encountered anything they disliked. The remaining disliked features each only had one participant mention; these included wanting more prominent accessibility options (text zooming and contrast), problems with the site tour, and concerns over the annotation rating system's effect on unpopular or alternative interpretations. In the section for extra comments, 3 participants thought the site needed general design work (the distraction of the background image of a page from the Ulysses print edition was noted in particular). One participant commented on the lack of diverse avatars, an issue Ulysses Seen artist Rob Berry is currently generously addressing.

Asked how they would usually approach reading a difficult book like Ulysses, 4 of 16 participants mentioned seeking annotations to help understand material. 5 participants had read at least part of a book on an e-reader in the past; 1 had read on a smartphone, 7 on websites via a laptop or desktop, and 4 had never read part of a book on any of these digital options; my designs should keep in mind that "commonplaces" of e-reading (e.g. how to navigate among pages) aren't necessarily known to every reader. 3 participants had read at least part of Ulysses before; 2 participants had never heard of the novel, while the remaining 11 had heard of but not read the novel. Asked whether they were more likely to read Ulysses now that they knew of this digital edition, 3 said yes, 8 said maybe,

90The site background was originally a hi-resolution photograph of a page from the Ulysses print manuscript, since replaced with a more placid background. 
and 5 said no. Again, publicity to make potential readers aware of Infinite Ulysses as an option seems important.

3.9.3 Open beta user survey The open beta web survey was available to anyone who created an Infinite Ulysses site account during the open beta period beginning March 9, 2015; data collection ended for the purposes of this report on March 21, 2015 (about two weeks into the open beta

period $)^{91}$. This survey was conducted with the site in its final state of appearance (i.e. the 3/7/2015 screenshot).

Twelve site users submitted a survey (see Appendix B for full survey questions). The set of participants covered a range of ages: users 18-24 (3), 25-29 (1), in their 30s (3), in their 40s (3), and in their 50s (2). On a site with 336 accounts $^{92}$, this self-selected group can't be read as fully representative, but their insights into the experience of using this digital edition are still extremely useful and suggest questions for future assessment metrics ${ }^{93}$. Below, I report and discuss some of the survey results (see Appendix A to view the full list of survey questions).

Users were prompted "Starting to read Ulysses using this site...", followed by ten possible statements; users could check any of these statements that fit their experience.

1. took too long ( $\mathbf{0}$ of $\mathbf{1 2}$ checked off)

2. took the right amount of time (3 of 12 checked off)

3. it was easy to jump in and get started (11 of 12 checked off)

4. there was too much to learn to use the site ( 0 of 12 checked off)

5. there were too many instructions to wade through ( 0 of 12 checked off)

6. there were not enough instructions ( 0 of 12 checked off)

7. a better demo or site tour needed ( 0 of 12 checked off)

8. I read some of the About pages (6 of 12 checked off)

9. I felt welcome on the site (10 of $\mathbf{1 2}$ checked off)

10. I didn't feel encouraged to add my own annotations ( 0 of 12 checked off) Encouragingly, none of the survey-takers felt that any of the negative statements about their site experience (\#1, 4, 5, 6, 7, and 10) applied, suggesting that no one felt the site took too long to start reading, that the site was too difficult or took too long to begin using, that the site needed a better demo or tour, or that they weren't encouraged to participate by adding their own annotations. All but one participant indicated that "it was easy to jump in and get started", and an encouraging number of participants indicated that they'd read some of the site's explanatory pages (6 of 13) and that they "felt welcome on the site" (10 of 12).

91I'll continue to solicit survey-taking and other user feedback; March 21st is just the cut-off date for purposes of data analysis in this report, which was part of my final submission to my doctoral dissertation committee on March 31, 2015.

92Site account creation was protected from spam and bot submission in several ways; new accounts were additionally checked against public lists of known email addresses used by spammers. Therefore, this number should express fairly accurately the amount of real people who signed up on the digital edition.

93Note that together with the Crowdflower surveys, a total of 28 site users filled out a survey about their user experience. 
What did you like about the site? 5 of 12 survey-takers mentioned liking the idea behind the site. 2 participants characterized the site design as clean and attractive, and 5 participants discussed liking how intuitive use of the site was and how quickly they were able to begin using the site's features. 5 participants noted they liked being part of a reading community via the site.

What would make the site better? Would anything need to change for you to use the site more and/or recommend it to someone else? Participants desired the following features or changes to existing features (initial thoughts on meeting these requests follow each in italics):

- Better way to navigate the entire book (not just paging forward or back). I plan to add both a way to search the book and a visualization-available on every book page-to see where you are within the book as well as jump to any page in the book.

- More annotations in later episodes of the book, perhaps by finding a way to encourage readers to annotate non-annotated pages. I'm planning on adding a core set of annotations myself as I reread the book; the site's initial two-hundredodd annotations were written this way. I'm also working to connect with authors of existing Ulysses annotation elsewhere towards displaying these on the site, and I want to create an interface for bulk-adding existing annotations to assist with this.

- Filters are limited to a particular page; for research use, being able to navigate among tags or see where a given tag occurred throughout the book would be useful. Moving filters off the book pages and onto user profiles as a set-andforget personalization form may help with regular attention to specific tags. I'll want to do some participatory design with interested scholars to build a tool that allows this kind of research navigation as well.

- An additional filter for different categories of annotation (e.g. question, comment, interpretation). This is a planned feature, with the "question" category in particular feeding into an "unanswered questions" queue à la StackExchange so that readers can easily find ways to help one another.

- Episode introductions. I could model these on the episode briefings/debriefings used on UlyssesUlysses.com. Since these may be longer than is comfortable to read as an annotation, I'll need to think about how and where to place this content.

- For classroom and personal use, a way to start with a blank slate but also pull in existing annotations. A button to toggle off all annotations on a page should be added to each book page. A planned feature aimed at classrooms and book clubs will be based on the current ability to "favorite" annotations; readers will be able to generate custom URLs that present the pages of the book with only their curated annotations (theirs or other readers') shown. Allowing custom editions to 
start from a blank page is a use case I hadn't considered, but it's success on Genius.com suggests it would be a good addition to the site.

Site usage. 3 survey-takers mentioned using the site in a classroom and 2 participants discussed using the site to make reading the novel more enjoyable. Several teachers have already discussed using the site in their classrooms this fall, so I'll be able to incorporate teacher and student feedback into the site at that point.

Past experiences with Ulysses. 2 participants had not previously read Ulysses, and 1 participant reported previous unsuccessful attempts at reading the novel. 5 participants reported reading the book once previously, and 4 participants reported having read the novel 3-5 times. Participants included 2 readers who had translated parts of Ulysses from English, and 2 who had taught Ulysses in a classroom. This set of users was far more familiar with the novel than the Crowdflower participants.

Next Steps. From user preferences indicated in the surveys and feedback, I've prioritized the following features for future inclusion in the site: more intuitive use of bookmark and book navigation, rich-text annotations, a design that accommodates viewing on tablets and other smaller screens, better magnification and contrast features for reading text, addressing the non-diverse user avatars, suggestions for users to follow ${ }^{94}$, and a set-andforget form for personalizing the experience across the site from the user profile page. Opinions on the overall site design were mixed (some praised it, some thought it needed work) ${ }^{95}$, and parsing how much of the complaints about the design referred just to the site's background image or buggy tour is unclear. Regardless, I'll continue working on the site's overall appearance to make it more accessible, attractive, and intuitive; in particular, I'll redesign the annotation sidebar on the book pages so that the space to read annotations isn't so cramped.

By far, the most frequently mentioned design issues on the digital edition were the background being too busy and the site tour being buggy. Both have since been replaced, but it's interesting to note that these were both features I initially thought users would definitely like. The background for the site was originally a high-resolution photograph I'd taken of a page in the 1922 Shakespeare \& Co. print edition of Ulysses. I liked the reference to the print edition on which the digital edition was based, and I thought added a bit of pleasant quirkiness to the site. I normally have a good eye for design (I've worked as a professional web developer for eight years now), and teaching HTML and CSS to students has made me keenly aware of the design flaws of busy photographic

94I want to be careful with user suggestions not to point to any grouping as somehow better, smarter, or more correct—which language like "expert" and "non-expert" might imply. Instead, when recommending user to follow I'll use terms that focus on what a particular group brings to the text and why a reader might be interested in following any of them (e.g. "people who have taught Ulysses", "readers who, like you, are experiencing the text for the first time").

95I regret not conducting user tests where participants first used my old UlyssesUlysses site, then the new Infinite Ulysses. This might have focused participants on the particular elements of design I'm most interested in perfecting. 
backgrounds - so it was strange how my feelings for the print edition blinded me to how the business of the background was hurting the site's appearance.

The old tour feature was based on Bootstrap Tour and worked by attaching the CSS for a specific web page element to some tutorial text. Instead of a static slideshow, you could have the tour guide you around a real example page from the book! This sounded like a great idea, but in practice it was terrible. Placing the tour on an actual book page meant that users wanted to try out features as they were described; for example, a user reading the popup pointing to and describing use of the highlight filtering feature might try inputting some text to that filter to see its effects. Unfortunately, clicking anywhere outside the tour popups brought the tour, generating multiple popups and making it impossible to end the tour. Whether the tour had bugged out from a user trying out a feature, or if a user just wandered to another page or off the site entirely without clicking the "end the tour" button, the tour would stalk you on every page of the site with a popup asking whether you wanted to return to the tour, without a clear way to stop this annoying behavior.

Wanting to support reasonable values for the site - making the design fun and referring to the print edition, and using a tour that would walk users around an actual book page on the site-distracted me from the real design problems with these features. Digital editions need user-testing to assess whether their approaches model real research and reading use.

Visits

\subsubsection{Google Analytics}

These results from Google Analytics represent the period from January 1, 2015 through March 21, 2015; note that only the front page of the site and "about" pages were accessible to anyone except a small group of invited early beta-testers until the beginning of the open public beta on March 9th. Much of the site activity representing real use of the book pages is confined to the two-week period from March 9th to the 21st, 2015 (as shown in the "Visits" timeline above). The spike on March 9th in the "Visits" chart shows 
how initial open beta publicity brought hundreds of people the site, but only a relatively small number of readers stayed to make repeated use of the site.

Visitors were mostly from the United States (857), followed by Great Britain (162), Canada (85), Ireland (66), and Brazil (60), with smaller counts from other countries. I discussed the site via email with one reader in Korea, and I discussed the site's predecessor UlyssesUlysses via Twitter with a reader from Norway in the past. More work will need to be done to reach readers in other countries and make the site accessible to those who don't speak English as their first language.

There were 2,056 total sessions ${ }^{96}$ of site use, with 7,616 total pageviews (total number of pages viewed; repeat viewings of the same page are included).

\begin{tabular}{|c|c|c|c|}
\hline \multicolumn{4}{|c|}{ Exit count from most popular book pages } \\
\hline Page & & Pageviews & Exits \\
\hline /ulysses/3 & ब & 986 & 203 \\
\hline /ulysses/4 & B & 251 & 42 \\
\hline /ulysses/5 & ब & 115 & 23 \\
\hline /ulysses/6 & 영 & 54 & 11 \\
\hline /ulysses/24 & \& & 53 & 8 \\
\hline /ulysses/7 & ब & 37 & 6 \\
\hline /ulysses/25 & ब & 34 & 0 \\
\hline /ulysses/8 & \& & 26 & 0 \\
\hline /ulysses/37 & \& & 24 & 6 \\
\hline /ulysses/9 & ब(ब) & 24 & 1 \\
\hline
\end{tabular}

Total time spent on most popular book pages

\begin{tabular}{|c|c|c|c|}
\hline Page & & iews & Time on Page \\
\hline /ulysses/3 & E & 986 & 13:39:59 \\
\hline /ulysses/4 & E & 251 & 03:18:42 \\
\hline /ulysses/5 & E & 115 & $01: 18: 42$ \\
\hline /ulysses/6 & E & 54 & 00:26:01 \\
\hline /ulysses/24 & E & 53 & $00: 51: 30$ \\
\hline /ulysses/7 & E & 37 & 01:07:59 \\
\hline /ulysses/25 & E & 34 & $00: 51: 22$ \\
\hline /ulysses/8 & E & 26 & 00:09:23 \\
\hline /ulysses/37 & E & 24 & 00:38:58 \\
\hline /ulysses/9 & E & 24 & $00: 12: 14$ \\
\hline
\end{tabular}

\section{Content by page}

\begin{tabular}{|c|c|c|c|c|c|c|c|c|}
\hline I & $\theta$ & 2,253 & $49.58 \%$ & & /ulysses/3 & 상 & 986 & 373 \\
\hline /user/register & ब & 415 & $24.82 \%$ & & /ulysses/5 & 용 & 115 & 82 \\
\hline /user/login & () & 195 & $16.92 \%$ & & /ulysses/24 & 용 & 53 & 26 \\
\hline /tour & 因 & 175 & $20.00 \%$ & & /ulysses/7 & 용 & 37 & 23 \\
\hline /about & B & 158 & $35.44 \%$ & $\begin{array}{l}\text { itı } \\
\text { fc }\end{array}$ & /ulysses/25 & 요 & 34 & 11 \\
\hline Juser & $\mathbb{B}$ & 144 & $15.28 \%$ & 35 & /ulysses/8 & 요 & 26 & 19 \\
\hline
\end{tabular}


The site had 1,579 unique site visitors: 1,116 unique laptop/desktop visitors (73.2\%), 335 unique smartphone visitors (18.7\%), and 128 unique tablet visitors (8\%). Possibly because the book pages were not usable under a certain browser width (at which point the text and annotation features were hidden), the average number of pages viewed per session and average session duration was highest for desktops/laptops (4.22 and 3 minutes 29 seconds), with tablets in the middle (3.33 and 2 minutes 34 seconds) and smartphone showing the lowest visitor engagement (1.83 and 49 seconds).

$79.86 \%$ of site sessions were referred from a social media site (i.e. clicked a link that took them to Infinite Ulysses). In particular, Twitter was responsible for 487 site sessions and Facebook for 350. These numbers speak to the usefulness of social media for getting the word out about academic projects. The Facebook number is interesting in that I don't have an account on that site; my only publicity activities were on Twitter, my LiteratureGeek.com blog, the MITH blog (responsible for 42 sessions), and my older prototype UlyssesUlysses.com (45 sessions), but mentions of the project ended up on that

\begin{tabular}{|lrr|}
\multicolumn{3}{|c}{ Number of visitors by number of returning visits to ... } \\
\hline Count of Sessions & Sessions & Unique Pageviews \\
\hline 1 & 1,578 & 3,673 \\
2 & 209 & 614 \\
3 & 72 & 386 \\
4 & 40 & 89 \\
5 & 22 & 76 \\
6 & 14 & 65 \\
7 & 10 & 19 \\
8 & 10 & 19 \\
9 & 7 & 19 \\
10 & 7 & 13 \\
\end{tabular}
network as well.

Visitors tended to enter the site, not surprisingly, from the front page (1,567 entrances), followed by the account creation page (172 entrances), and the first page of the novel (53 entrances; though note these numbers may be skewed because of the period when uninvited visitors could only view the front page and some of the explanatory pages). These three most popular entrance pages are followed by visitors entering on the site credits page (22), suggesting some visitors decided to check out the site after publicity emphasizing the many people and projects who made Infinite Ulysses possible.

New visitors made up $88.3 \%$ of site users, with only $11.7 \%$ of users returning for a second or further visit. Unfortunately, the data doesn't capture what percent of non-return visitors were potential Ulysses readers who decided not to use the site, versus people interested in the project but not interested in reading Ulysses at the current time. The "Number of visitors by number of returning visits" chart (above, right) shows how many sessions were from users who visited the site 1,2, or more times (see the "Count of Sessions" column); we can see, for example, that 72 users returned to the site twice, and that 22 users each visited the site 5 separate times. 
A look at the most visited pages on the site ("Content by page", above) offers no surprises, with most site visitors hitting the front page, the signup page, and the first few pages of the book.

Filtering to just pages of the book, however, lets us see where users were reading; "Users on most popular book pages" (above) shows the number of times a page of the book was viewed (pageviews) and how many users saw that page (users; note one user might view a page multiple times). From the popularity of pages 3 (the first page of the print book were the novel begins, and correspondingly the first page of the book on the digital edition), 4, 5, and 6, we may suspect that most visitors began the novel at the beginning. Pages 24 and 25 (the first and second pages of the second episode of the novel) were also popular; perhaps returning readers jumped to the second episode to see what a page would look like that hadn't been most people's first choice to read and annotate.

"Total time spent on most popular book pages" (above) shows the cumulative attention (in time spent on a page) from site users on book pages. Page 3 (the first page of the novel) shows a considerably higher time, probably not because of its difficulty as a reading page but because it was the first page many readers encountered, where they would still have been learning to use the site's features.

"Exit count from most popular book pages" (above) shows for how many users a given book page was the last page they viewed before leaving the site. We see that page 3 was a point where many users left the site (though not necessarily after spending significant time reading and testing features on that page). Later pages show significantly less users exiting after encountering them; to say that returning users were more likely to return again sounds tautological, but it's reassuring if many people who made the choice to read beyond the first page of the novel didn't subsequently change their minds.

\subsubsection{Results from Inspectlet}

Two services for tracking aggregations of where users clicked and scrolled, Crazy Egg and Inspectlet, were used to gain a sense of how users moved around a given page; they began tracking site use on March 7, 2015 (two days before the open beta announcement). These services offer options such as a scroll heatmap, showing what percent of page visitors made it to various points farther and farther down a page, and heat and confetti maps, showing how many

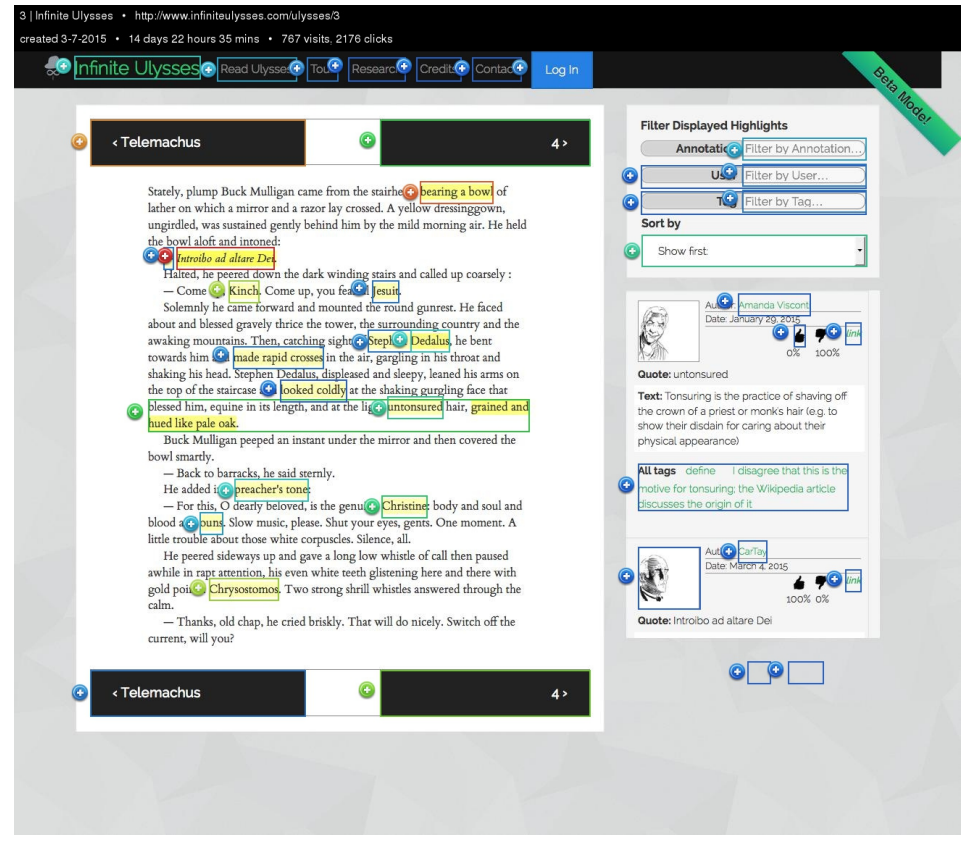


users had clicked on particular locations on the page. These haven't yielded any unexpected insights for Infinite Ulysses so far, but another option - the clickmap - has been quite useful. Inspectlet's clickmaps (above) associate specific elements on a page (e.g. a div, link, or text field) with the number of clicks that element received. This allows us to gather a count of how many times any given annotation was clicked by a reader wishing to view it, plus the usage of other page elements (e.g. the "Sort by" dropdown for prioritizing displayed annotations). Total clicks accrued to an annotation depend on how long the highlight has been available to click, so an annotation available when the first users hit the site might accrue more clicks than an annotation only added the day before data gathering ended.

The image underneath the click notation matches the look of the site when the click tracking began; although the design has since changed, element attributes stayed the same and thus tracking should have continued seamlessly. The relative number of users with access to the book pages when the site design looked various ways suggests that all clicks on annotations that were already on the site at the beginning of tracking were recorded. Annotations added subsequent to the beginning of tracking should be included in these counts, but I'm not seeing evidence here of people clicking on them. This may be caused by relatively new annotations not being clicked on, or it may be a flaw in the way data was gathered as the page appearance developed. As the site sees more use, I'll work toward verifying these click counts represent user-site interactions completely.

With that caveat, below are the top nine most-clicked elements on the first page of the novel (page 3) as gathered between March 7-21, 2015 ${ }^{97}$ :

\begin{tabular}{|l|l|}
\hline Page element & Number of clicks \\
\hline "Introibo ad altare Dei" highlight & 164 \\
\hline "bearing a bowl" highlight & 150 \\
\hline "Chrysostomos" highlight & 111 \\
\hline "Kinch" highlight & 107 \\
\hline "grained and hued like pale oak" highlight & 67 \\
\hline "Christine" highlight & 57 \\
\hline The "Sort by" dropdown & 54 \\
\hline "untonsured" highlight & 55 \\
\hline
\end{tabular}

97Note that in the spreadsheets of click count available in the public repo (page 3, page 4), sometimes one annotation is counted in two separate ways, depending on whether the user clicked on the <a href $>$ or the <span> surrounding the highlight, for example. Under the theory that these both represent attempts to click on the same annotation highlight, such counts have been combined for analysis in this report. 
"preacher's tone" highlight

These highlights were all already present on the page when the first beta-testers hit the site; although they now have additional annotations associated with them, each has at least one annotation authored by me associated to it, which meant that they were all present and available to be clicked on by any beta-tester visiting the page. Given that all were available for an equal amount of time, it's interesting to note that the two mostclicked annotations correspond to the order one encounters annotations when reading the text from the beginning, which accords with predicted reader behavior of reading the first line of the text in normal word order, at least, before perhaps halting normal reading and beginning to try out the page's features.

The third most-clicked annotation is the last annotation one would encounter when reading through the text from start to finish. It isn't clear whether readers didn't click the intervening annotations as much because they highlighted less difficult text, or if the word "Chrysostomos" just jumped out at people as confusing. The most-clicked annotations after "Chrysostomos" also don't match up with reading order; perhaps after clicking the first two available annotations, readers began to only click on highlights when they wanted to know more about some text, and the click counts thus represent reader difficulty or curiosity about a highlight. Eye tracking software (or mouse tracking software, which decently approximates eye movement) would help us understand whether the presence of highlights made people jump around the text instead of reading left-to-right and up-to-down.

On the second page of the book (page 4), the following elements received the most visitor clicks:

\begin{tabular}{|l|l|}
\hline Page element & Number of clicks \\
\hline "saved men from drowning" highlight & 38 \\
\hline "a black panther" highlight & 29 \\
\hline "jesuit" highlight & 29 \\
\hline "Saxon" highlight & 23 \\
\hline "dactyls" highlight & 22 \\
\hline "Your absurd name" highlight & 21 \\
\hline "Hellenic" highlight & 15 \\
\hline "his watcher" highlight & 15 \\
\hline
\end{tabular}


\begin{tabular}{|l|l|}
\hline The "Sort by" dropdown & 11 \\
\hline
\end{tabular}

The number of readers has dropped significantly since the first page; the first page of the book saw 373 access the page a total of 986 times, while the second page of the book saw 152 readers (less than half of those who viewed the first page) access the page a total of 251 times. Apparently, readers were more likely to return to the front page than the second page multiple times, perhaps because use of the bookmark feature was not clear enough and they needed to use the links that only led to the beginnings of episodes. Again, number of clicks doesn't follow reading order; the most-clicked annotation is the last one on the page, while the second most-clicked annotation is the penultimate annotation on the page (though its popularity may be explained by multiple associated annotations causing its highlight to be a deeper yellow than the other highlights on the page).

\subsubsection{Annotation statistics}

On March 28, 2015, 24 site users had authored at least 1 annotation. Of those, 16 had authored 2 or more annotations, 7 had authored 5 or more annotations, and 3 had authored 15 or more annotations (the author's 247 , and 50 and 19 from the other two accounts). The site had 347 accounts at this point, with 383 total annotations and 120 unique annotation tags; as 247 of those annotations were by the site creator, other users authored a total of 136 annotations during this period. Authoring annotations isn't the only way of engaging with Infinite Ulysses; people who haven't created user accounts can read the text and annotations, and logged-in users can read text and annotations as well as tag, vote on, and favorite annotations.

Of site visitors who stayed on the site to read, only a small number added any annotations, suggesting:

- Soliciting more user feedback on how readers would like to use the site, identifying whether readers' annotation needs are being met by the current design and whether other unidentified reading needs could be better supported.

- Extending the core set of annotations provided by the site creator to every page of the book (currently, these are mostly covering pages in the first two episodes of the novel, which aren't as difficult to read as the novel's remaining episodes).

- Reaching more readers with time to spend on reading the book (and annotating as they go). Scrapping the original plan to have the site ready for an open beta at the beginning of January meant that New Year's resolutions to read Ulysses and winter/spring term classrooms didn't use the site; I suspect the key to making the site's activity thrive will be testing and adoption by teachers and book clubs.

- Better encouraging readers to annotate through more user-testing of the annotation process: How could it be made more intuitive and quick to use? Can it 
be designed to better support readers who want to annotate frequently as they move down a page?

- Better encouraging readers to sign up for accounts by speeding up the process and making the benefits of a site account more obvious.

\begin{tabular}{|l|l|l|}
\hline Episode of Ulysses & Book page & $\begin{array}{l}\text { Total number of annotations on } \\
\text { page (383 total annotations in } \\
\text { book) }\end{array}$ \\
\hline Telemachus (first episode in book) & 3 (first page of book) & 41 \\
\hline Telemachus & 4 & 24 \\
\hline Nestor (second episode in book) & 31 & 19 \\
\hline Nestor & 25 & 18 \\
\hline Telemachus & 6 & 15 \\
\hline Telemachus & 5 & 15 \\
\hline Telemachus & 7 & 14 \\
\hline Nestor & 24 (first page of episode) & 14 \\
\hline Telemachus & 20 & 13 \\
\hline Telemachus & 18 & 13 \\
\hline
\end{tabular}

As of March 28, 2015, the book pages with the top ten highest annotation counts were all in the first two episodes of the book; a later episode doesn't show up until 13th place (page 37, the first page of the third episode Proteus, with 10 annotations). There were $709^{98}$ unique book pages with text from the novel on which to place annotations. 56 of the book pages received one or more annotations (around $7.8 \%$ of the book's 709 pages). The first two episodes make a better showing, with only one of 34 total pages in these two episodes without one or more annotations. 333 of the site's 383 annotations were on these first two episodes (near 86.9\%); 50 annotations of total annotations were on the other 16 episodes (near 13.1\%). This may be attributable to the relative easiness of understanding these early chapters, to new readers beginning at the beginning of the novel, and to the effects of my seeding these first two episodes with annotations before the open beta began. A full chart showing number of annotations per book page for any page with annotations can be perused at www.infiniteulysses.com/most-annotated-book-pages.

98The edition matches digital book pages to print pages in the 1922 first printing, beginning on page 3 and ending on page 732; there are 19 duplicate pages that alias to the first page of each episode and the book's cover; pages 1, 2, 51, and 52 do not contain novel text. This means a total of 709 book pages are available for annotation on the site. 
These statistics show a reality extremely far from the speculative situation of millions of users and annotations, yet the numbers of people who looked at the site, created accounts, and added annotations are still heartening when compared to the usual exposure for a single-author dissertation project. Even with a realistic projection for use of the site and the relatively low commitment of annotations during the open beta, the edition garnered enough annotations to make this thought experiment immediately useful. Designing for too many annotations for any given reader to encounter is useful on any site offering public annotation, whether the annotation count reaches the millions or the tens.

What matters more than total annotation count ? The number of annotations per phrase, per page, and per chapter can quickly distract from the text, even if there are only three annotations for a phrase or twenty on a page. The first or most popular pages of a text, as with Infinite Ulysses' pages 3 and 4 (the first and second pages of the novel), can receive a disproportionate amount of annotation from new readers testing the site and from visitors interested in examining the site's functionality but not in staying to read through the entire text. Annotations can have different purposes, such as questions, contextualization, translations, definitions, and interpretations; annotations can approach the text with different backgrounds, assumptions, or levels of granularity (e.g. defining a difficult word versus a detailed interpretation of what's happening in one sentence in light of the history of Irish politics). Basing my design off a thought experiment addressing hypothetical thousands of annotations turned into a real experiment addressing a smaller number of annotation purposes, preoccupations, and audiences.

Site users reported liking and seeing a need for the features that filter and sort annotations (right). The current application of these abilities is limited: users need to re-enter their filter terms and re-select their sorting preference every time they change the page, and the site provides no suggestions of existing users and tags a particular reader might wish to filter for. These issues arose from the experimental nature of this beta phase. By spending just enough code and design effort to create a prototype that users can explore and respond to, I've avoided wasting effort developing a feature that users didn't want; future work can incorporate knowledge of what users valued about the early versions of this feature. In the future, the site will shift the filtering and sorting options to users' profile pages, where they can set and forget their preferences.

So, what does success look like for a participatory digital edition? For this two-week period of publicity and beta-testing, simply garnering 100 other pairs of eyes on the site would have been a success (assuming an

\section{Filter Displayed Highlights} Annotation Filter by Annotation... \begin{tabular}{l|l} 
User & Filter by User...
\end{tabular} Tag Filter by Tag...

\section{Sort by}

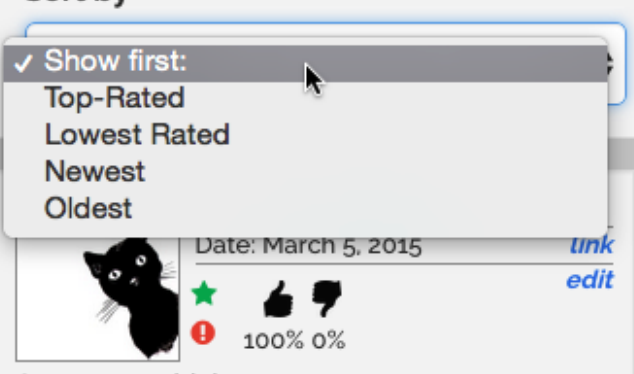

Quote: on which

Text: Ambiguity - it sounds as though the 
glaring issues with the edition would be surfaced through these visits). The statistics in Section 3.9.4 show this goal was far overreached, with statistics such as 1,579 unique site visitors, 2,056 total sessions of site use, and 7,616 total pageviews. The first two pages of the novel were seen (986 pageviews by 373 unique users and 251 pageviews by 152 unique users, respectively) and used (41 and 20 user-authored annotations, respectively). Insofar as the goal was to get eyes on the site, early feedback on visitor experience, and generate discussion around digital editions as sites for public humanities participation, this beta period was successful.

While statistics on site visits support optimism as to generating the publicity needed to reach potential repeat site users, statistics on returning site readers, and on use that is demonstrably part of reading the novel on the site rather than one-time exploration of the site's features, suggest room for improvement. Readership nearly halves from the third to fourth pages of the novel, and nearly halves again from the fourth to the fifth pages. New, one-time site visitors far outweighed returning users. Users other than the site creator authored 136 annotations during these first three weeks of the public beta, but this total has yet to match the 247 site annotations authored by the site creator; another metric for success will be met when user-authored annotation surpass the number of annotations authored by the site's personally motivated creator. The two site "power users" who have returned to the site nearly daily and added a total of 69 annotations between them are encouraging - the site at least supports these two motivated return readers - but for the site to truly be participatory, a far higher percentage of returning site users needs to be actively annotating rather than passively reading.

The Wikibooks-based Ulysses discussed in Section 2.5 is a participatory project that seems to only have active participation from its creator. Is a participatory project successful if it draws readers, but not active participants in the conversation (through annotations or other interactions)? Early site feedback suggests interest in the idea fueling the site, but it isn't clear from site analytics how well the idea is actually executed. I struggled to set minimum statistics that suggested success for my project's goals that didn't feel personally biased or arbitrary. More site visits, more returning visitors, and more site interaction are good, but how much of each is needed before these statistics support a claim that the project is not just public, but participatory? Further discussion in the digital humanities and textual scholarship communities is needed to reach a consensus as to interpreting these numbers. Future metrics will need to reassess the edition's success through further analysis of returning users and adoption by teachers and researchers.

\subsection{Future data collection}

Data analysis for the site will continue regularly as site use develops. Establishing now what data I expect to see after a year of the digital edition's availability, as well as what questions I expect to address with further data collection, will be useful in highlighting 
unexpected findings after further data gathering. After a year of use, I expect to see more readers who return to the site to read through whole episodes of the book or through the entire novel; at the moment, it's unclear whether the high percentage of single-visit users represents many people who are just interested in the project visiting once to check the site out, or whether many readers with the time and interest to take on Ulysses visit the site but don't decide to use it. Further publicity and word-of-mouth should garner new readers, including readers from other countries than currently represented; I might gather enough data to think about how a reader's home country or first language, and the Ulysses translations available there, map to their interpretations of the text. Design improvements and new features will attract readers on the fence about reading through the digital edition.

Several planned moments of public display should each contribute to a rise in returning readers:

- The addition of a link to Infinite Ulysses in the main menu of the Modernist Versions Project website (March 9, 2015)

- Teachers using Infinite Ulysses as a classroom tool (e.g. in UMD's "Multi-media Odyssey" Ireland study-abroad trip, Dr. Theresa Coletti's Fall 2015 English 601 (Literary Research and Critical Contexts) graduate course at UMD, and Dr. Brian Richardson's Fall 2015 English undergraduate courses.

- A museum installation and presentation at the Rosenbach Museum \& Library in Philadelphia (home of an important Ulysses manuscript and excellent public outreach programs) during their Bloomsday celebration on June 16, 2015

- Concurrent June 16, 2015 release of the 1.0 version of the site (design upgrades and new features)

- Interlinking between the Ulysses Seen webcomic version of Ulysses and Infinite Ulysses during Summer 2015 and after will bring readers of the webcomic to the digital edition

I'm expecting to see more user-authored annotations and tags, and more favoriting and voting on annotations, and more variation among vote rankings. Some authors regularly creating high-quality annotations will emerge. I'll also probably see unexpected uses of the site: annotations or tags used for purposes I didn't predict. 


\section{Section 4: Reimagining editions}

Editing seeks to establish texts that are proximate to a source of value. Insofar as it is concerned with proximity alone, editing is objective and scientific; insofar as its is concerned with the sources of value, editing is subjective and ethical. Every edition, every textual investigation, represents an assertion of value.

- Gary Taylor, "The Renaissance and the End of Editing"99

I've discussed Infinite Ulysses alongside scholarly editions such as the Shelley-Godwin Archive because of the overlaps in terms of audience, content, and usage. But is Infinite Ulysses a scholarly edition? This section will separate common methodologies and forms from the textual scholarship values they seek to embody, using this clarification to consider other processes and products that hold true to these values. We'll begin with an overview of the variety of edition types and an analysis of textual scholarly values since the earliest work in this field.

Scholarly editions have been conceptualized as:

1. vessels for the centuries-old work of interpreting documents and what they say about the larger text they participate in ${ }^{100}$,

2. cultural preservation or a way for readers to "get near" a text ${ }^{101}$,

3. the remixing of multiply useful documents to create new texts for research and reading,

4. useful substitutes for artifacts you can't physically access or for readers without the editorial level of textual expertise ${ }^{102}$,

5. a way of reading ${ }^{103}$

Earlier, I defined digital editions as texts (literary or otherwise) prepared for online reading and research according to some critical ideal for presentation, methodology, and content. There are further values (attention to versioning history) and features (use of facsimile) that vary in importance according to what text is at issue and who is editing it. Digital editions guarantee carefully justified methodologies and meticulous attention to the text that reaches the reader.

Types of edition that have been largely recognized as scholarly edition options by the community include genetic, synoptic, parallel-text (or otherwise versioned), diplomatic, facsimile, eclectic, critical, variorum, old or modernized spelling, copy-text, recensionist,

99Taylor, Gary. “The Renaissance and the End of Editing”, in Palimpsest: Textual Theory and the Humanities, ed. George Bornstein and Ralph G. Williams (1993), 130.

100E.g. "Critical editions are essential: they are demanded by the very nature of verbal works... [They inhabit] an intangible medium. Any tangible representation of such a work... cannot be the work itself."' G. Thomas Tanselle, "Editing without a Copy-Text". In Textual Editing and Criticism. Ed. Erick Kelemen. 258.

101Taylor, Gary. "The Renaissance and the End of Editing”, in Palimpsest: Textual Theory and the Humanities, ed. George Bornstein and Ralph G. Williams (1993), 121-149.

102Tanselle, G. Thomas. A Rationale of Textual Criticism.

103McGann, Jerome. “Ulysses as Postmodern Text: The Gabler Edition”. Criticism 27.3: 1985. 283-305. 
best-text, diplomatic, scribal, documentary, and social-text editing editions ${ }^{104}$. Some of these types are not exclusive, but each foregrounds a particular set of scholarly values while sharing in the values that mark all as scholarly editions. As newer types of scholarly edition come into the fold, the core values of scholarly editions change.

To define just what Infinite Ulysses is and isn't, let's look at what the term "edition" means by examining how editors' scholarly values have developed over time. Note that throughout this section, the term "scholarly" is only applied when a specific set of textual scholarship methodologies is implied; references to editions without a prepending "scholarly" allude to a broader body of projects meeting textual scholarship values, as will be explored below.

\subsection{A brief history of edition values}

Karl Lachmann, the 19th-century scholar generally recognized as the progenitor of the genealogical method still used in much editing today, was one of the first scholars to position textual scholarship as a scientific endeavor. Lachmann demonstrated how recension, the establishment of existing textual versions in hierarchy of relative authority, could help editors recreate earlier versions that were no longer available. Later scholars found that Lachmann's approach did not support texts with corrupt variants, or texts where multiplicity and corruption made modeling their versions hierarchically difficult.

The work of McKerrow and the earlier twentieth-century New Bibliographers brought a focus to the book as an artifact that could be objectively described and situated in a history of materials and printing practices. This movement arose from access to huge collections of books in one place and time, which made systematizing descriptions (e.g. collating) and large-scale research (e.g. the Short Title Catalogue covering decades and then centuries of play).

New Bibliography led to theorists such as McKenzie and McGann's attention to the social life of the book - throughout its composition, publication, and reception - as part of an edition's purview. This cataloging and description eventually led to the bibliographic and especially iconic (visual, illustrative) elements of the book being set on the same level of interpretive resonance as a book's linguistic content by scholars such as McGann, Tinkle, and Bornstein. Concurrently, Randall McLeod argued that the developing economic and technological feasibility of print facsimile editions placed an unavoidable responsibility on editors to link their critical decisions to visual proof.

104Many of these edition types were taken from "The Editor's Theory of Text" section of the MLA's Guidelines for Editors of Scholarly Editions. 
A non-exhaustive, roughly chronological list of values associated with various approaches to scholarly editing follows ${ }^{105}$ :

\begin{tabular}{|c|c|c|}
\hline Proponent & Values & In Practice \\
\hline 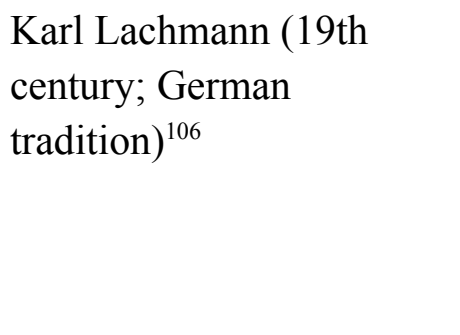 & $\begin{array}{l}\text { 1. Textual scholarship as scientific } \\
\text { endeavor } \\
\text { 2. Establish genealogy of the text } \\
\text { by recognizing complex } \\
\text { relationships among available } \\
\text { versions by perceived authority }\end{array}$ & $\begin{array}{l}\text { 1. Create and make public your } \\
\text { editorial methodology; adhere } \\
\text { rigorously to that methodology in all } \\
\text { editorial choices } \\
\text { 2. Use expert knowledge to rank texts } \\
\text { genetically }\end{array}$ \\
\hline $\begin{array}{l}\text { General Pre-Greg (Anglo- } \\
\text { American tradition) }\end{array}$ & $\begin{array}{l}\text { 1. Approximate authorial intent, not } \\
\text { final authorial intent }\end{array}$ & $\begin{array}{l}\text { 1. Best text approach (no recognition of } \\
\text { changing authorial intents over time) }\end{array}$ \\
\hline $\begin{array}{l}\text { New Bibliography (Early } \\
\text { 20th century) }\end{array}$ & $\begin{array}{l}\text { 1. Materiality of books is important } \\
\text { 2. Books can be objectively } \\
\text { described and then situated in a } \\
\text { history of materials and printing } \\
\text { practices }\end{array}$ & $\begin{array}{l}\text { 1. Address book as material artifact } \\
\text { 2. Methodology and editorial statement } \\
\text { should describe text's material } \\
\text { properties and their history, and use this } \\
\text { information when making editorial } \\
\text { decisions }\end{array}$ \\
\hline $\begin{array}{l}\text { W.W. Greg's "The } \\
\text { Rationale of Copy-Text" } \\
\text { (1950) }\end{array}$ & $\begin{array}{l}\text { 1. Contests old notions of authority } \\
\text { and the composition-to-printing } \\
\text { flow }\end{array}$ & $\begin{array}{l}\text { 1. Don't automatically grant authority } \\
\text { to last edition published while author } \\
\text { was alive } \\
\text { 2. Authority can be divided among texts } \\
\text { (e.g. introduce substantives and } \\
\text { accidentals from various sources, } \\
\text { leading to...) } \\
\text { 3. Produce eclectic editions (multiple } \\
\text { sources, and historical, artifactual } \\
\text { precursor not necessary) } \\
\text { 4. Use latest manuscript for accidentals } \\
\text { but first published edition for } \\
\text { substantives }\end{array}$ \\
\hline $\begin{array}{l}\text { Critique génétique } \\
\text { (genetic criticism), }\end{array}$ & $\begin{array}{l}\text { 1. Focus on the process of writing, } \\
\text { not the result of writing }\end{array}$ & $\begin{array}{l}\text { 1. The "genetic edition" that } \\
\text { "reproduc[es] the complete genetic }\end{array}$ \\
\hline
\end{tabular}

105For a thorough bibliography of textual scholarship history, see G. Thomas Tanselle's 2002 Introduction to Scholarly Editing seminar syllabus for the Rare Book School.

106Lernout, Geert. "Chapter 3: Continental Editorial Theory". In Cambridge Companion to Textual Scholarship. Eds. Fraistat, Neil and Julia Flanders. Advanced copy. New York: Cambridge University Press. 2012. 73.

107Because printers introduced accidental errors, but texts at this stage capture the agreement between the printer and what the author most wanted as the final appearance of their text. 


\begin{tabular}{|c|c|c|}
\hline $\begin{array}{l}\text { beginnings in the } 1960 \mathrm{~s} \\
\text { (e.g. Louis Hay) }\end{array}$ & & $\begin{array}{l}\text { dossier" of a written work }{ }^{109} \\
\text { 2. Surviving documents are analyzed, } \\
\text { transcribed, and ordered } \\
\text { 3. No privileging of some "final" } \\
\text { textual form }\end{array}$ \\
\hline $\begin{array}{l}\text { Randall McLeod and } \\
\text { unediting }(1982)^{110}\end{array}$ & $\begin{array}{l}\text { 1. Technology allowing easier } \\
\text { publication of facsimile texts } \\
\text { motivates rigorous editorial work, } \\
\text { allows true critical discussion of an } \\
\text { edition by scholarly peers }\end{array}$ & $\begin{array}{l}\text { 1. Critical decisions need to be linked } \\
\text { to visual proof in facsimile form. }\end{array}$ \\
\hline $\begin{array}{l}\text { Jerome McGann (e.g. } \\
\text { 1983, "A Critique of } \\
\text { Modern Textual } \\
\text { Criticism") }\end{array}$ & $\begin{array}{l}\text { 1. Explore the social life of the } \\
\text { book } \\
\text { 2. Contests old focus on author's } \\
\text { authority }\end{array}$ & $\begin{array}{l}\text { 1. Editorial statements discuss the text's } \\
\text { publication and reception } \\
\text { 2. Editorial statements acknowledge all } \\
\text { participants in the history of a text (e.g. } \\
\text { printers, scribes) contribute authority }{ }^{111}\end{array}$ \\
\hline $\begin{array}{l}\text { G. Thomas Tanselle's } A \\
\text { Rationale of Textual } \\
\text { Criticism (1989) }\end{array}$ & $\begin{array}{l}\text { 1. A "work" is distinct from its } \\
\text { manifestations as "texts". } \\
\text { 2. Editors must establish textual } \\
\text { reliability }{ }^{112} \text {. }\end{array}$ & $\begin{array}{l}\text { 1. Editors seek the work behind the text } \\
\text { (documents) under consideration. } \\
\text { 2. An edition's users need to know what } \\
\text { they are reading. }\end{array}$ \\
\hline $\begin{array}{l}\text { D.F. McKenzie's } \\
\text { Bibliography and the } \\
\text { Sociology of Texts (1999) }\end{array}$ & $\begin{array}{l}\text { 1. Make textual scholarship relevant } \\
\text { to literary studies } \\
\text { 2. Explore the social reasons why } \\
\text { texts were created and received in a } \\
\text { certain way }\end{array}$ & $\begin{array}{l}\text { 1. Editorial statements discuss how } \\
\text { form of the text affects its meaning } \\
\text { 2. Editorial statements discuss } \\
\text { reception together with composition } \\
\text { and transmission }\end{array}$ \\
\hline $\begin{array}{l}\text { McGann, Tinkle, } \\
\text { Bornstein, and other } \\
\text { theorists of the iconic page }\end{array}$ & $\begin{array}{l}\text { 1. Bibliographic and especially } \\
\text { iconic (visual, illustrative) elements } \\
\text { of the book being set on the same } \\
\text { level of interpretive resonance as a } \\
\text { book's linguistic content }\end{array}$ & $\begin{array}{l}\text { 1. Re-emphasis on old New } \\
\text { Bibliography values of textual } \\
\text { materiality and descriptive bibliography } \\
\text { 2. New emphasis on visual design of } \\
\text { text as textual argument and visual } \\
\text { design of edition as editorial argument }\end{array}$ \\
\hline
\end{tabular}

108Lernout, Geert. "Chapter 3: Continental Editorial Theory". In Cambridge Companion to Textual Scholarship. Eds. Fraistat, Neil and Julia Flanders. Advanced copy. New York: Cambridge University Press. 2012. 80.

109Ibid.

110McLeod, Randall. “UN Editing Shak-speare”. Sub-stance. 10(4)-11(1). 1981/1982. 26-55.

111The "originary moment" of authorial intent became one of many factors to consider.

112 "There is no way that we can talk about such works without assuming the responsibility of deciding just what we are talking aboutwithout in effect becoming editors, since the works exist only by virtue of our specifying, in the light of one set of considerations or another, what they contain”. Tanselle, G. Thomas. A Rationale of Textual Criticism. University of Pennsylvania Press. 2011. Reprint. 33. 
This chart represents, of course, only a generalizing overview of various schools of editing thought — but through abstractions, we can identify the overlapping intellectual values behind diverse methodological practices.

\subsection{Values and value embodiments}

We see the culmination of these scholarly value trends in today's distillations of the field's significant properties. The MLA Guidelines for Editors of Scholarly Editions provide a concise list of current edition values applicable to both print and digital scholarly editions ${ }^{113}$, paraphrased here:

- Present a reliable text (through accuracy, adequacy, appropriateness, consistency, and explicitness)

- Make clear what the edition promises; keep those promises

The Guidelines caution that each edition's instantiation of these values may be different, but advises certain features that are frequently used to meet these values: a general introduction; contextualizing annotations; documentation of changes to and variants of the text;

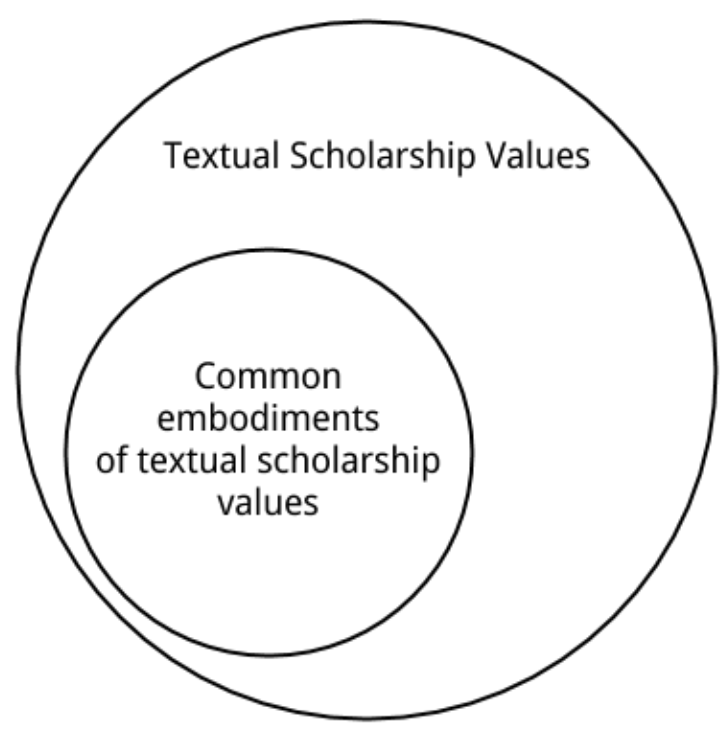

Both the RIDE and MLA scholarly edition guidelines acknowledge that the common embodiments of textual scholarly values aren't the only way to perform those values.

publicly available proofreading methodology; and statements establishing the text's history, physical forms, representation via the visual appearance of the edition, and rationale for all editorial decisions. Appropriateness of the medium chosen to embody the edition is also valued.

$R I D E$, a "review journal for digital editions and resources"114 provides "Criteria for Reviewing Scholarly Digital Editions"115 that attempt to be broadly applicable but also acknowledge that

any SDE [scholarly digital edition] can define different legitimate goals. There may be sound methodological reasons to refrain from textual reconstruction or emendation, to use no critical apparatus for the documentation of textual variance, or to select a particular perspective during the transcription. Hence, there are only three necessary conditions for an SDE:

- a justification of the editorial method adopted and a clear description of the rules that guided the edition,

- compliance with scholarly requirements towards content and quality, which includes that the self-stated rules are followed,

113From the page last updated June 29, 2011. http://www.mla.org/cse guidelines 
- and an editorial concept that is not restricted to the technological limitations of print technology but that realizes a "digital paradigm"

As with the MLA Guidelines, a public, clear, and rigorously honored discussion of methodology is identified as a significant property of scholarly editions. RIDE's value of using digital affordances to their fullest is an interesting choice in its acknowledgement of the critical effect of media on argument; the MLA Guidelines similarly discuss appropriateness of technological form and features and provides guidelines specific to digital editions. Both guidelines acknowledge that the most common scholarly embodiments of these values are not the only possible embodiments: edition forms and methodologies are manifestations of textual scholarship values, but these common manifestations are only some of the possible means for reifying these values. We will thus attempt to abstract the values and goals of the field of textual scholarship from the ways we have grown accustomed to seeing these values performed.

In the history of textual editing and in today's values as defined by the MLA and RIDE, I see an emphasis on two manifestations of scholarly value:

- An edition's methodology: is available to be read by others; rigorously and consistently controls an editor's decisions; is based on expert knowledge of the text and textual scholarship; conveys the values, biases, and arguments of the editor; adds to scholarly knowledge about the text in a manner that is more than the sum of editorial tasks such as proofreading and versioning (theoretical innovation); and adequately justifies an editor's choices in the eyes of the textual scholarship community.

- The form of an edition will include: a reliable text (one for which the reader can know the provenance, the goals for presenting the text, and any alterations and decisions involved in transcribing the text to digital space), certain features that support the methodological requirements (e.g. contextualizing annotations) ${ }^{116}$, and use the full possibilities of current technology to address editorial challenges (e.g. with the advent of cheap facsimiles, editors need to do some work to justify not including this important textual evidence in their edition)

These expected embodiments reify the following values for the field of textual scholarship:

1. Professionalism as a textual scholar, performed through methodological qualities. A scholarly editor should thoroughly demonstrate the reliability of their judgment for the choices made in the creation of the edition.

2. Expertise as a textual scholar, performed through an edition's contribution to the scholarly community. A scholarly editor should use their expertise to convey

116Adherence to forms that have succeeded across the textual scholarship community suggest reliability even when the edition in question is outside your historical field (thus, the pressure to include features that are common in other editions). This seems to be an outgrowth of establishing editorial reliability rather than a value in its own right. 
an argument appropriate to the text under consideration through their edition (this "theory of the text" may stem from a more traditional concern such as a hypothesis on the method of the text's production, or advance an idea not yet tested through an edition). To ground this theory, an edition must present a "reliable" text — one for which the provenance, editorial goals and choices, and the rigorous preparation method are known (readers and readers must know what they are reading).

\subsection{Is Infinite Ulysses a scholarly edition?}

I would not characterize Infinite Ulysses as a scholarly edition. "Scholarly edition" carries a rich history as a textual scholarship term of art; a scholarly edition embodies the values explored above in specific ways, using specific formats and methodologies:

- Traditional scholarly editing activities (e.g. emendation, recension, and conjecture $^{117}$; or transcription and ordering, depending on the school of thought) went into the object's production. For a work to be "edited", the editor must have worked at the level of individual words to convey the text appropriate to their argument.

- Although both the MLA and RIDE definitions allowed room for varied approaches to conveying methodological information and including textual apparatus, a scholarly edition carries an expectation that most of this information will be conveyed in a written essay format.

- Formal peer review is an expected piece of a scholarly edition's promise of reliability to its users. For non-scholarly editions, formal peer review can also be useful, but its application is less urgent and can take various shapes such as evidence of research or pedagogical use, public impact, and other informal metrics.

- The prepared text and textual apparatus (e.g. contextualizing annotations) are part of the entire scholarly edition project that undergoes formal peer scrutiny. With a non-scholarly edition, the pieces representing scholarly effort and thus inviting peer review can vary. For Infinite Ulysses, a reliable scholarly group outside the edition provided the edition's text; the edition's annotations are not part of the creator's critical work but are largely authored by other edition users.

"Scholarly edition" as opposed to "edition" carries much the same distinction as "scholarly editing" does to "textual scholarship"; both contain words that seem to point at the same activities and values, but the former means something very specific by virtue of long tradition. Infinite Ulysses did not involve recension, conjecture, or similar textual scholarship tasks. The focus of its methodological statements are on the digital edition as a form, rather than on Ulysses as an edited text.

117See Kari Kraus' "Conjectural Criticism: Computing Past and Future Texts" for work translating these activities to the digital. 
What is the purpose of calling something an edition? Insistence on a term meaning a specific something because you need a term to refer to that specific something should not be enough to retain a limited meaning for a term, or we can't usefully communicate. The line of differentiation may be whether an established history for the words' use exists within the scholarly community; "scholarly edition" carries a history, but "edition" as separate from scholarly edition does not feel convincingly tied to a small subset of editorial values - perhaps because so much of the time we're willing to spend on semantics has been wrapped up in defining "scholarly edition" so that we can develop better ways of evaluating and comparing them.

As we explore whether various textual projects achieve the status of edition by performing these values, we should keep in mind the purpose of field-specific semantics. Retaining this specific meaning for "scholarly edition" lets textual scholars converse easily about a foundational artifact from our field. Retaining this specialized meaning also reflects our field's attitude toward professionalism by guaranteeing reliability to users from outside the field of textual expertise. Identifying in detail what a scholarly edition should do can, on the other hand, act as a guideline for research that wishes to approach or achieve these values without necessarily employing all the methods scholars have used to do so in the past. That is: it is ultimately more important to textual scholarship whether Infinite Ulysses frames itself as an edition and actively innovates ways of achieving textual scholarship values, than whether or not the community agrees on the label to apply to the textual project. The above definition of scholarly editions should meet the standards a textual scholar might worry Infinite Ulysses doesn't meet. There's a term of art for those particular methods and forms, and my goal here is to define non-scholarly editions in a way that also produce textual knowledge while allowing for more varied means of achieving that knowledge.

What Infinite Ulysses currently allows and performs does not make it a scholarly edition, but it is the product of critical work, and it is the artifact with which a scholar must engage to critically engage with my critical work. Are there changes to the site that would make it more resemble a scholarly edition, without deviating from its mission to support a participatory conversation around Ulysses through crowd-authored annotations?

The introduction of versioning to the edition would be another method of moving the digital edition closer to a scholarly edition ${ }^{118}$. This could occur on a simple level by comparing Infinite Ulysses' version of the MVP 1922 text to the Project Gutenberg e-text, with a focus on educating readers about textual reliability and authority through a simple version comparison. Alternatively, true textual versioning ${ }^{119}$ could be implemented by

118Using Alyssa Arbuckle's rubric for the shortcomings of The Waste Land app as a public digital edition (discussed further in Section 4.7), addressing textual versions would make Infinite Ulysses meet all the standards for which The Waste Land falls short.

119Subject, of course, to other public domain texts of Ulysses becoming available; currently the only reliable and reusable digital alternative to Infinite Ulysses' Modernist Versions Project 1922 Shakespeare \& Co. text is the MVP's facsimiles and transcription of 
embedding an existing tool such as the Versioning Machine, or by using annotations (perhaps with special "versioning" and "x version of Ulysses" tags) to point out other textual options on a page.

Although it is not a scholarly edition, Infinite Ulysses is an edition. Whether a textual project uses common textual scholarship means of performing textual scholarship values does not answer whether the textual project performs those values (and is therefore an edition). Indeed, textual scholar Erick Kelemen introduces a volume intended as an introduction to textual scholarship with a discussion of the "many kinds of editions" that embody textual scholarly values:

Within the category of critical editions there are several kinds, a diversity that arises from divergent purposes and theoretical grounds...That different editors will produce different [kinds of] edition will seem obvious, but it is worth saying because a major tendency in editorial theory since at least the mid-twentieth century has been to try to eliminate this subjective character of editing by codifying its procedures and by spelling out the rules by which an editor makes choices in deciding what to print ${ }^{120}$. (emphasis added)

Any edition represent one possible embodiment of a text, dependent on editorial values ("purposes and theoretical grounds"). Kelemen points to attempts at establishing detailed standards for scholarly editions as running contrary to this diversity, even as such guidelines benefit the field in terms of evaluation and modeling of best practices.

\subsection{Infinite Ulysses as an edition}

We'll now explore how Infinite Ulysses fits these distilled community values for editions. Later, we'll address how loosening the rules for what is or isn't an edition can both help textual scholars discover new ways of reifying their intellectual values, and encourage textual projects from outside the academic field to develop toward our textual goals.

With the understanding of the relationship between common embodiments of editorial values and the values themselves, Infinite Ulysses does apply some of the typical textual scholarship practices listed above:

\begin{tabular}{|l|l|}
\hline $\begin{array}{l}\text { Common manifestations of textual } \\
\text { scholarship values }\end{array}$ & Does Infinite Ulysses include these? \\
\hline $\begin{array}{l}\text { Methodology available to be read by } \\
\text { others }\end{array}$ & $\begin{array}{l}\text { Discussions of values, design and code methodology, and } \\
\text { how particular decisions were made are available both on the } \\
\text { site's research statement and around 40 research blog posts } \\
\text { on LiteratureGeek.com throughout the course of the project. } \\
\text { These could be presented in greater depth to fit the needs of a }\end{array}$ \\
\hline
\end{tabular}

Samuel Roth's "pirated" Two Worlds Monthly version of the novel.

120Kelemen, Erick. "Textual Criticism and Kinds of Editions". In Textual Editing and Criticism. Ed. Erick Kelemen. 80-81. 


\begin{tabular}{|c|c|}
\hline & scholarly edition. \\
\hline $\begin{array}{l}\text { Methodology rigorously and consistently } \\
\text { controls an editor's decisions }\end{array}$ & $\begin{array}{l}\text { My stated scholarly values have demonstrably permeated the } \\
\text { project (see Sections 3.4-3.6) and my reasons for alterations } \\
\text { to the Modernist Versions Project text are shared on the } \\
\text { edition. These instances do not, however, meet the need for } \\
\text { an overall methodology for the project (theory, textual } \\
\text { changes, code, design, and all the other pieces listed in the } \\
\text { dissertation manifest) in enough detail that each decision and } \\
\text { piece of work can be checked against the methodology and } \\
\text { critiqued by another textual scholar. }\end{array}$ \\
\hline $\begin{array}{l}\text { Methodology is based on expert } \\
\text { knowledge of the text and textual } \\
\text { scholarship }\end{array}$ & $\begin{array}{l}\text { Yes. My M.S.I. and Ph.D. work represents seven years of } \\
\text { specialized research and membership in scholarly } \\
\text { communities targeted at innovating digital edition interfaces } \\
\text { and building on previous digital work with Ulysses. }\end{array}$ \\
\hline $\begin{array}{l}\text { Methodology conveys the values, biases, } \\
\text { and arguments of the editor }\end{array}$ & Yes (see Section 3.4-3.6). \\
\hline $\begin{array}{l}\text { Methodology adds to scholarly knowledge } \\
\text { about the text in a manner that is more } \\
\text { than the sum of editorial tasks such as } \\
\text { proofreading and versioning (theoretical } \\
\text { innovation) }\end{array}$ & $\begin{array}{l}\text { Yes. The project methodology has been focused on } \\
\text { innovating textual forms and theory. }\end{array}$ \\
\hline $\begin{array}{l}\text { Edition must present a "reliable" text-- } \\
\text { one for which the provenance, editorial } \\
\text { goals and choices, and the rigorous } \\
\text { preparation method are known (readers } \\
\text { and readers must know what they are } \\
\text { reading). }\end{array}$ & $\begin{array}{l}\text { Yes. The burden of the text's reliability falls on the Modernist } \\
\text { Versions Project's preparation of the text. My subsequent } \\
\text { alterations to the text are documented, but would need to be } \\
\text { more fully justified to fit a scholarly edition. }\end{array}$ \\
\hline $\begin{array}{l}\text { Methodology adequately justifies an } \\
\text { editor's choices in the eyes of the textual } \\
\text { scholarship community }\end{array}$ & $\begin{array}{l}\text { Some preliminary, informal feedback on the project from } \\
\text { fellow textual scholars is promising (e.g. the Modernist } \\
\text { Versions Project), but such a claim requires a formal review } \\
\text { process and time for members of the community to formulate } \\
\text { responses and critiques }{ }^{121} \text {. }\end{array}$ \\
\hline $\begin{array}{l}\text { Edition's form incorporates certain } \\
\text { features that support the methodological } \\
\text { requirements }\end{array}$ & Yes (see Section 3.4-6). \\
\hline Edition's form uses the full possibilities of & Yes. The project builds on innovations in web annotation \\
\hline
\end{tabular}

121E.g. I'll be contacting scholars whose theories on a hypertextualized Ulysses I've cited for feedback. 


\begin{tabular}{|l|l|}
\hline $\begin{array}{l}\text { current technology to address editorial } \\
\text { challenges }\end{array}$ & $\begin{array}{l}\text { among other open-source code projects to achieve a long- } \\
\text { theorized but never tested textual performance. }\end{array}$ \\
\hline
\end{tabular}

To some extent, the failure of Infinite Ulysses to include a "methodology rigorously and consistently controls an editor's decisions" results from the newness of textual innovations being made in the form of digital functionalities; there are not yet many examples of methodologies for such projects that address tasks in the purview of the research programmer at the same level of detail as the traditional editorial statements.

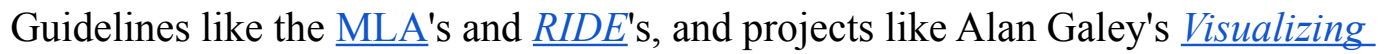
Variation code suite and the Shelley-Godwin Archive's code- and design- aware textual statements, lay a good foundation for further exploration of what equally rigorous statements for technological methodology beyond textual encoding should look like. Infinite Ulysses needs to do further work in shaping what a rigorous methodology for design and code could do by publishing such a statement so that the textual community may critique and improve it.

Is the editorial project of Infinite Ulysses the edition of Ulysses, or is it the interface of the site as a vessel for texts like Ulysses (with an understanding that Ulysses may be the only text in that grouping)? Filling in the chart above emphasized for me that some of the common textual scholarship properties my edition does perform applied more to the "vessel" of the text - the interface and site - than they did to the "edition" proper. Differences among Infinite Ulysses the edition, InfiniteUlysses.com the site, and the dissertational project around Infinite Ulysses need to be parsed better so that it's clear which of these three options has its methodology thoroughly documented, and which need more public, detailed justification.

How text-agnostic is the project that produced Infinite Ulysses? I'm making my code available for reuse with other texts; would switching out the text in the interface still produce an edition (if we agree with my argument that Infinite Ulysses is indeed an edition)? Can the Infinite Ulysses code only work for other texts if changes are made to functionality or appearance (e.g. changing the curation and moderation features to fit a text that will only be annotated in the classroom or in a scholarly circle)? I've begun work with developers on two other digital editions (Shelley-Godwin Archive and Romantic Circles) to see how well code and design from Infinite Ulysses port to other texts, experiments that will help me explore these questions further.

Determining whether a scholarly artifact fits a descriptive term of art should be based on how well the artifact fits the values that produced other examples of that term of art, rather than on whether the artifact resembles those other manifestations. Infinite Ulysses does perform the values of textual scholarship established above. I've demonstrated the 
reliability of my judgment for the textual, project, appearance, and functionality choices performed through the creation of the edition (see chart immediately above for specific examples and link). The MLA Guidelines' accuracy, adequacy, appropriateness, consistency, and explicitness are met at least to the extent reached by other artifacts judged by the textual scholarship community to be editions. Grounding the site's textual innovations is a reliable text of Ulysses: a text for which the provenance, editorial goals and choices, and the rigorous preparation method are known. The Infinite Ulysses text is based on the Modernist Versions Project transcription prepared by two scholars, with proofreading fixes and re-asserted typographical choices made by me and recorded for public perusal on the edition site. As discussed above, further work at an explicit methodology for technical choices would both serve the scholarly community and deepen the project's edition-ness.

I've used my expertise in digital edition interface design to convey an argument appropriate to the text: building on Joycean theories around a digital Ulysses to test and further these theories of the effect of hypertextualization on the text, and building on digital humanities theory around participatory humanities projects through a participatory experiment providing analyzable data as well as advancing the discussion around meaningful crowdsourcing with some suggestions for alternate participation scholarly uses. Although the MLA and RIDE guidelines recognize most editions perform their "theory of the text" through an editorial essay, both guidelines also leave room for alternative interpretations of how textual theories may be performed by an edition.

\subsection{Diversifying embodiments of textual scholarship values}

It's possible for a digital scholarly object to be both "scholarly" and an "edition" without necessarily fitting the connotations of "scholarly edition". Tanselle suggests, "One can simply suggest textual alterations in an essay or in conversation, without actually publishing a new edition, in order to make it possible for others to incorporate those alterations into the text and experience the work in the form thus created or recreated" ${ }^{122}$; textual scholarship can advance through other forms that the edition. Below, three examples of work acknowledging textual scholarship values outside the lines of an edition:

- Jstor's Understanding Shakespeare connects each line of Shakespeare's plays to articles on Jstor that reference that line; this ability overlays the Folger Shakespeare Library scholarly editions of the plays edited by Barbara Mowat and Paul Werstine.

- Alan Galey's Visualizing Variation "explores the possibilities of a digital humanities project whose principal investigator is also its lead programmer. It also

122Tanselle, G. Thomas. A Rationale of Textual Criticism. University of Pennsylvania Press. 2011. Reprint. 28. 
explores the possibilities of doing digital humanities interface design outside the context of a single editing project"123.

- Contrast the print variorum for Charles Darwin's On the Origin of Species (left, below) to Ben Fry's "On the Origin of Species: The Preservation of Favored Traces" (right, below), based on scholarly transcriptions of the editions, which visualizes changes among the various editions (note that you can actually hypothetically read the editions from Fry's edition by hovering over the image). A value of the variorum is to span all textual versions, but is that value met if the text is not practically readable (perhaps; the text is certainly consultable)? Fry's work, on the other hand, values a sense of the extent and location of changes among the editions as they develop over time, and that value is achieved. Darwin Online's digital variorum functions similarly to Fry's work while sharing the print variorum's consultability, so perhaps the question should be how an edition's value can be judged if existing technologies are not adequate to reach those values.

With the variety of textual manifestations above, we've begun to explore the connection between the values and goals of textual scholarship and the embodiment of these values and goals. What other embodiments, existing or hypothetical, could these values take?

And where might these embodiments fits in

$3 I_{3}: C$ It is not probable that variability existing typologies of textual edition?

313:e contingent, under all circumstances.

314 The effects of variability are modified by various degrees of inheritance and of reversion.

314:e The greater or less force of inheritance and reversion d mine whether variations shall endure.

315 Variability is governed by many unknown laws, more especi by that of correlation of growth.

315:e correlation.

315:f laws, of which correlated growth is probably the most portant.

316 Something may be attributed to the direct action of the co tions of life.

316:e to the definite action of the conditions of life, but how $\mathrm{m}$ we do not know.

316:f Something, but how much we do not know, may/life.

317 Something must be attributed to use and disuse.

3I $f f$ Some, perhaps a great, effect may be attributed to the creased use or disuse of parts.

$3^{18}$ The final result is thus rendered infinitely complex.

319 In some cases, I do not doubt that the intercrossing of spe aboriginally distinct, has played an important part in the or of our domestic productions.

3rg:c cases the intercrossing/has probably played/domestic bre

3rg:e intercrossing of aboriginally distinct species, has probably 319:f species appears to have played/our breeds.

320 When in any country several domestic breeds have once 1 established, their occasional intercrossing, with the aid of seiection, has, no doubt, largely aided in the formation of new subbreeds; but the importance of the crossing of varieties has, I believe, been greatly exaggerated, both in regard to animals and to those plants which are propagated by seed.

$320: c$ varieties has been

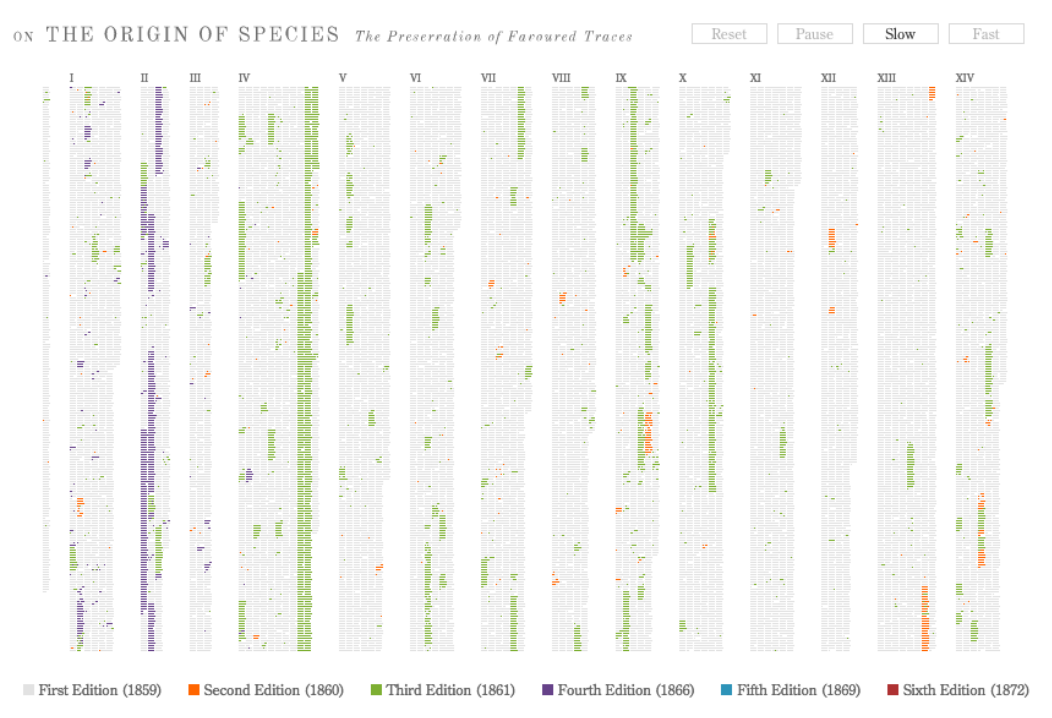

123Galey, Alan. Visualizing Variation. Digital humanities project website. http://individual.utoronto.ca/alangaley/visualizingvariation 
Ray Siemens et al. propose a digital edition typology structured around approaches for "handling and engaging with its textual materials": "from edited electronic text plus analytical tools for its readers (dynamic text), to text plus a static set of additional supporting materials in digital form for reader navigation and subsequent analysis (hypertextual edition), to text augmented by both dynamic analytical means and hypertextually-linked access to fixed resources plus automated means of discovering and interrelating external resources (dynamic edition) ${ }^{124 "}$. Siemens et al. further propose we're just now feeling out the typologies of a "social edition"—an edition wedded with Web 2.0 technologies ${ }^{125}$ — just as we did the digital edition when first wedding Web 1.0 abilities to the tradition of print editions ${ }^{126}$. Such editions explore the new possibilities for textual knowledge allowed by collaborative annotation, user-derived content, folksonomy tagging, community bibliography, and shared text analysis ${ }^{127}$. Siemens et al. note that these features move away from some assumed textual scholarly values (e.g. deemphasizing editorial authority ${ }^{128}$ ) and explore new ones (e.g. privileging the process of understanding a text over the resulting edition ${ }^{129}$ ).

I'm partial to G. Thomas Tanselle's chart of edition typologies (below) because his groupings somewhat depend on scholarly values: is it important that the approach be historically aware? may alterations to the text or editorial judgment be used to achieve the editorial goal? is the text imagined as a solo or collaborative work? should the edition reconstitute the text as it was at a specific moment in its history - and if so, which moment, and must that moment be represented by an existing document?

If we shift our focus from what a scholarly edition usually seems to do, to the values underlying those methods - as the discussion of Infinite Ulysses as an edition above does -we can examine which of these methods are the only option for embodying a given value - and whether there are other ways of embodying edition values that became overlooked as we mistook common edition mechanics as the only way to embody intellectual values.

Moving beyond the semantics of "scholarly or not scholarly?" lets us consider other aspects of digital editions; for example, we can shift our focus from the edition's core text to the edition's annotations. On a participatorily annotated edition such as Infinite

124Siemens, Ray et al. "Pertinent Discussions Toward Modeling the Social Edition: Annotated Bibliographies". Digital Humanities Quarterly 6(1). 2012.

125I.e. Web mechanics that rely on user-generated content and other user interactivity.

126Siemens, Ray et al. "Toward Modeling the Social Edition: An Approach to Understanding the Electronic Scholarly Edition in the Context of New and Emerging Social Media". 18. (Also available as LLC 2012 27[4]. 445-461.)

127Ibid., 12.

128Ibid., 16.

129Ibid., 17. 
Ulysses, what is the audience for an annotation? Do different annotations have different audiences? What does the act of creating a different type of annotation entail for each author?

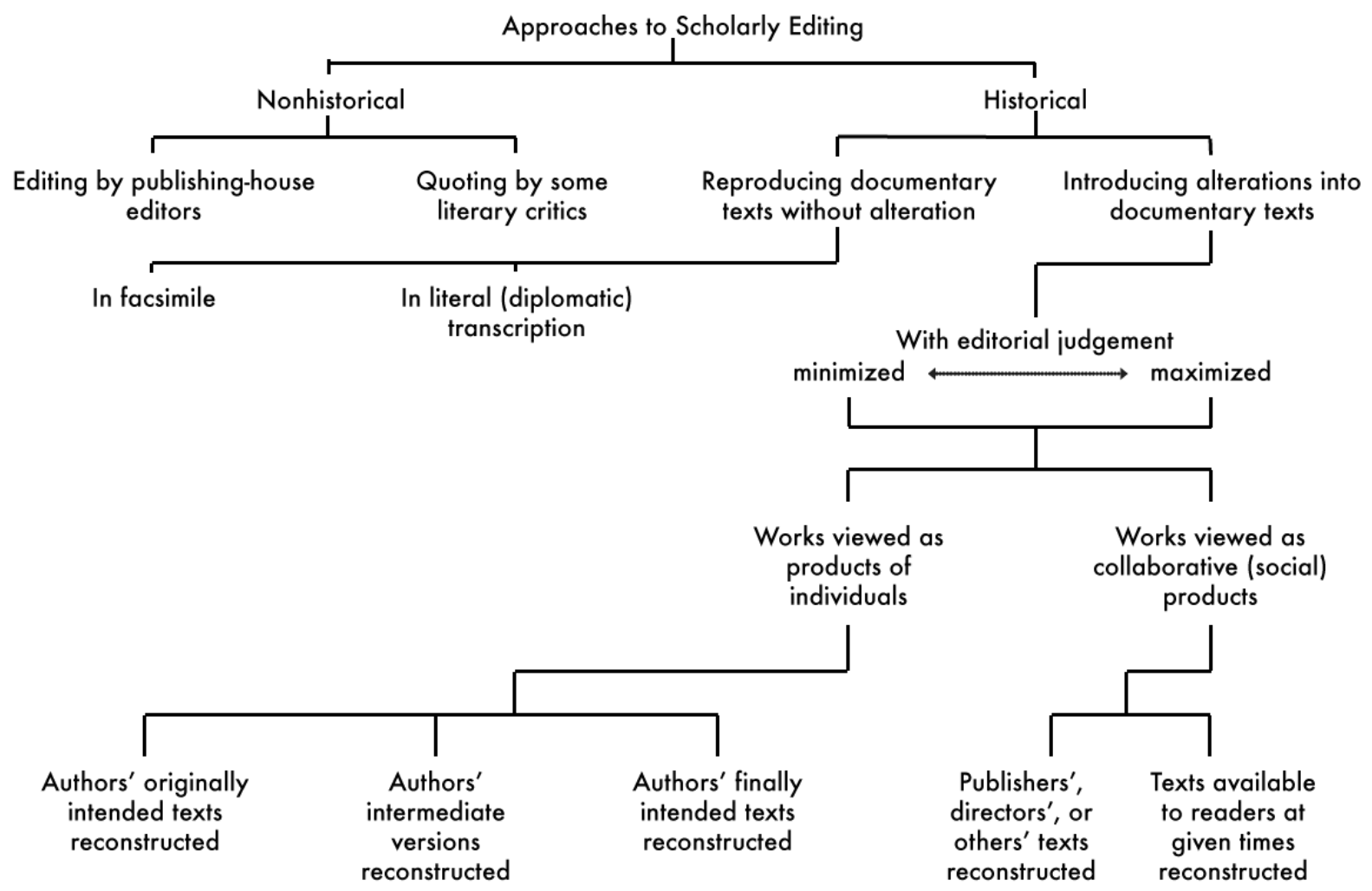

G. Thomas Tanselle's scholarly edition typology ${ }^{130}$

One can imagine, for example, a literature professor creating annotations to support a scholarly journal article (annotation for scholarly community), to capture thoughts during a re-read that might be useful to revisit at some point (annotation for self), and to help their students through a reading of the novel (annotation for first-time readers). With many possible uses for the edition, Infinite Ulysses has future work to do in personalizing the granularity of annotations to different readers (and even, as with our professor example, the same reader at different times). A Shakespearean scholar may want to read analyses of Joyce's allusions to a specific play, while a first-time reader may just want to know what the play is called and what its mention means in the context of the novel. A

130Re-typeset by the author. From Tanselle, G. Thomas. "The Varieties of Scholarly Editing". In Scholarly Editing: A Guide to Research. Ed. D. C. Greetham. Modern Language Association of America, 1995. 11. 
future version of the edition may allow a reader to identify their purpose at the beginning of a given session on the site (e.g. annotating for self, for students) and add a tag to all annotations they created during that session to help other readers sift through various levels of annotation granularity. Infinite Ulysses allows us to translate theoretical problems (what is the audience for a contextualizing annotation?) into experiments with results that can be fed into future versions of the edition.

\subsection{What does the label "edition" help us know?}

What isn't an edition? For the term to remain meaningful, surely there are some textual projects that don't adhere to the values of textual scholarship and thus cannot usefully be called editions. A series of provocations to reconsider the boundaries of edition form follow; these aren't meant to be final decisions on the appropriate semantics for each case, but rather a starting point for examining assumptions about textuality and scholarly method, and how reimagining textual works as editions can add to our knowledge around textuality.

Note that these possibilities all presuppose that current editorial values are on some level "correct". Scholarly editor Gary Taylor used a speculative experiment to demonstrate that much of our current textual knowledge and values are heavily influenced by an early focus on Shakespeare's writing ${ }^{131}$. By imagining an alternative history of textual scholarship focused on Middleton rather than Shakespeare, Taylor demonstrates that textual scholars would have confronted earlier - and thus probably hold different ideas about — crucial issues such as authority ${ }^{132}$, genre division ${ }^{133}$, and the nature of a textual "work" 134 . Further work in this vein of reimagining edition semantics might push back against textual scholarship values that seem tied to a specific author or technology.

Is a literature reading app without scholarly oversight an edition? In a comparison of two candidates for consideration as public-facing digital editions, Alyssa Arbuckle distills

131Taylor, Gary. “The Renaissance and the End of Editing”, in Palimpsest: Textual Theory and the Humanities, ed. George Bornstein and Ralph G. Williams (1993), 121-50.

132Middleton's play A Game of Chess "survives in six manuscripts and two substantive editions- the mere existence of manuscripts in the author's own handwriting does not solve all textual problems, or render editors superfluous." (false assumptions that a focus on Shakespeare impeded from correction; Taylor 134) 133Whereas the existence of Mr William Shakespeares Comedies, Histories, \& Tragedies forced "simplistic genre divisions" on the plays, "Middleton's generic range is at least as great as Shakespeare's, but there is no authoritative or contemporary division of his work into such categories" (Taylor 134-135).

134The civic pageant A Magnificent Entertainment was a multi-author collaboration only ever printed in two separated parts (one with Jonson's work, and one with Dekker and Middleton's), "undermin[ing]... a distinction, which editors of Shakespeare take for granted: that the limits of a work coincide with the limits of a text." (Taylor 135-136) 
multiple theorizations about the makeup of the ideal digital edition ${ }^{135136137138139140141142143}$ to a consensus on their significant properties: "a clear editorial mandate, a concise textual apparatus, a comprehensive bibliographic history, multiple versions of the text, an aesthetically pleasing interface, and the capacity for user interoperability and annotation" ${ }^{144}$. She finds that although The Waste Land iPad app ${ }^{145}$ comes up short when held to the standards of scholarly digital editions, it still offers a useful model for an edition type that "promotes access to and interaction with a textual artifact, while maintaining certain tenets of dependable, authoritative literary editions", what she calls a "public digital edition". Arbuckle reads the various shortcomings of the app as more rather than less reason to consider it an edition: its failings demonstrate the necessity of public textual scholarship involvement.

Arbuckle's review of the app in juxtaposition with a public edition closer to scholarly ideals is a reminder that innovations in textual scholarship thinking are a result of loosening or re-examining the definitions of our terms of art. The Waste Land app doesn't meet the values of "edition" defined above ${ }^{146}$, but situating The Waste Land as an edition - albeit a seriously flawed one_-allowed Arbuckle to make innovative suggestions for a more public-facing textual scholarship.

Can audio of a text be an edition? The Leaves of Grass Open Audiotext offers a foundation familiar to textual scholars: a diplomatic transcript backed by TEI encoding (with plans for contextualizing annotations) as a digital reading text. Users can listen to recordings of multiple readers vocally interpreting the same text:

...How much is lost when we read only with our eyes. Unfortunately, "Song of Myself" is a poem that is much read but seldom heard. This is a particular problem since Whitman's long idiosyncratic line can look like prose to many

135Clement, Tanya. 2011. "Knowledge Representation and Digital Scholarly Editions in Theory and Practice." Journal of the Text Encoding Initiative. 1. 1-14.

136McGann, Jerome. 1991. The Textual Condition. Princeton: Princeton UP.

137---. 2001. Radiant Textuality: Literature After the World Wide Web. New York: Palgrave.

138---. 2006. From Text to Work: Digital Tools and the Emergence of the Social Text. 16. 49-62.

139Robinson, Peter. 2010. "Electronic Editions for Everyone." In Text and Genre in Reconstruction. Ed. Willard McCarty. Cambridge: Open Book Publishing. 145-64.

140Shillingsburg, Peter. 2006. From Gutenberg to Google. Cambridge: Cambridge UP.

141Siemens, Ray, with Alex Garnett, Corina Koolen, Cara Leitch, Meagan Timney, and the ETCL, INKE, and PKP Research Groups. 2012. "Toward Modeling the Social Edition: An Approach to Understanding the Electronic Scholarly Edition in the Context of New and Emerging Social Media." Literary and Linguistic Computing. 27(4). 445-61.

142Smith, Martha Nell. 2004. "Electronic Scholarly Editing." In A Companion to Digital Humanities. Eds. Susan Schreibman, Ray Siemens, and John Unsworth. Oxford: Blackwell. 306-22.

143Vetch, Paul. 2010. "From Edition to Experience: Feeling the Way towards User-Focused Interfaces." In Electronic Publishing: Politics and Pragmatics. Ed. Gabriel Egan. Tempe, Arizona. 171-184. 144Arbuckle, Alyssa. "Considering The Waste Land for iPad and Weird Fiction as models for the public digital edition". Digital Studies. 2014.

145Arbuckle: "The Waste Land for iPad application, an edition of T.S. Eliot's poem The Waste Land (1922) developed by Touch Press in collaboration with Faber \& Faber, and released in June of 2011".

146"Professionalism as a textual editor performed through methodological qualities", and "Expertise as a textual editor performed through an edition's contribution to the scholarly community" 
readers... this audiotext emphasizes the oral register of the poem, thus enabling users to better apprehend the relations between sound and sense. ${ }^{147}$

The audio is presented as core piece of the edition, rather than ancillary to the written text; users are encouraged to remix the various audio readings to experiment with interpretive effect, or experience a "director's cut" as a sort of reading endorsed by the edition. The site doesn't thoroughly discuss the methodologies behind the diplomatic transcription or the audio readings ${ }^{148}$, but the introduction suggests that such work did go into the making of the edition and just fails to be recorded on the site. The application of expertise was again obvious, though undocumented on the site: a new relationship to Whitman's poetry through the juxtaposition of multiple audio performances. As with Arbuckle's assessment of The Waste Land app, it feels useful here to consider the Leaves of Grass Open Audiotext as an edition that offers textual innovations to the scholarly community, but needs to more fully document its scholarly processes.

Can a museum exhibit be an edition? To what extent are our assumptions about what is and isn't an edition bound up in the physical affordances of the codex? For print editions this makes some sense, although other printing possibilities than codices have existed as long as codices have. For textual engagements in other spaces, more attention to textual scholarly values rather than traditional value manifestations might aid design innovation. In the digital space, for example, Jon Saklofske's NewRadial prototype makes a compelling argument to abandon print restrictions when moving from a print to digital $\operatorname{archive}^{149}$.

The Long Now of Ulysses exhibit at the University of Victoria ${ }^{150}$ imagines reimagines Ulysses' discourse field as the public "afterlife" of the text. The exhibit was available for a limited time at the University of Victoria's Maltwood Gallery, and the installations live on via web pages. Considering the textual design of the exhibit suggests that commonplaces of edition design such as permanency, limited dimensionality, and location independence may not be required by textual scholarship values.

If we think of this exhibit as an edition, its text is clearly the 1992 Shakespeare and Co. first printing of Ulysses. But where is the text? If an edition must include its text, which text? If the answer is "a text that can be read", readable how-as originally envisioned (i.e. reading the ordered characters as linguistic signs)? As envisioned by whom? How can we know the text wasn't originally envisioned differently, but the requirements of contemporary technology altered its final form? Does the text need to be part of the

147Leaves of Grass: Introduction

148A brief online search didn't turn up methodological discussion elsewhere on the web.

149Saklofske, Jon. “NewRadial: Revisualizing the Blake Archive”. Poetess Archive Journal 2.1 (2010).

150The University of Victoria Maker Lab in the Humanities has a number of projects that innovate the form of textual editions,

including through topic modeling and word frequency. 
edition's "package", or may some editions assume that an easily obtainable version of a text will be accessed by the user in addition to the edition? ${ }^{151}$

Can a textual experiment be an edition? Editions, Blake Archive editor Morris Eaves claims, "are problem-solving mechanisms; without problems to solve, new editions would not be needed." 152 Editions attend to questions about texts and textuality that haven't yet been adequately addressed through an edition and its methodological choices. Much attention in the form of editions has been paid to issues of textual transmission, or some final state of composition; comparatively less attention has been paid to focusing on the stages of a text's composition ${ }^{153}$; much less attention has been paid to forms of composition that emphasize remixing techniques such as Grangerizing and commonplacing.

Whitney Anne Trettien's prototype digital edition of a Little Gidding Harmony explores the composition of a work created through the cutting up and chronological rearranging of the New Testament Gospels ${ }^{154}$. Trettien's edition not only highlights the separate pieces making up each page, but also pulls out the various clippings so you can experience them unattached to a page just as the authors did during the construction process. Her discussion of the prototype shows discomfort with applying the term "edition" to it: its readers are interested in composition rather than product, and "the product itself doesn't face the problems that so much of textual criticism has been designed to deal with" such as multiple variants. She further innovates through imagining the "cut-up method" of the Harmony's composition as itself editorial work, making the modern editor's role "to pull apart the already harmonized text". Trettien found that the current usage of "edition" and its common manifestations didn't support her theories of text, turning instead to ideas like geographical mapping to support her methodology. Re-examining what it is to be an edition - and pulling in useful knowledges from outside textual scholarship, as Trettien does - can be a way of letting editions solve unaddressed textual problems.

These projects suggest a reimagining of the term "edition" through new embodiments of traditional values. The variety of their critical textual performances is a reminder that while semantics are useful for encouraging and shaping professionalism, scholars should be wary of too stringent gate-keeping and frequently reassess of semantics to allow for scholarly innovation in the field. In the following sections, we'll turn from edition form to functionalities suggested by edition metaphors.

151The Long Now exhibit worked with specific selections from throughout the novel: "Because the sections selected for our exhibit have been removed from their original literary context, and inserted into a new algorithmic one, they have taken on a fundamentally new form that must be studied as a unique "text”, representative specifically of the 'Long now of Ulysses."'-David Carlton 152Eaves, Morris. “Electronic Textual Editing: Multimedia Body Plans: A Self-Assessment”. Text Encoding Initiative website. http://www.tei-c.org/About/Archive new/ETE/Preview/eaves.xml

153Though growing since the 1960s, with the advent of critique génétique.

154Trettien, Whitney Anne. "Towards a Prototype of a Digital Harmony". Diapsalmata blog. 


\subsection{Edition literacies}

An innovation of Hans Walter Gabler's edition of Ulysses ${ }^{155}$ is its "synoptic" text: a genetic apparatus for tracing the history of the novel's composition, performed through a marked-up copy of the right-hand page's reading text on every left-hand page ${ }^{156157}$. This markup took the form of small diacritical symbols that differentiate within a given episode among composition variants, allowing all variants to appear on the same page.
to said sternly. He added in a preacher's tone:
-For this, $O$ dearly beloved, is the genuine ${ }^{\wedge}\langle\Delta\rangle$ christine^: body and soul and blood and ouns. Slow music, please. Shut your eyes, gents. One moment. A little trouble about those white corpuscles. Silence, all.
He peered sideways up and gave a long slow ${ }^{\circ}$ whistle of call, ${ }^{\circ}$ then
25 paused awhile in rapt attention, his even white teeth glistening here and there with gold points. Chrysostomos. ${ }^{{ }^{5} 5}[\mathrm{Th} \mathrm{Tee}] \mathrm{Tw}^{3}$ strong shrill whistles answered through the calm. ${ }^{7}$
-Thanks, old chap, he cried briskly. That will do nicely. Switch off the current, will you?

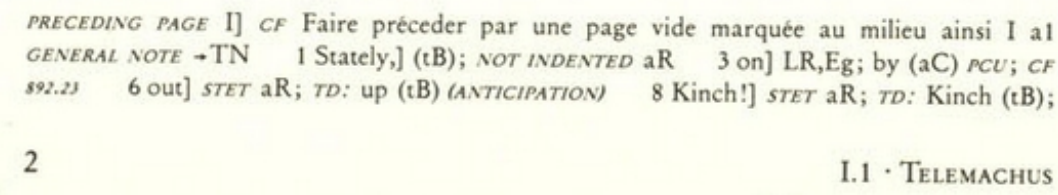

I.1 - Telemachus

In his afterword to the edition, Gabler identifies this apparatus as meant "to be read and used as a text" and prioritizes this synoptic text over the reading text on the right-hand pages $^{158}$.

Jerome McGann, in an early review of the edition, praised Gabler's resituation of focus from the reading text onto another textual option: "Gabler has shown that another text of Ulysses can be imagined and concretely rendered - a text that does not simply offer a large mass of minor textual variations from the previously conceived text, but that completely overhauls the way we might think about the text as a whole"159. McGann argues that this unusual precedence forces us to think in new ways about how we encounter the text: the reading text only seems stable — and the synoptic text only seems "processive"—as "a function of certain conventions of reading which have or have not been mastered":

The diacritics in Gabler's edition are a grammar of an artificial language and should present no serious problems for readers of imaginative works, which are

155Joyce, James. Ulysses: A Critical and Synoptic Edition. Eds. Hans Walter Gabler, Wolfhard Steppe, and Claus Melchior. Garland Press. 1984.

156Note that while this edition example is print rather than digital (unlike many of my textual examples), the synoptic text approach

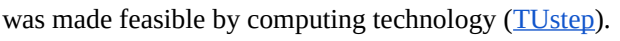

157Other innovations include Gabler's novel melding of German, French, and Anglo-American theoretical approaches (Lernout 77). 158Joyce, James. Ulysses: A Critical and Synoptic Edition. Eds. Hans Walter Gabler, Wolfhard Steppe, and Claus Melchior. Garland Press. 1984. 1901.

159McGann, Jerome J. "'Ulysses' as a Postmodern Text: The Gabler Edition". Criticism. Summer 1985. $27(3) .291$. 
always mediated by artificial grammars... When we shall have learned to "read" the synoptic text as we read the reading text, we shall have gone a long way toward understanding the nature of texts in general.

For McGann, the reading text is "a pallid, chill, and drear document disappointingly abstract, simple, and one-dimensional", while the synoptic text with its "artificial language" is "complex, and many-levelled", richly preserving "both the facts and the relationships of many kinds of detail"160.

McGann limits the possibilities for such artificial languages (on texts understood as genetic constructs) to these texts' composition or production ${ }^{161}$ —recognizable textual scholarship concerns. What might happen if we allowed intricate textual languages to carry other types of information? If we imagine editorial apparatuses as literacies-as ways of reading requiring a similar effort to master as any language - entirely new ways of presenting information and relationships open up, both in print and digital space. Infinite Ulysses, for example, might develop visually intuitive ways of "reading" the text's audience experience through users' annotations and the metadata around those annotations. One can imagine a system of notation like Gabler's capturing reader experiences and understanding of the text as they accrue on the edition, or some other learnable language for reading the text through data not on its composition, but on its contemporary reception.

Textual projects such as PoemViewer's visualizations of poems, the Enfolded Hamlet's work with typographically differentiated inline variants (and related variorum projects), or Ben Fry's "On the Origin of Species: The Preservation of Favored Traces" all use visual iconography to forge new languages sharing information that couldn't practically be presented and understood without the support of a new literacy for reading and rendering ideas; many practitioners of information visualization already understand their work as visual language. As textual scholars design new features for digital editions, how might understanding such features not as apparatus but as the focus of an edition change how we read that text? Reimagining the edition opens the possibility not just of new edition forms and methodologies, but of new ways of encountering texts.

160Ibid., 299.

161McGann, Jerome J. "'Ulysses' as a Postmodern Text: The Gabler Edition". Criticism. Summer 1985. 27(3). 292. 


\section{Section 5: Next Steps}

Infinite Ulysses and the dissertational project around it proposed small but actionable changes to the fields of literary studies, the digital humanities, and textual scholarship:

Participatory projects. Infinite Ulysses provided an example of a small but eager audience for a participatory digital humanities project. The code and design work that allows textual annotations to be curated and moderated are being tested on at least two other digital editions (the Shelley-Godwin Archive and Romantic Circles); further work toward packaging and documenting the code will allow for digital humanists with less technical expertise to set up similar participatory annotation projects for their own texts, theories, and testing. Early site use data suggests that the site's design and functionalities represent one route for digital editions to support public participation through personalization of annotations to reader and researcher needs.

Meaningful interactions. Infinite Ulysses provided a modest example of public digital edition visitors adding value to a text through contextualizing and interpretive annotations over a three-week period. The project also outlined a number of ways digital humanities researchers may use non-critical participation to advance scholarly knowledge.

Edition design and data. Infinite Ulysses experiments with digital edition editorial statements by providing a detailed explanation of scholarly values and how these were manifested through project design and code. This discussion, manifested in this whitepaper, research blog posts, and writing on the edition site, explores a feature that might bring digital edition editorial statements closer to textual scholarship values. Preliminary data gathering and analysis provided support or pointed out flaws in digital edition design, while also providing text-agnostic knowledge about publicity for and public use of participatory digital editions.

The edition re-examined. Regardless of your feelings on the "edition-ness" of the various textual projects discussed in this section, these scholarly textual artifacts all draw on the values and skills of textual scholarship. These projects also suggest new forms and methods for improving our scholarly work. Examining core assumptions in a scholarly field - values, affordances, "necessary" or common features, and design metaphors — can open new possibilities for humanities knowledge.

The next step for this project will be the pursuit of several new questions that arose from my research. I'll want to explore the possibilities for "non-critical" participation listed in Section 2, looking for projects that have tested these possibilities and creating wireframes and prototypes exploring the untested participation methods among my suggestions. I'll 
want to think further about design that specifically scaffolds critical digital edition participation; any functionalities I theorize can be tested through implementation on Infinite Ulysses. I'll also continue analysis of site data and user feedback, using these to reassess the edition's curation and moderation functionalities as more readers and classrooms use the site. Finally, I'll add to the discussion around editorial statements for digital editions by crafting a more detailed methodological statement for Infinite Ulysses and then submitting the edition for formal review. These steps should both improve Infinite Ulysses as a textual resource, and add to our body of knowledge about designing a more public, participatory digital humanities. 


\section{Sources built on the text of Ulysses}

Craven, Robert. Concord Project: Ulysses by James Joyce. Online Ulysses concordance. http://www.doc.ic.ac.uk/ rac101/concord/texts/ulysses

Ehrlich, Heyward. James Joyce Text Machine. http://andromeda.rutgers.edu/ ehrlich/jitm

Genius.com contributors. "Ulysses (Chap. 1 - Telemachus)". http://genius.com/Jamesjoyce-ulysses-chap-1-telemachus-annotated

Hans Walter Gabler with Wolfhard Steppe and Claus Melchior, eds. Ulysses: The Corrected Text. Vintage International. 1986.

---. Ulysses: A Critical and Synoptic Edition. Garland Press. 1984.

Joyce, James. "Circe” episode autograph manuscript. From Ulysses. EL4. J89ul 922 MS. Fall 1920. The Rosenbach Museum.

Kidney, Eoghan. In Ulysses. An under-development virtual reality project. http://fundit.ie/project/in-ulysses-proteus-part-1

Modernist Versions Project. "Pirated" Ulysses (from Samuel Roth's Two Worlds Monthly). http://web.uvic.ca/ mvp1922/portfolio/samuel-roth

---. Ulysses (Shakespeare \& Co. 1922, 1st edn).

http://web.uvic.ca/ mvp1922/portfolio/ulysses-shakespeare-co-1922-1st-edn

Naxos. Joyce’s Ulysses: A Guide. App. http://www.naxos.com/catalogue/apps/app.asp? $\underline{\mathrm{ID}=\mathrm{NAPP} 0705 \mathrm{~B}}$

Project Gutenberg. Ulysses. Crowd-transcribed public domain e-text; produced by Col Choat and David Widger. https://www.gutenberg.org/files/4300/4300-h/4300-h.htm

Schiminovich, Samuel. 2000. Ulysses: A marked up version. http://www.columbia.edu/ fms5/ulys.htm

Ward, Brendan. Annotations to James Joyce's Ulysses. https://en.wikibooks.org/wiki/Annotations to James Joyce $\% 27 \mathrm{~s}$ Ulysses

\section{Bibliography}

Alice Grant Consulting. "Evaluation of Digital Cultural Content: Analysis of Evaluation Material". (Link now dead: http://www.culturalcontentforum.org/publications/audience/audience analysis.pdf). Digital Cultural Content Forum, 2003.

Annotator.js. Web annotation tool. http://annotatorjs.org

Arbuckle, Alyssa. "Considering The Waste Land for iPad and Weird Fiction as models for the public digital edition". Digital Studies. 2014.

Arbuckle, Alyssa et al. "Social Knowledge Creation: Three Annotated Bibliographies". 
Scholarly and Research Communication. 5(2). 2014. http://src-

online.ca/index.php/src/article/view/150/299

Armand, Louis, ed. Joycemedia: James Joyce, Hypermedia and Textual Genetics.

Syracuse University Press, 2006.

Attridge, Derek. Joyce Effects: On Language, Theory, and History. London: Cambridge Univ. Press. 2000.

Attridge, Derek as cited in Marino, Mark C. "Ulysses on Web 2.0: Towards a Hypermedia Parallax Engine". James Joyce Quarterly. 44(3). 2007.

http://www.jstor.org/stable/25571051

Barab, Sasha and Kurt Squire. "Design-Based Research: Putting a Stake in the Ground". The Journal of the Learning Science 13.1: 1-14.

Bauer, Jean. DAVILA. Digital humanities tool. 2011.

Belojevic, Nina and Jon Johnson. Hyperlit. Long Now of Ulysses museum exhibit and online exhibit. University of Victoria Maker Lab.

https://ninabelojevic.wordpress.com/portfolio/hyperlit

Berry, Rob with Throwaway Horse LLC. Ulysses Seen. iPad app and webcomic. http://ulyssesseen.com

Blamires, Harry. The New Bloomsday Book: A Guide Through Ulysses. Routledge. 1996.

Bolter, Jay David. Writing Space: Computers, Hypertext, and the Remediation of Print. 2nd ed. Routledge, 2001.

Boone, Alice, Ben Vershbow, and Eddie A. Tejeda. Candide 2.0. The New York Public Library. http://candide.nypl.org/text

Bordalejo, Barbara, ed. Darwin Online. Digital variorum. http://darwinonline.org.uk/Variorum

Bornstein, George and Theresa Tinkle, eds. The Iconic Page in Manuscript, Print, and Digital Culture. University of Michigan Press, 1998.

Bowers, Fredson. "Current Theories of Copy-Text, with an Illustration from Dryden." Modern Philology. 48. 1950-51.

Britain from Above. Digital humanities project. http://www.britainfromabove.org.uk

Brooklyn Museum. "Help us pin Brooklyn to the map!" Brooklyn Museum and HistoryPin project blog post. https://www.brooklynmuseum.org/community/blogosphere/2011/06/21/help-us-pinbrooklyn-to-the-map

Burdick, Anne, et al. Digital_Humanities. MIT Press. 2012.

Broglio, Ron, ed. Digital Designs on Blake. Romantic Circles Praxis Series. Series ed. 
Orrin N. C. Wang. 2005. http://rc.umd.edu/praxis/designsonblake

Citizen Archivist Dashboard. National Archive. http://www.archives.gov/citizen-archivist

Clement, Tanya. "Knowledge Representation and Digital Scholarly Editions in Theory and Practice". Journal of the Text Encoding Initiative. 1. 2011.

Coles, Katharine, Min Chen, et al. PoemViewer. Oxford e-Research Centre at the University of Oxford. http://ovii.oerc.ox.ac.uk/PoemVis/index.html

Dehaene, Stanislas. Reading in the Brain: The New Science of How We Read. Penguin Books. 2009.

The Design-Based Research Collective. "Design-Based Research: An Emerging Paradigm for Educational Inquiry". Educational Researcher. 32(1). 5-8.

Dickinson Electronic Archive. "Emily Dickinson Writing a Poem: Manuscript Ordering Exercise". http://archive.emilydickinson.org/safe/exercises/reorder.html

Dosky, Laura. "Making it New Again: Crowdsourced Readings of James Joyce's Ulysses". Long Now of Ulysses museum exhibit and online exhibit. University of Victoria Maker Lab. https://ulysseslongnow.wordpress.com

Drucker, Johanna. Figuring the Word: Essays on Books, Writing, and Visual Poetics. New York: Granary Books. 1998.

---. "Graphesis: Visual Knowledge Production and Representation". Poetess Archive Journal. 2(1). 2010. https://journals.tdl.org/paj/index.php/paj/article/download/4/50

---. "Humanities Approaches to Graphical Display". Digital Humanities Quarterly. 5(1). 2011. http://digitalhumanities.org/dhq/vol/5/1/000091/000091.html

---. Speclab: Digital Aesthetics and Projects in Speculative Computing. University of Chicago Press. 2009.

Drucker, Johanna and Emily McVarish. Graphic Design History: A Critical Guide. Pearson. 2008.

Eaves, Morris. "Electronic Textual Editing: Multimedia Body Plans: A Self-Assessment". Text Encoding Initiative website. http://www.teic.org/About/Archive_new/ETE/Preview/eaves.xml

Edwards, Charlie. "The Digital Humanities and Its Users". Debates in the Digital Humanities. Online edition (2013). http://dhdebates.gc.cuny.edu/debates/text/31

Eliot, T.S. The Waste Land. iPad app version. Touch Press with Faber \& Faber. 2011.

Erwin, Micah. "Archivist declares medieval manuscript fragment crowdsourcing project success". Harry Ransom Center Cultural Compass blog. http://blog.hrc.utexas.edu/2014/01/20/archivist-declares-medieval-manuscript-fragmentcrowdsourcing-project-success 
Finkelstein, David, and Alistair McCleery. An Introduction to Book History. New York: Routledge. 2005.

Fitzpatrick, Kathleen. Planned Obsolescence: Publishing, Technology, and the Future of the Academy. MediaCommons Press. 2009. http://mcpress.media-

commons.org/plannedobsolescence

Flanders, Julia. "The Productive Unease of 21st-century Digital Scholarship". Digital Humanities Quarterly. 3(3). 2009.

http://digitalhumanities.org/dhq/vol/3/3/000055/000055.html

Folsom, Ed. "Database as Genre: The Epic Transformation of Archives". Walt Whitman Archive website. Reprinted from PMLA.

http://www.whitmanarchive.org/about/articles/anc.00142.html

Fraistat, Neil. "Textual Addressability and the Future of Editing." European Romantic Review. 23(3). 2012. 329-333.

Fraistat, Neil and Julia Flanders, eds. Introduction. Cambridge Companion to Textual Scholarship. Advanced copy. New York: Cambridge University Press. 2012.

Fry, Ben. "On the Origin of Species: The Preservation of Favored Traces". Visualization approach to Darwin's text. http://benfry.com/traces

Galey, Alan. Visualizing Variation. Digital humanities project website. http://individual.utoronto.ca/alangaley/visualizingvariation

Galey, Alan and Stan Ruecker. "How a Prototype Argues." Literary and Linguistic Computing. 25(4). 2010. 405-424.

Gilbert, Eric. "Widespread Underprovision on Reddit". CSCW'13. February 23-27, 2013. San Antonio, Texas, USA.

http://comp.social.gatech.edu/papers/cscw13.reddit.gilbert.pdf

Gifford, Don. Ulysses Annotated: Notes for James Joyce's Ulysses. With contributions by Robert J. Seidman. University of California Press. 2008.

Greg, W.W. “The Rationale of Copy-Text”. Studies in Bibliography. 3. 1950-1951. 19-37.

Groden, Michael. "Introduction to 'James Joyce's Ulysses in Hypermedia'”. Journal of Modern Literature. 24(3/4). 2001. 359-362.

---. "Perplex in the Pen-and in the Pixels: Reflections on The James Joyce Archive, Hans Walter Gabler's Ulysses, and James Joyce's Ulysses in Hypermedia". Journal of Modern Literature. 22(2). Winter 1998/1999. 225-244.

---. "Problems of Annotation in a Digital Ulysses" . Hypermedia Joyce Studies. 4(2). 2003-4. http://www.oocities.org/hypermedia joyce/groden.html

Harley, Diane et al. Use and Users of Digital Resources: A Focus on Undergraduate Education in the Humanities and Social Sciences. Center for Studies in Higher 
Education. 2006.

Harry Ransom Center. Flickr group for manuscript fragments (images no longer available on site; link was https://www.flickr.com/photos/ransom center fragments and an archival copy missing the photo images at https://web.archive.org/web/20130906042250/http://www.flickr.com/photos/ransom cent er fragments)

Hawkins, Ann R., ed. Teaching Bibliography, Textual Criticism and Book History. London: Pickering \& Chatto. 2006.

Hayles, N. Katherine. "Translating Media: Why We Should Rethink Textuality". The Yale Journal of Criticism. 16(2). Fall 2003. 263-290.

Hitchcock, Tim et al. "Crime in the Community". (2010-2011). Study exploring user experience of the Old Bailey Proceedings Online. http://hridigital.shef.ac.uk/crime-inthe-community

Howsam, Leslie. Old Books and New Histories: An Orientation to Studies in Book and Print Culture. University of Toronto Press. 2006.

Hume, Robert. "Aims and Uses of Textual Scholarship ". PBSA. 99(2). June 2005. 197230 .

Hutchison, Coleman et al. Leaves of Grass Open Audiotext. https://www.laits.utexas.edu/leavesofgrass

James Joyce Online Notes. Open-access journal. Eds. Harald Beck and John Simpson. Advisory eds. Hans Walter Gabler and Fritz Senn. http://www.jjon.org

Jstor Labs and Folger Shakespeare Library. Understanding Shakespeare. http://labs.jstor.org/shakespeare

Karlsson, Lina and Linda Malm. "Revolution or Remediation? A Study of Electronic Scholarly Editions on the Web". HumanIT. 7(1). 2004. 1-46. http://etjanst.hb.se/bhs/ith/17/lklm.pdf

Kelemen, Erick. Textual Editing and Criticism. New York: W.W. Norton and Company. 2009.

---. "Textual Criticism and Kinds of Editions". In Textual Editing and Criticism. Ed. Erick Kelemen.

Kidd, John. "The Scandal of Ulysses". The New York Review of Books. June 30, 1988. http://www.nybooks.com/articles/archives/1988/jun/30/the-scandal-of-ulysses-2

Kirschenbaum, Matthew G. "Editing the Interface: Textual Studies and First Generation Electronic Objects." Text: An Interdisciplinary Annual of Textual Studies. 14. 2002. 1551.

Kliman, Bernice W. Enfolded Hamlet. http://triggs.djvu.org/global- 


\section{language.com/ENFOLDED/index.php}

Kraus, Kari. "Conjectural Criticism: Computing Past and Future Texts". Digital Humanities Quarterly. 3(4). 2009. http://www.digitalhumanities.org/dhq/vol/3/4/000069/000069.html

Kraut, R. E., Resnick, P. (2011). Building successful online communities: evidence-based social design. Cambridge, MA: MIT Press.

Kuniavsky, Mike. Smart Things: Ubiquitous Computing User Experience Design. Burlington: Morgan Kaufmann. 2010.

Lacuna Stories. Collaborative annotation digital humanities project. http://www.lacunastories.com

Leonardi, Paul M. "Digital Materiality? How Artifacts Without Matter, Matter. First Monday. 15(6). 2010.

Lernout, Geert. "Chapter 3: Continental Editorial Theory". In Cambridge Companion to Textual Scholarship. Eds. Fraistat, Neil and Julia Flanders. Advanced copy. New York: Cambridge University Press. 2012. 69-88.

---. "Controversial Editions: Hans Walter Gabler's Ulysses". Text: An Interdisciplinary Annual of Textual Studies. 16. 2006. 229-41.

Lindberg, Kaj Magnus. "Solving the problem that the topmost comments get all upvotes". Debiki forum. 2013. http://www.debiki.com/-9qb49/solving-problem-first-comment-getsall-upvotes

Loizeaux, Elizabeth Bergmann and Neil Fraistat. Reimagining Textuality: Textual Studies in the Late Age of Print. University of Wisconsin Press. 2002.

London Lives. Digital edition (http://www.londonlives.org) and wiki (http://www.hrionline.ac.uk/londonliveswiki/tiki-index.php?page=Welcome).

Long Now of Ulysses museum exhibit and online exhibit. University of Victoria Maker Lab. http://maker.uvic.ca/ulysses

Lukens, Jonathan and Carl DiSalvo. "Speculative Design and Technological Fluency". IJLM. 3(4). 2012. 23-40.

Malamed, Connie. Visual Language for Designers: Principles for Creating Graphics that People Understand. Rockport Publishers, 2011.

Malka, Ariel. He liked thick word soup. App. http://chronotext.com/WordSoup

Manovich, Lev. The Language of New Media. MIT Press. 2002.

Marino, Mark C. "Ulysses on Web 2.0: Towards a Hypermedia Parallax Engine". James Joyce Quarterly. 44(3). Spring 2007. 475-499.

Mark Twain Project Online. The Mark Twain Papers in collaboration with UC Press. 


\section{http://www.marktwainproject.org}

McGann, Jerome J. Black Riders: The Visible Language of Modernism. Princeton University Press. 1993.

---. A Critique of Modern Textual Criticism. University of Chicago Press. 1983.

---. "Database, Interface, and Archival Fever". PMLA. 112.5. 2007. 1588-1592.

---. "From Text to Work: Digital Tools and the Emergence of the Social Text."

Romanticism on the Net. 41-42. 2006.

---. Radiant Textuality: Literature After the World Wide Web. New York: Palgrave. 2001.

---. The Textual Condition. Princeton University Press. 1991. 69-83.

---. "'Ulysses' as a Postmodern Text: The Gabler Edition". Criticism. XXVII(3). Summer 1985. 283-306.

McGann, Jerome J., ed. The Complete Writings and Pictures of Dante Gabriel Rossetti: A Hypermedia Archive. http://www.rossettiarchive.org

McKenzie, D. F. Bibliography and the Sociology of Texts. London: British Library. 1986.

Mekler, Elisa et al. "Do points, levels and leaderboards harm intrinsic motivation?: an empirical analysis of common gamification elements". Proceedings of Gamification '13: Proceedings of the First International Conference on Gameful Design, Research, and Applications. 66-73.

Messick, S. (1992). "The interplay of evidence and consequences in the validation of performance assessments". Educational Researcher 23(2), 13-23 as cited by and with Sasha Barab and Kurt Squire, "Design-Based Research: Putting a Stake in the Ground". The Journal of the Learning Sciences. 13(1). 2.

Middleton, Rowley, et al. A/The Old Law. Ed. Jeffrey Masten. In Thomas Middleton: The Collected Works. Series eds. Gary Taylor et al. Oxford University Press. 2010.

MLA Guidelines for Editors of Scholarly Editions. Modern Language Association. Viewed after last revision on June 29, 2011. http://www.mla.org/cse guidelines

MLA Committee on Information Technology. "Guidelines for Evaluating Work with Digital Media in the Modern Languages". Modern Language Association. Version reviewed January 2012. http://www.mla.org/resources/documents/rep it/guidelines evaluation_digital

Modernist Commons. Digital editing platform. http://modernistcommons.ca

Modernist Versions Project. Digital editing project website. http://web.uvic.ca/ mvp1922

Moulthrop, Stewart. "After the Last Generation: Rethinking Scholarship in the Days of Serious Play." In Proceedings of Digital Arts and Culture Conference. IT-University, Copenhagen. Copenhagen, Denmark. 2005. 208-215. 
Mueller, Martin. "Collaboratively Curating Early Modern Texts". August 9, 2011. Essay drafted for Project Bamboo. https://wikihub.berkeley.edu/display/pbamboo/Essay+ Collaboratively + Curating + Early + Modern + English + Texts

Muller, Michael J. "Participatory Design: The Third Space in HCI". In The HumanComputer Interaction Handbook. 1051-1068.

Murphy, Andrew. "Electric Shakespeares, The Arden Shakespeare CD ROM". Computers and the Humanities. 32(5). 1998. 411-420.

National Initiative for a Networked Cultural Heritage. The NINCH Guide to Good Practice in the Digital Representation and Management of Cultural Heritage Materials: XII. Assessment of Projects by User Evaluation. 2003. http://www.nyu.edu/its/pubs/pdfs/NINCH Guide to Good Practice.pdf

New York Public Library Labs. What's on the menu? http://menus.nypl.org

New York Public Library Labs and Lionel Pincus and Princess Firyal Map Division. Building Inspector. http://buildinginspector.nypl.org

The New York Times. "Madison: Help preserve history with just one click". http://madison.nytimes.com/?smid=tw-nytimes

Nguyen, Lilly, and K. Shilton. "Appendix F: Tools for Humanists (Tools for Humanists Project, Final Report)". Council on Library and Information Resources. 2008. http://www.clir.org/pubs/reports/pub143/appendf.html

Nielsen, J. "ㅂeuristic evaluation". In Nielsen, J., and Mack, R.L. (Eds.), Usability Inspection Methods. John Wiley \& Sons, New York, NY. 1994.

Norris, Margot. Virgin and Veteran Readings of Ulysses. Palgrave Macmillan. 2011.

Nowviskie, Bethany. "Collex: Collections and Exhibits for the Remixable Web".

Electronic Book Review. Spring 2007. 1-17.

---. "Interfacing the Edition". Text of conference talk.

http://www2.iath.virginia.edu/bpn2f/1866/interface. html

---. Speculative Computing: Instruments for Interpretive Scholarship. Diss. University of Virginia. 2004.

O'Malley, Michael. "Building Effective Course Sites: Some Thoughts on Design for Academic Work".

Originally Inventio 2(1). 2000. Republished: "Essays on History and New Media". Roy Rosenzweig Center for History and New Media. RRCHNM 20.

Piper, Andrew. Dreaming in Books: The Making of the Bibliographic Imagination in the Romantic Age. University of Chicago Press. 2009.

Pope, Rob. Textual Intervention: Critical and Creative Strategies for Literary Studies. Taylor \& Francis Group. 1995. 
Praxis Program. Ivanhoe. 2013-2015 interpretation game based on 2000 prototype by Jerome McGann, Johanna Drucker, and Bethany Nowviskie.

http://ivanhoe.scholarslab.org

---. Prism. Scholars' Lab, University of Virginia Libraries. Digital humanities tool. http://prism.scholarslab.org/

Price, Ken. "Edition, Project, Database, Archive, Thematic Research Collection: What's in a Name?". The Walt Whitman Archive website.

http://whitmanarchive.org/about/articles/anc.00346.html

Ramsay, Stephen. Reading Machines: Towards an Algorithmic Criticism. University of Illinois Press. 2011.

Reddit. https://www.reddit.com

RIDE: A review journal for digital editions and resources. Published by IDE.

Robinson, Peter. 2010. "Electronic Editions for Everyone." In Text and Genre in Reconstruction. Ed. Willard McCarty. 145-64. Cambridge: Open Book Publishing.

Rochfort Smith, Teena, ed. A four-text edition of Shakspere's Hamlet : 1. quarto 1, 1603 -- 2. quarto 2, 1604 -- 3. folio 1, 1623 -- 4. a revized text : in parallel columns. 1883.

Folger Shakespeare Library. http://luna.folger.edu/luna/servlet/detail/FOLGERCM1 6 6 872264 157765:-Hamlet-A-four-text-edition-of-Sha

Rockwell, Geoffrey. "What's New is Old Again: Studying Interface with Perseus". Abstract and video of presentation. Theorti.ca blog. January 13, 2015. http://theoreti.ca/? $\mathrm{p}=5636$

Romantic Circles: A refereed scholarly Website devoted to the study of Romantic-period literature and culture. General Eds. Neil Fraistat and Steven E. Jones. Site managers: Dave Rettenmaier and Kyle Bickoff. Published by University of Maryland. http://www.rc.umd.edu

Roy Rosenzweig Center for History and New Media. Histories of the National Mall. George Mason University. http://mallhistory.org

---. Papers of the War Department. George Mason University. http://wardepartmentpapers.org

---. Scripto plugin for Omeka. George Mason University. http://scripto.org/omeka

Sahle, Patrick. "A catalog of Digital Scholarly Editions... some particularly interesting editions / projects". http://www.digitale-edition.de/vlet interesting.html

Sahle, Patrick et al. "Criteria for Reviewing Scholarly Digital Editions, version 1.1." Institut für Dokumentologie und Editorik. http://www.i-de.de/publikationen/weitereschriften/criteria-for-reviewing-scholarly-digital-editionsversion-1-1 
Saklofske, Jon. "NewRadial: Revisualizing the Blake Archive". Poetess Archive Journal. 2(1). 2010. https://journals.tdl.org/paj/index.php/paj/article/viewFile/8/54

Saklofske, Jon and Jean-Marc Griffin. NewRadial. Digital humanities code repository. 2009. http://sourceforge.net/projects/newradial

Sample, Mark. "When Does Service Become Scholarship?” Blog post. February 8, 2013. http:/www.samplereality.com/2013/02/08/when-does-service-become-scholarship/

Schreibman, Susan et al. Versioning Machine. http://v-machine.org

Schulze, Robin. Becoming Marianne Moore: Early Poems, 1907-1924. University of California Press. 2002.

The Shakespeare Quartos Archive. Digital literary archive. http://www.quartos.org/

Shakespeare, William. The Taming of the Shrew. Ed. Barbara Hodgdon. 3rd ed. Arden Shakespeare. 2010.

Shelley-Godwin Archive. http://shelleygodwinarchive.org

Shillingsburg, Peter. From Gutenberg to Google. New York: Cambridge University Press. 2006.

Siemens, Ray et al. "Pertinent Discussions Toward Modeling the Social Edition:

Annotated Bibliographies". Digital Humanities Quarterly. 6(1). 2012.

http://www.digitalhumanities.org/dhq/vol/6/1/000111/000111.html

Siemens, Ray et al. "Toward Modeling the Social Edition: An Approach to Understanding the Electronic Scholarly Edition in the Context of New and Emerging Social Media". 18. (Also available as $L L C$. 27(4). 2012. 445-461.) http://web.uvic.ca/ siemens/pub/2011SocialEdition.pdf

Simon, Nina. The Participatory Museum. http://www.participatorymuseum.org

---. "Tagging in Museums \#blowinguppersonal \#notwhatweplanned". Museum 2.0 blog. http://museumtwo.blogspot.com/2014/03/tagging-in-museums-blowinguppersonal.html

Smith, Martha Nell. 2004. "Electronic Scholarly Editing." In A Companion to Digital Humanities. Eds. Susan Schreibman, Ray Siemens, and John Unsworth. Oxford:

Blackwell. 306-22

Smithsonian. Smithsonian Digital Volunteers: Transcription Center. https://ranscription.si.edu

The Social Edition of the Devonshire Manuscript. Eds. The Devonshire MS Editorial Group (Raymond Siemens et al.).

https://en.wikibooks.org/wiki/The Devonshire Manuscript

Spalding, Tim. "When tags work and when they don't: Amazon and LibraryThing". LibraryThing Thing-ology blog. February 20, 2007. 
http://blog.librarything.com/thingology/2007/02/when-tags-work-and-when-they-dontamazon-and-librarything

Spyridakis, Jan et al. "Using structural cues to guide readers on the internet". Information Design Journal. 15(3). 242-259.

StackExchange. http://stackexchange.com

Stroud, N. J., Scacco, J. M., Muddiman, A. and Curry, A. L. "Changing Deliberative Norms on News Organizations' Facebook Sites". Journal of Computer-Mediated Communication. 2014.

Sutherland, Kathyrn. "Chapter 2: Anglo-American Editorial Theory". In Cambridge Companion to Textual Scholarship. Eds. Fraistat, Neil and Julia Flanders. Advanced copy. New York: Cambridge University Press. 2012. 49-68.

Tanselle, G. Thomas. A Rationale of Textual Criticism. University of Pennsylvania Press. 2011. Reprint.

---. Bibliographical Analysis: A Historical Introduction. Cambridge University Press. 2009.

---. "Editing without a Copy-Text". In Textual Editing and Criticism. Ed. Erick Kelemen. 258.

---. "The Varieties of Scholarly Editing". In Scholarly Editing: A Guide to Research. Ed. D. C. Greetham. Modern Language Association of America. 1995. 9-32.

TAPAS (TEI Archiving Publishing and Access Service) Project. Digital humanities initiative. http://tapasproject.org

Taylor, Gary. "The Renaissance and the End of Editing". In Palimpsest: Textual Theory and the Humanities. Eds. George Bornstein and Ralph G. Williams. University of Michigan Press. 1993. 121-50.

TEI: P5 Guidelines. Released 2007 with subsequent updates. Text Encoding Initiative Consortium.

Thomas, Lindsey. "Open Access and the Digital Humanities". 12/16/2013 post on the Postcolonial Digital Humanities blog. http://dhpoco.org/blog/2013/12/16/open-accessand-the-digital-humanities

Thompson, Ann. "Teena Rochfort Smith, Frederick Furnivall, and the New Shakspere Society's Four-Text Edition of Hamlet". Shakespeare Quarterly. 49(2). Summer 1998. 125-139.

Transcribe Bentham: A Participatory Initiative."Transcription Desk". University College London. http://www.transcribe-bentham.da.ulcc.ac.uk/td/Transcribe Bentham

Trettien, Whitney Anne. "Towards a Prototype of a Digital Harmony". Diapsalmata blog. http://blog.whitneyannetrettien.com/2013/11/towards-prototype-of-digital-harmony.html 
Uncle Tom's Cabin and American Culture. Digital humanities archive. Directed by Stephen Railton. http://utc.iath.virginia.edu

Unsworth, John. "Scholarly Primitives: what methods do humanities researchers have in common, and how might our tools reflect this?". Part of a symposium on "Humanities Computing: formal methods, experimental practice" sponsored by King's College, London. May 13, 2000. http://people.lis.illinois.edu/ unsworth/Kings.500/primitives.html

Utell, Janine M. "The Archivist, the Archaeologist, and the Amateur: Reading Joyce at the Rosenbach". Journal of Modern Literature. 31. 2008. 53-65.

Vetch, Paul. 2010. "From Edition to Experience: Feeling the Way towards User-Focused Interfaces." In Electronic Publishing: Politics and Pragmatics. Ed. Gabriel Egan. 171-84.

Visconti, Amanda. Digital Dos Passos. Digital humanities project website (2010-2011). http://digitaldospassos.com

---. Infinite Ulysses. Digital edition (2013-current). http://www.infiniteulysses.com

---. "Recovering Teena Rochfort-Smith: Complex Edition Prototype, Female Victorian Editor". LiteratureGeek.com research blog (2012). http://www.literaturegeek.com/2012/11/12/recovering-teena-rochfort-smith-complexedition-prototype-female-victorian-editor

---. "Songs of Innocence and of Experience:" Amateur Users and Digital Texts. Master's thesis; University of Michigan School of Information (2010). deepblue.lib.umich.edu/handle/2027.42/71380

---. "Teena Rochfort-Smith". Reuses language submitted by author as part of a Wikipedia article on November 12, 2012. https://en.wikipedia.org/wiki/Teena_Rochfort-Smith

---. UlyssesUlysses. Digital humanities project website (2008-2009). http://www.ulyssesulysses.com

Wainwright, Kaitlin. "Consider the Comments: Why Online Comments are Important for Public Historians". ActiveHistory.ca blog. http://activehistory.ca/2014/10/consider-thecomments-why-online-comments-are-important-for-public-historians

Walt Whitman Archive. Eds. Folsom, Ed. and Kenneth Price. Digital humanities archive. http://whitmanarchive.org/

Warwick, C., Melissa Terras, P. Huntington, and N. Pappa. "If You Build It Will They Come? The LAIRAH Study: Quantifying the Use of Online Resources in the Arts and Humanities through Statistical Analysis of User Log Data". Literary and Linguistic Computing. 23(1). 2008. 85-102.

Warwick, Claire. "Chapter 1: Studying users in digital humanities". Digital Humanities in Practice. Eds. Claire Warwick, Melissa Terras, and Julianne Nyhan. 2012. 1.

Warwick, Claire, Melissa Terras and Julianne Nyhan, eds. Digital Humanities in Practice. 
Facet Publishing, 2012.

Wayne, Valerie. "The Sexual Politics of Textual Transmission.” In Textual Formations and Reformations. Eds. Laurie E. Maguire and Thomas L. Berger. University of Delaware Press. 1998. 179-210.

Werner Marta L., ed. Emily Dickinson's Open Folios: Scenes of Reading, Surfaces of Writing. University of Michigan Press. 1996.

Whalen, Christopher. "Piously Forged Palimpsests": Hans Walter Gabler's Synoptic Text of Ulysses". English Graduate Conference presentation. University Of Oxford English Literature Department. May 30, 2008.

https://www.academia.edu/1653768/ Piously_Forged Palimpsests_Hans_Walter_Gablers Synoptic Text of Ulysses

William Blake Archive. Morris Eaves, Robert Essick, and Joseph Viscomi, eds. Digital humanities archive. http://www.blakearchive.org/blake

Williams, William Proctor and Craig S. Abbot, An Introduction to Bibliographical and Textual Studies. New York: Modern Language Association of America. 2009.

Witmore, Michael. "Text: A Massively Addressable Object". Blog post. December 21, 2010. http://winedarksea.org/?p=926

Young, Indi. Mental Models: Aligning Digital Strategy with Human Behaviour. New York: Rosenfeld, 2008.

Zillig, Brian Pytlik. TokenX text analysis, visualization, and play tool. Walt Whitman Archive. http://whitmanarchive.org/resources/tools/index.html 


\section{Appendix A: Crowdflower User Survey}

Task Title: Hey, book lovers! Try out my Social Book Website and Answer Some Questions

This is a good task for someone who likes books! I've built a platform where you can read James Joyce's novel Ulysses (often called the most important book of the twentieth century). The site allows you to highlight and add comments or questions to phrases in the book, read annotations left by other users, and use various social features (voting, favoriting, tagging, and filtering) to see just the annotations that fit your individual reader needs. I'd like you to:

1. Create an account on the site

2. Read at least one page of the novel on the website

3. After you've done Steps 1 and 2, answer the questions in the survey I estimate this should take 6-15 minutes of your time. The payment is set low to discourage scammers (since surveys can't test for validation), but I will be giving bonuses to make your payment total \$2.50 if you complete the task and question thoughtfully and in good faith (15 minutes at \$10/hour payment rate $=\$ 2.50)$. Thanks for your help!

- [Click here to visit the site, sign up, and read one page of the book on the site.]

- Provide the username you signed up for at InfiniteUlysses.com

- Enter the code found at www.InfiniteUlysses.com/crowdflower code in this field after using the site (only accessible after you've logged in).

- Provide your CrowdFlower ID so I know who to give the bonus for completing this task in good faith.

What's your relationship to Ulysses? Never heard of it, Heard of it, Have read part of it before

Which age option describes you? 13 or younger, 14-18, 19-22, 23-29, 30s, 40s, 50s, $60 \mathrm{~s}, 70 \mathrm{~s}, 80 \mathrm{~s}, 90 \mathrm{~s}$

Which browser do you use to read on the site? Firefox, Chrome, Safari, Internet Explorer

On which device have you done most of your reading on this website? Laptop computer, Desktop computer, Tablet, Phone

On what digital devices have you read all or part of a book in the past? E-reader (e.g. Kindle, nook), Website on laptop or desktop computer, Smartphone 
What did you like about the site?

What didn't you like about the site?

Educational background (I strongly believe that getting an academic degree is only one of many ways to approach learning. Please tell me about your educational background; for example: how much school you've taken, other things you've done to learn, and how you approach reading a difficult book like Ulysses.)

Check if you're currently in school or a degree program.

Check if you're a teacher.

Knowing this site exists, are you more likely to read Ulysses at some point in the future? Yes, Maybe, No

Any other comments or questions about the site? 


\section{Appendix B: Open Beta User Survey}

1. "Starting to read Ulysses using this site..." (check any that apply)
a. took too long
b. took the right amount of time
c. it was easy to jump in and get started
d. there was too much to learn to use the site
e. there were too many instructions to wade through
f. there were not enough instructions
g. a better demo or site tour needed
h. I read some of the about pages (e.g. about the research behind this website)
i. I felt welcome on the site
j. I didn't feel encouraged to add my own annotations

2. What did you like about the site?

3. What would make the site better? Would anything need to change for you to use the site more and/or recommend it to someone else?

4. "I'd use this _ way in my reading / teaching / work"

5. Age dropdown: 17 or younger, $18-24,25-29,30 \mathrm{~s}, 40 \mathrm{~s}, 50 \mathrm{~s}, 60 \mathrm{~s}, 70 \mathrm{~s}, 80 \mathrm{~s}, 90 \mathrm{~s}$

6. Device on which read the most of site: laptop, desktop, tablet, phone

7. Browser used (if known):

8. If you're currently in school, what grade or degree program?

9. Educational background (I strongly believe that getting an academic degree is only one of many ways to approach learning. Please tell me about your educational background; for example: how much school you've taken, other things you've done to learn, and how you approach reading a difficult book like Ulysses.)

10. Had you read any of Ulysses before using this site? How much of the book and/or how many times? What were your past experience with the book like?

11. If you're leading others through Ulysses while using this site, please describe the people you're leading (grade level, general age, number of people) and how you're going about the experience. Are you a teacher (what grades?), book club leader, or something else?

12. Anything else you'd like to share with me? 


\section{Appendix C: On this dissertation's format and methodology}

My field of interest is textual scholarship, a sub-field within literary studies that concerns itself with the scholarly acts of editing and edition-making, as well as preserving literary texts; more specifically, I'm interested in digital editing, which migrates these traditional scholarly practices to the online world, opening up possibilities for new ways of reading and studying literary texts. Much of the recent activity in textual studies as a discipline has followed this path, as an examination of the program for the annual Society for Textual Scholarship conference would confirm.

The most productive and efficacious (in terms of scholarly impact) way to push the current research, reading, and teaching capabilities of the digital edition further is to actually demonstrate them in practice, through the hands-on work of designing, building, and testing a digital platform for new editing practices. In many respects, my project is not much different from the previously accepted practice of producing a scholarly edition, complete with commentary and editorial apparatus, as a dissertation. A full manifest of this dissertation's work and deliverables can be found here; the purpose of all technical work (such as creation of PHP and Javascript code) is described using non-technical language.

Justifying the format of your work is a useful thought exercise I'd recommend to every dissertator (really, to any scholar). Choose how you best think through and convey your critical thinking so that you end up with the best possible support for your scholarly argument:

- What format best supports what you're arguing?

- What format best reaches the most people who can use and build on your work? (other students, scholars, interested public)

- If you used a different format, what would be possible? What would you lose and gain? What would you learn? 


\section{Appendix D: Wireframes and Screenshots}

All wireframe (static) and prototype (interactive) screenshots can also be viewed from

this folder in the public code repository.

UlyssesUlysses.com: 2008-2009 precursor to Infinite Ulysses

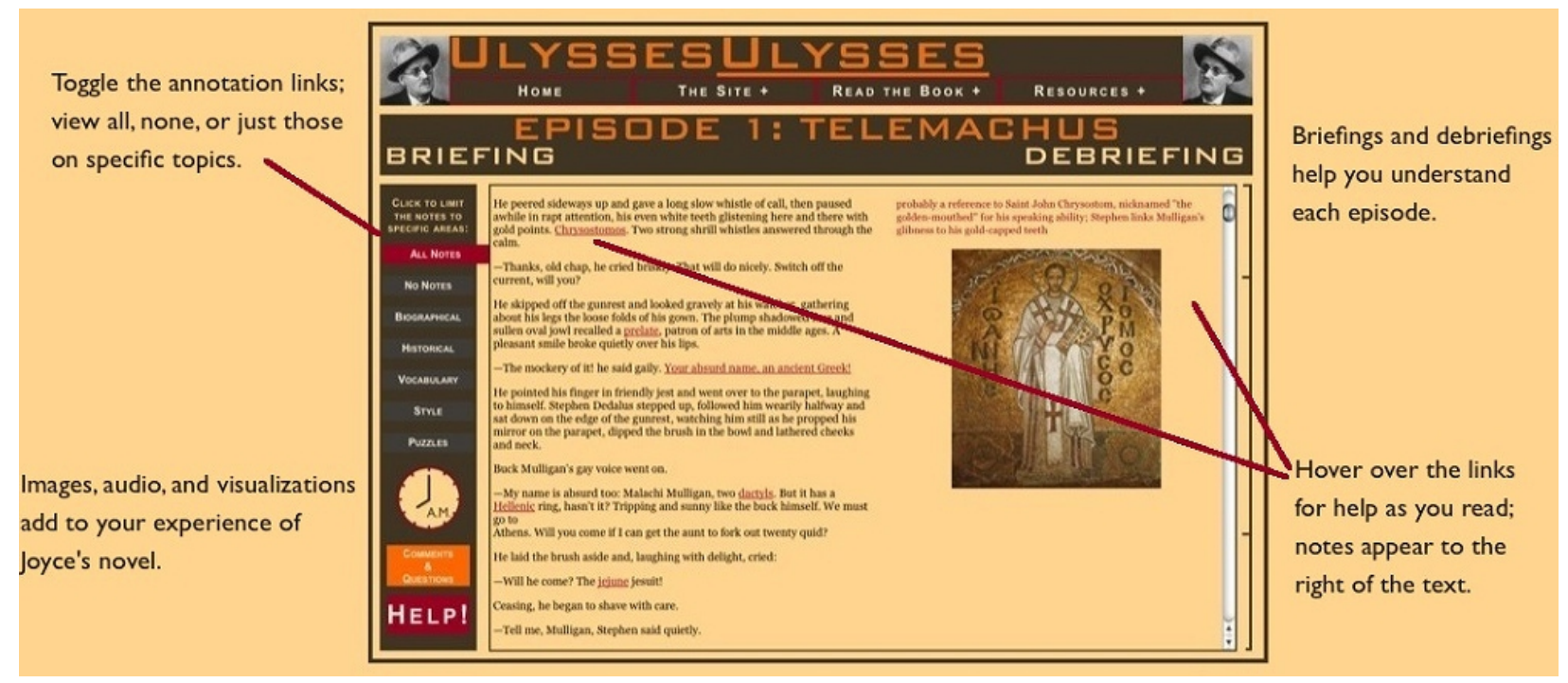


4/13/2013:

Infinite Ulysses: Reading Page

First Digital Wireframe: 4/13/2013

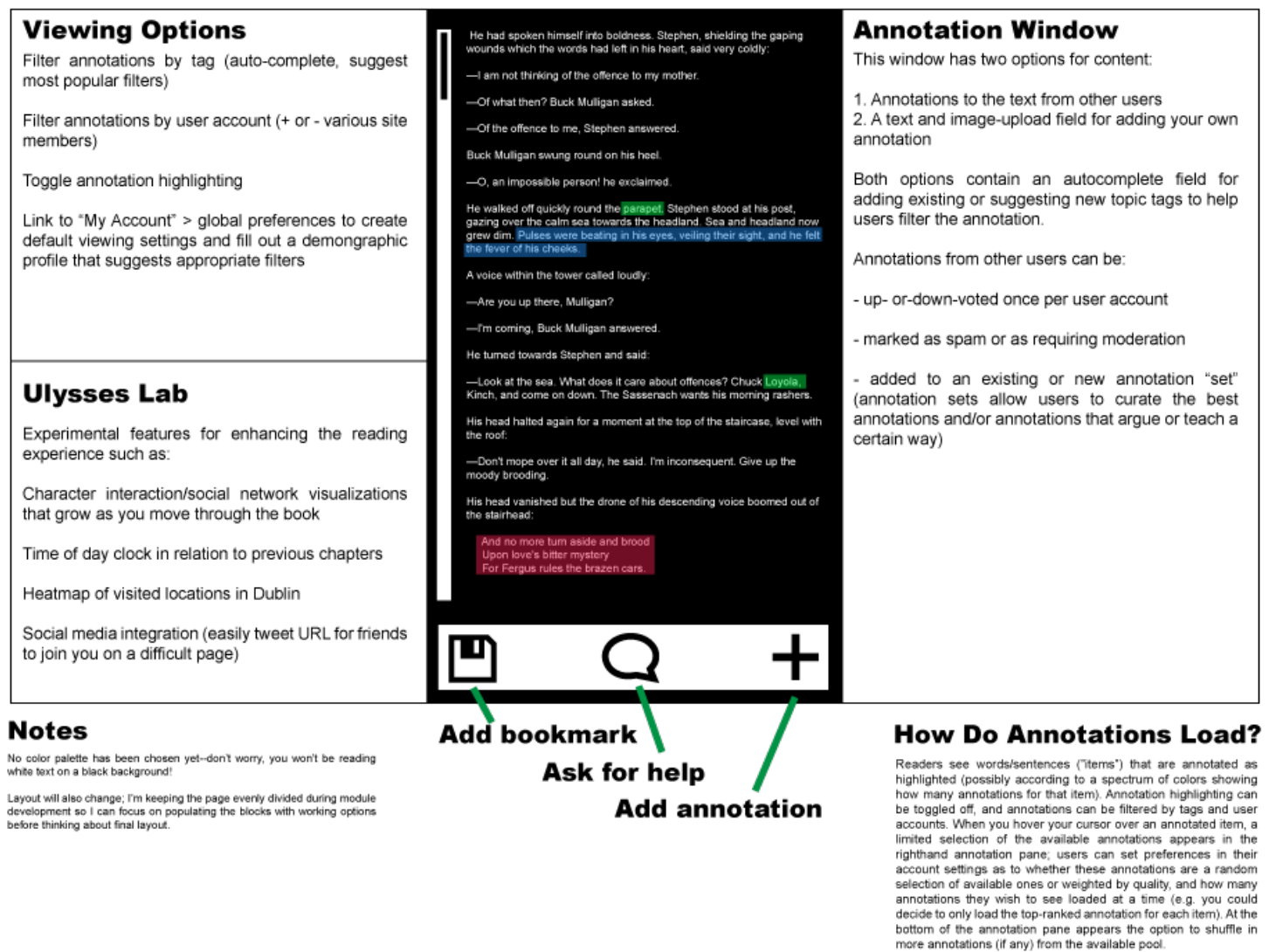


4/13/2014:

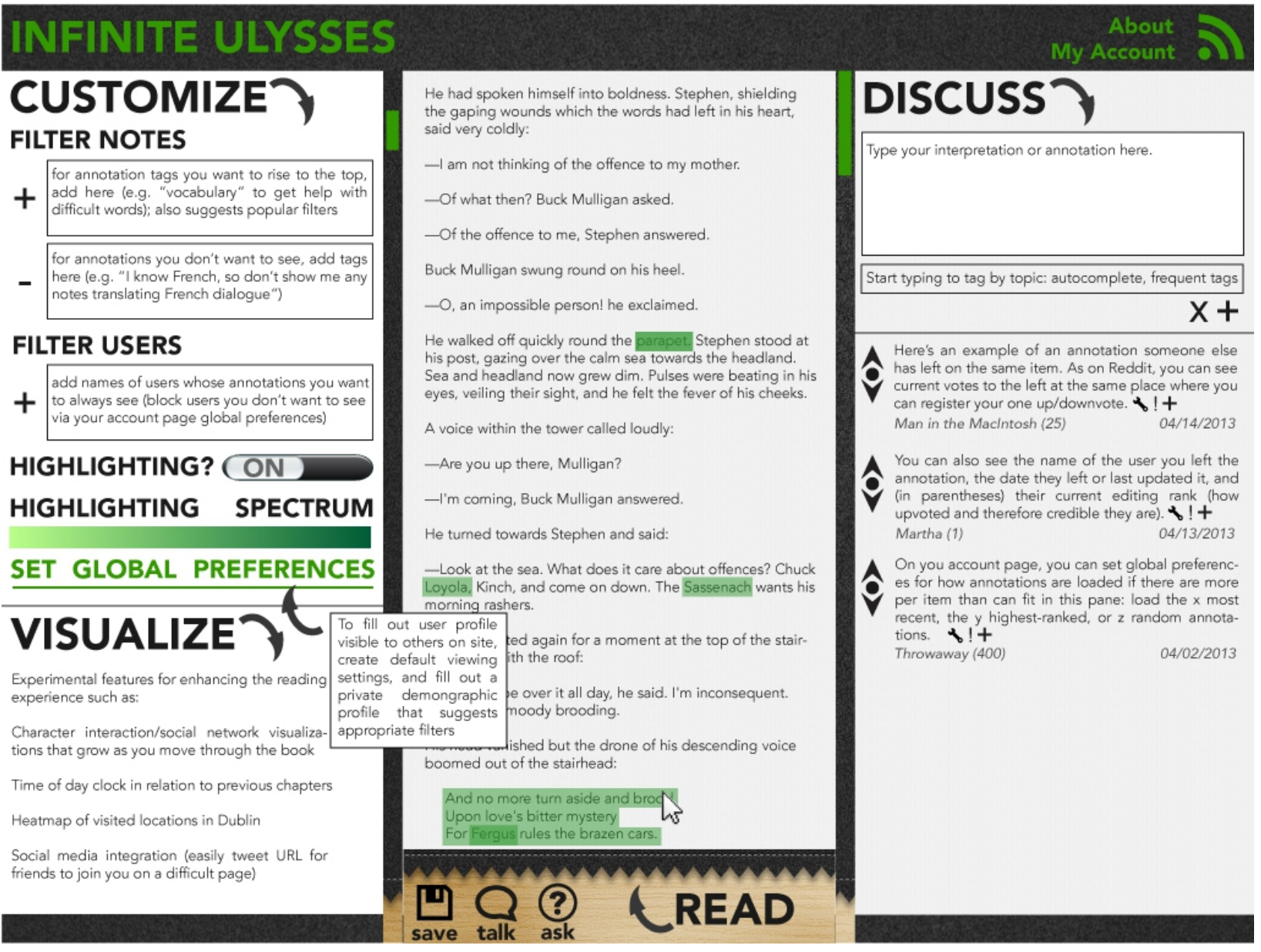

4/20/2014: 


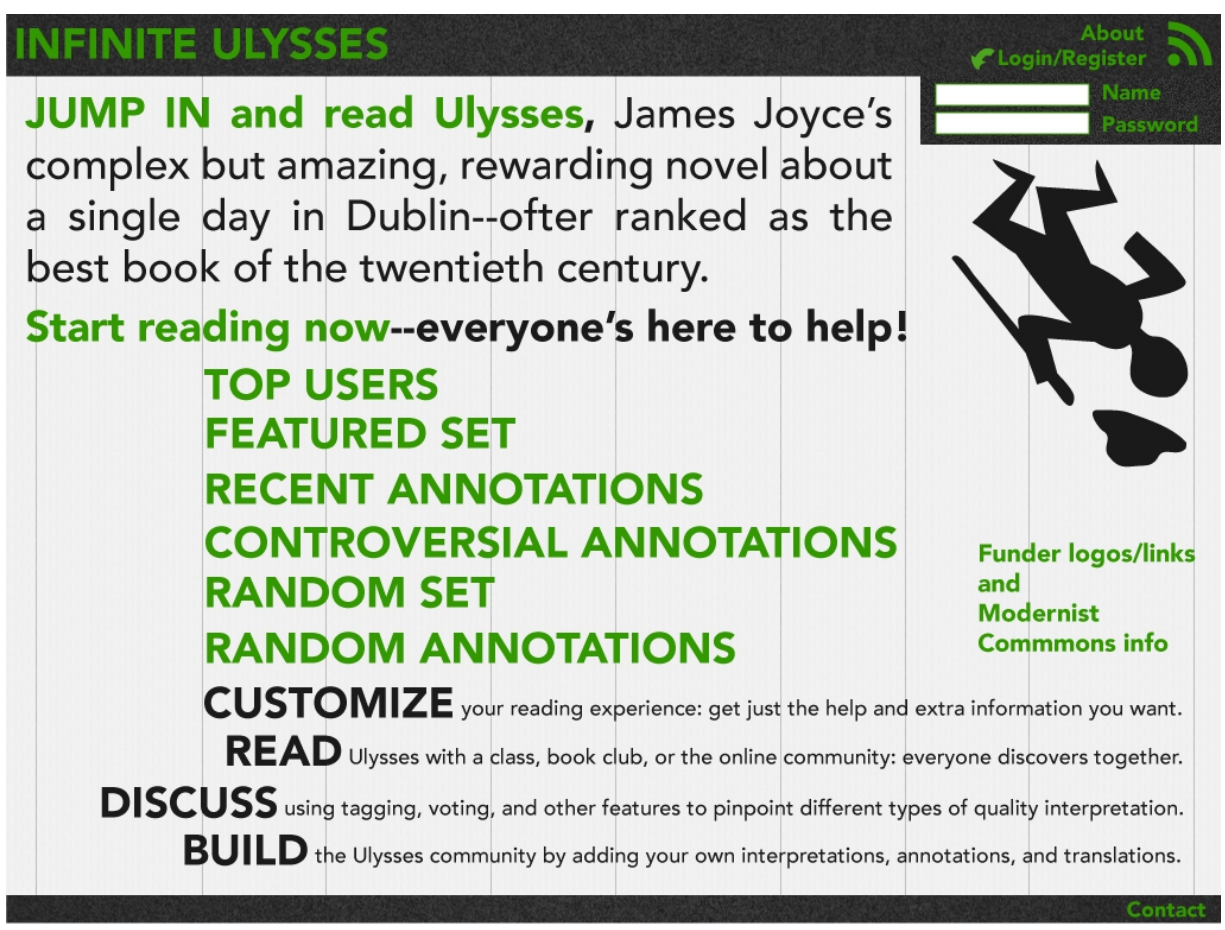

12/18/2014:

\section{\begin{tabular}{l|l|l|l|l} 
Home & Ulysses: First Page & About This Research $~$ & About This Slte & Contact
\end{tabular}}

\section{\$ Infinite Ulysses: Alpha}

\section{annotation-}

filters

\section{Customize}

Sort all annotations for this page using the drop-down, or click on a highlight to only see and sort annotations on that text.

Votes

Filter to $\mathrm{x}$ or higher points

Only show users with at least this many points from upvoted annotations and comments.

Sort by

Choose sorting: : By Amanda Visconti. December 15th, 2014, at 8:49 am

Thumbs

$50 \% \bigcirc 0 \%$

Tovr.
$<$ Ulysses

Stately, plump Buck Mulligan came from the stairhead, bearing a bowl of lather on which a mirror and a razor lay crossed. A yellow dressinggown, ungirdled, was sustained gently behind him by the mild morning air. He held the bowl aloft and intoned: - Introibo ad altare Dei.

Halted, he peered down the dark winding stairs and called up coarsely :

- Come up, Kinch. Come up, you fearful Jesuit.

Solemnly he came forward and mounted the round gunrest. He faced about and blessed gravely thrice the tower, the surrounding country and the awaking mountains. Then, catching sight of Stephen Dedalus, he bent towards him and made rapid crosses in the air, gargling in his throat and shaking his head. Stephen Dedalus, displeased and sleepy, leaned his arms on the top of the staircase and looke coldly at the shaking gurgling face that blessed him, equine in its length, and at the light untonsured hair, grained and hued like pale oak. Buck Mulligan peeped an instant under the mirror and then covered the bowl smartly.

- Back to barracks, he said sternly.

He added in a preacher's tone:

- For this, O dearly beloved, is the genuine Christine: body and soul and blood and ouns. Slow music, please. Shut your eyes, gents. One moment. A little trouble about those white corpuscles. Silence, all.

He peered sideways up and gave a long low whistle of call then paused awhile in rapt attention, his even white teeth glistening here and there with gold points. Chrysostomos. Two strong shrill whistles answered through the calm.

- Thanks, old chap, he cried briskly. That will do nicely. Switch off the current, will you?

$\leq$ Ulysse

Comments 


\section{Come read Ulysses with us!}

We welcome readers of every background to join our conversation. Whether you're a first-time reader, enthusiast, a teacher, student, scholar, book club member, or bring another viewpoint to our community, we value your thoughts and invite you to contribute your comments, interpretations, questions, and answers to the novel.

\section{Your custom Ulysses}

Customize the annotations you'll see to your interests. Current top tags on annotations:

\section{spoiler religion what style test}

\section{Join $3+$ readers of Ulysses!}

( 3 readers used this site in the past 24 hours)

Today's most popular pages of Ulysses: 3533323130

\section{Start reading now}

Tour features

\section{Recent activity}

Amanda Visconti commented on the excerpt "Kinch": A nickname Amanda Visconti commented on the excerpt " $\mathrm{S}$ ": Ulysses is divided into three sections, and the first letter of each appears in large type in later printings (though not the first printing, from which this text is taken). The first three episodes (focusing on Stephen Dedalus) begin with S, the section encompassing the bulk of the novel (focusing on Leopold Bloom) begins with $M$, and the last section (three episodes which follow Stephen and Leopold and then relate a monologue by Molly Bloom) begins with P. "SMP" supposedly refers to the first initials of the three main characters: Stephen Dedalus, Molly Bloom, and Poldy (Molly's pet name for Leopold) Bloom.

Amanda Visconti commented on the excerpt "Kinch": Mulligan's nickname for Stephen, who he describes as a "knife-blade" (the OED defines a kinch as a type of knot and I've never been able to find the word defined as a knife, but for the purposes of the novel it makes the most sense to go with Mulligan's definition). This nickname, which alludes to the sharpness of Stephen's intellect, is used somewhat patronizingly-Mulligan recognizes that Stephen has greater intellectual powers than him and is passively-aggressively jealous, but is also aware that Stephen does not use his mind to as great a social advantage as Mulligan does.

Amanda Visconti commented on the excerpt "Jesuit": A Catholic order that organized many schools in Ireland. The Jesuits were characterized as skilled equivocators, using craftiness to answer unanswerable religious questions and also protecting the order during the time it was suppressed by the Pope. Stephen has been taught by Jesuits; Mulligan fears his subtle intellect, which often allows him to provide answers through roundabout logic (see his discussion of Hamlet, mentioned later in this episode and explored more fully in the episode Scylla and Charybdis).

1/20/2015:

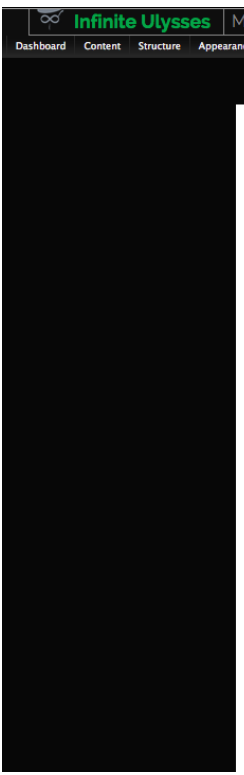

\section{Customize}

Navigate:.+

Filter by:

Annotation Filter by Annotation.-.

User Filter by User_.

Tag Filter by Tag_-

Only show annotations with at least this many votes or

Votes

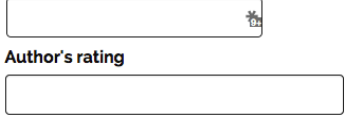

Sort all annotations for this page using the drop-down or click on a highlight to only see/sort annotations on the highlighted

Sort by

Choose sorting: $\rightarrow$
$<$ Telemachus

\section{4>}

Stately, plump Buck Mulligan came from the stairhead, bearing a bowl of lather on which a mirror and a razor lay crossed. A yellow dressinggown, ungirdled, was sustained gently behind him by the mild morning air. He held the bowl aloft and intoned:

- Introibo ad altare Dei.

Halted, he peered down the dark winding stairs and called up coarsely :

- Come up, Kinch. Come up, you fearful Jesuit.

Solemnly he came forward and mounted the round gunrest. He faced about and blessed gravely thrice the tower, the surrounding country and the awakin mountains. Then, catching sight of Stephen Dedalus, he bent towards him and made rapid croses in the air, aroling in his throat and shaking his head. Stephen made rapid crosses in the ar, gargling in his throat and shaking his head. Steph ling looked coldly at the shaking gurgling face that blessed him, equine in its length, and at the light untonsured hair, grained and hued like pale oak.

Buck Mulligan peeped an instant under the mirror and then covered the bowl smartly.

- Back to barracks, he said sternly.

He added in a preacher's tone:

- For this, $\mathrm{O}$ dearly beloved, is the genuine Christine: body and soul and blood and ouns. Slow music, please. Shut your eyes, gents. One moment. A little trouble about those white corpuscles. Silence, all.

He peered sideways up and gave a long low whistle of call then paused awhile

1/26/2015: 


\section{$<$ Telemachus}

Stately, plump Buck Mulligan came from the stairhead, bearing a bowl of lather on which a mirror and a razor lay crossed. A yellow dressinggown, ungirdled, was sustained gently behind him by the mild morning air. He held the bowl aloft and intoned:

- Introibo ad altare Dei

Halted, he peered down the dark winding stairs and called up coarsely :

- Come up, Kinch. Come up, you fearful Jesuit.

Solemnly he came forward and mounted the round gunrest. He faced about and blessed gravely thrice the tower, the surrounding country and the

awaking mountains. Then, catching sight of Stephen Dedalus, he bent towards him and made rapid crosses in the air, gargling in his throat and shaking his head. Stephen Dedalus, displeased and sleepy, leaned his arms on the top of the staircase and looked coldly at the shaking gurgling face that blessed him, equine in its length, and at the light untonsured hair, grained and hued like pale oak.

Buck Mulligan peeped an instant under the mirror and then covered the bowl smartly.

- Back to barracks, he said sternly.

He added in a preacher's tone:

- For this, O dearly beloved, is the genuine Christine: body and soul and blood and ouns. Slow music, please. Shut your eyes, gents. One moment. A little trouble about those white corpuscles. Silence, all.

He peered sideways up and gave a long low whistle of call then paused awhile in rapt attention, his even white teeth glistening here and there with gold points. Chrysostomos. Two strong shrill whistles answered through the calm.

- Thanks, old chap, he cried briskly. That will do nicely. Switch off the current. will vou?

$<$ Telemachus

\section{- Customize}

Filter highlights:

Annotation Filter by Annotation...

\begin{tabular}{l|l|}
\hline User & Filter by User___ \\
\hline Tag & Filter by Tag..__ _ourt by
\end{tabular}

sort by

- Prioritize

Choose sorti
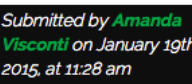

\section{6}

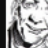

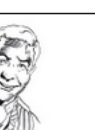

$50 \% \quad 50 \%$

Quote: Introibo ad altare De

Text: A line spoken by a priest during a Latin Catholic mass. meaning "I will go to the altar of God:

language Latin

(-) language Latin

2/3/2015: 


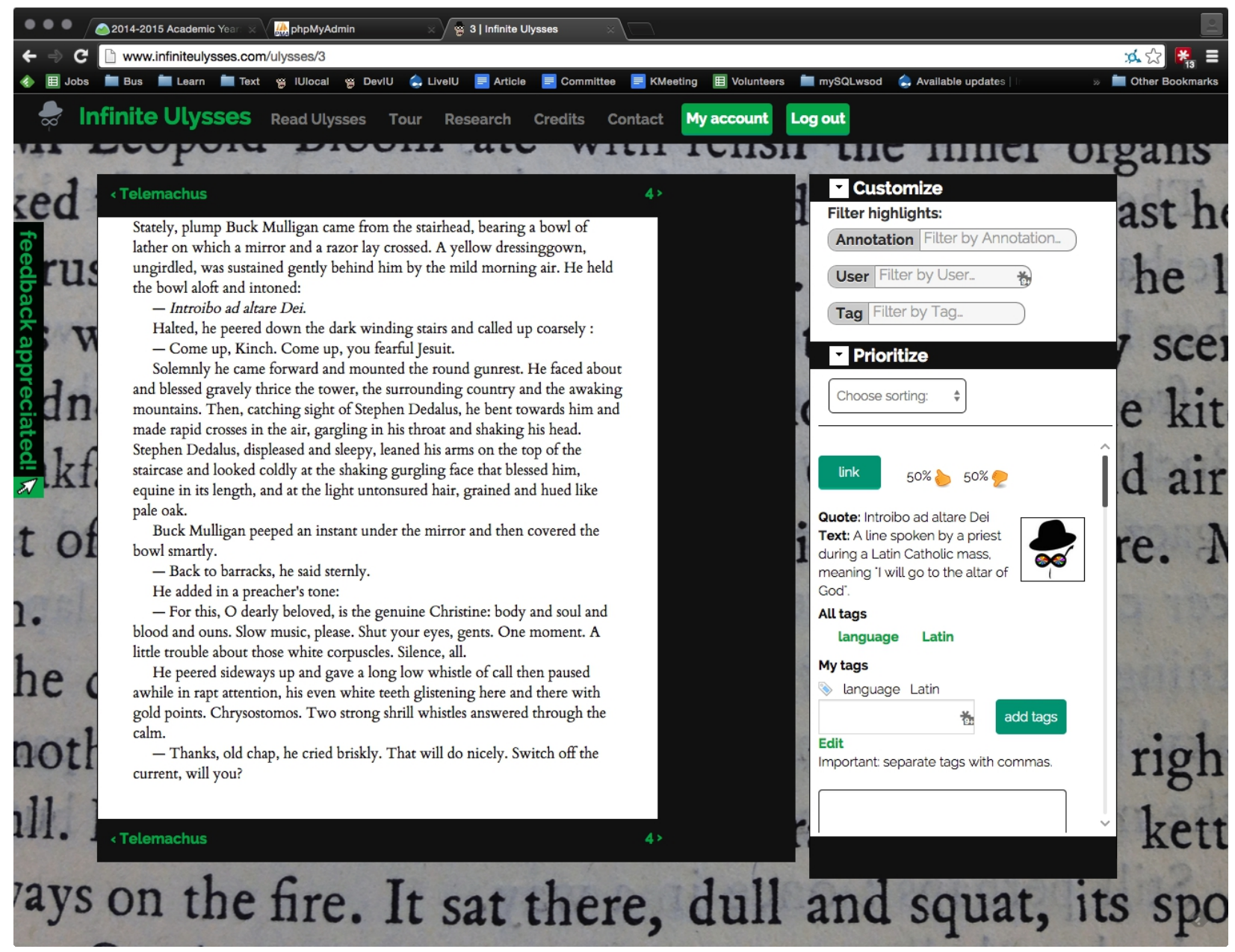


2/4/2015:

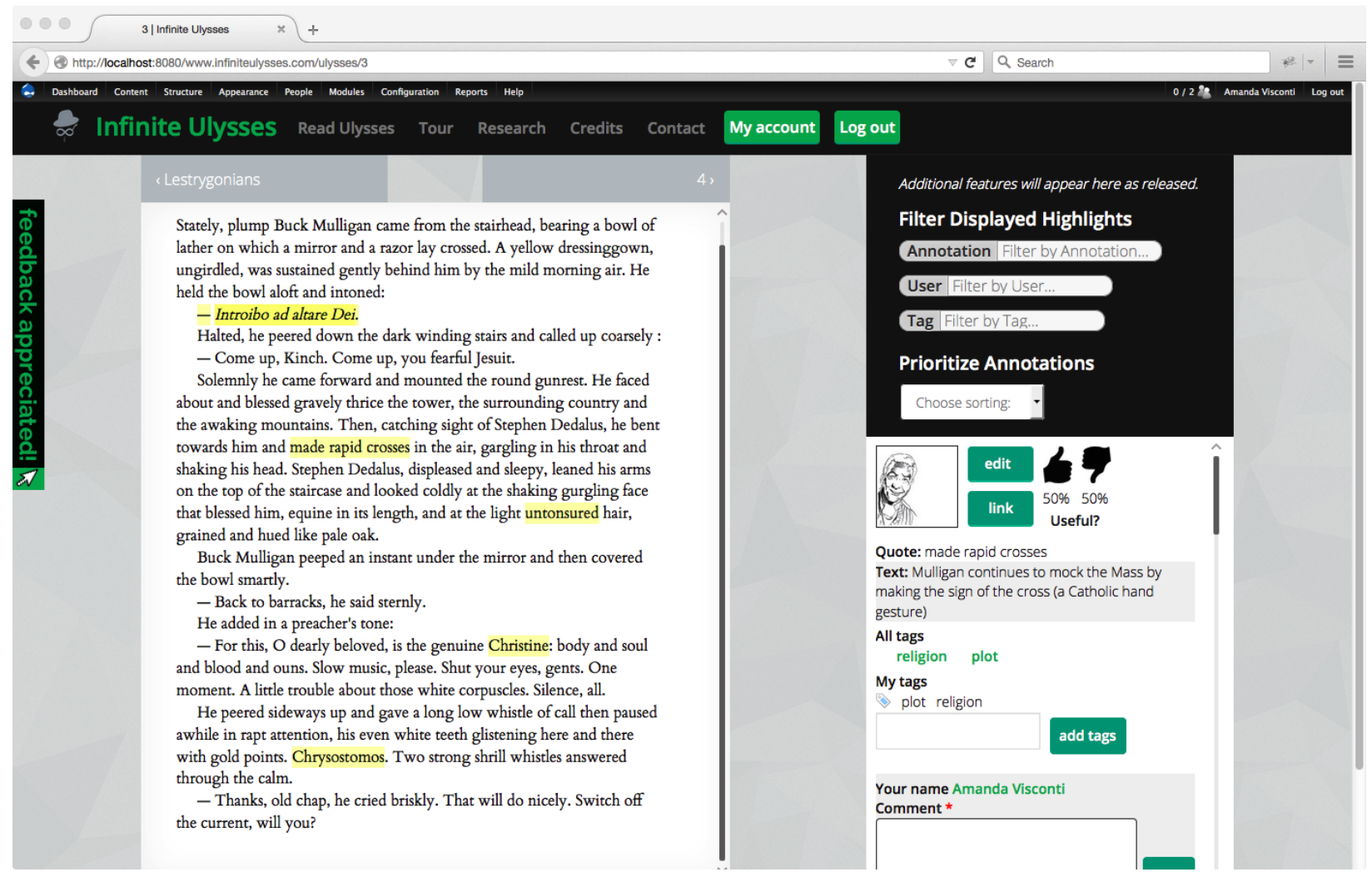


2/9/2015:

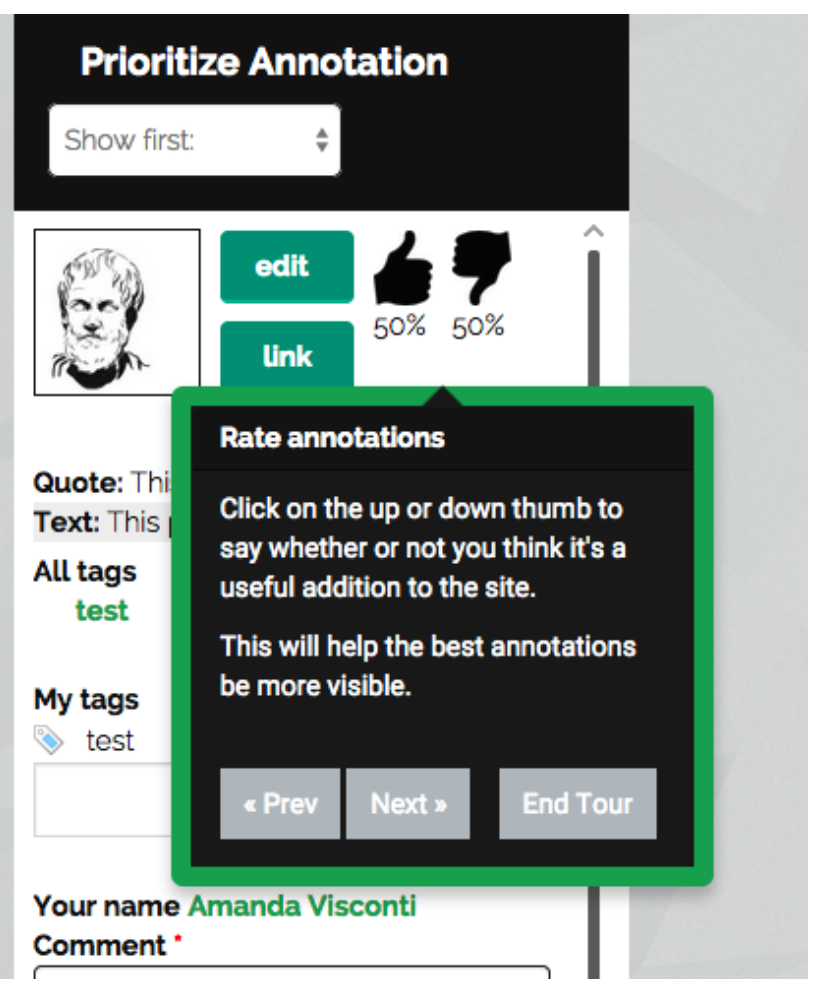

2/16/2015: 


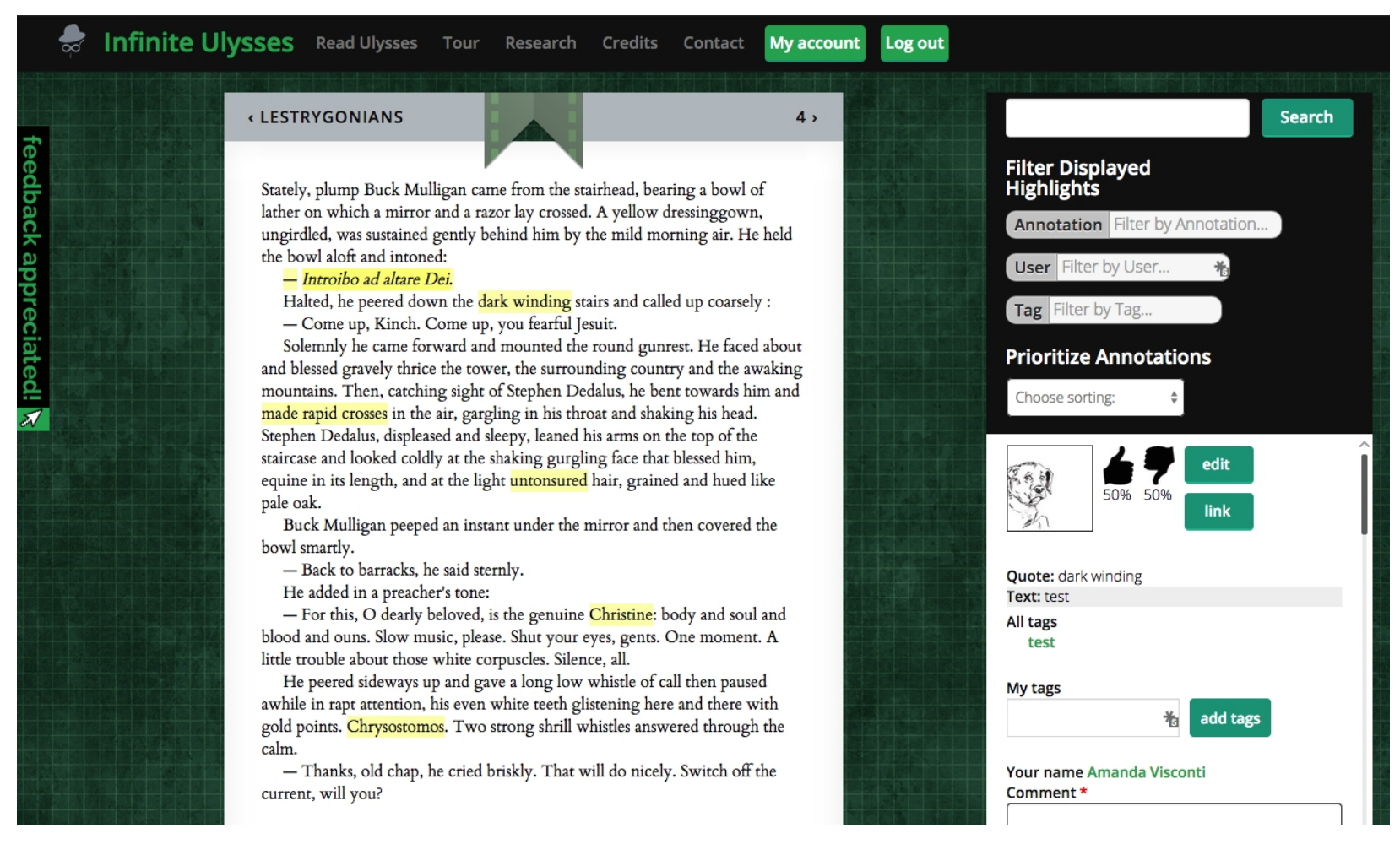

2/23/2015: 


\section{Infinite Ulysses Read Ulysses Tour Research Credits Contact Myaccount Log out}

\section{$<$ Telemachus}
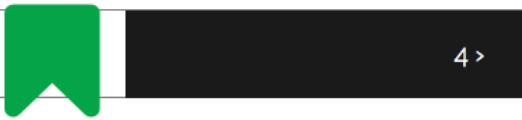

Stately, plump Buck Mulligan came from the stairhead, bearing a bowl of lather on which a mirror and a razor lay crossed. A yellow dressinggown, ungirdled, was sustained gently behind him by the mild morning air. He held the bowl aloft and intoned:

- Introibo ad altare Dei.

Halted, he peered down the dark winding stairs and called up coarsely :

- Come up, Kinch. Come up, you fearful Jesuit.

Solemnly he came forward and mounted the round gunrest. He faced about and blessed gravely thrice the tower, the surrounding country and the awaking mountains. Then, catching sight of Stephen Dedalus, he bent towards him and made rapid crosses in the air, gargling in his throat and shaking his head. Stephen Dedalus, displeased and sleepy, leaned his arms on the top of the staircase and looked coldly at the shaking gurgling face that blessed him, equine in its length, and at the light untonsured hair, grained and hued like pale oak.

Buck Mulligan peeped an instant under the mirror and then covered the bowl smartly.

- Back to barracks, he said sternly.

He added in a preacher's tone:

- For this, $\mathrm{O}$ dearly beloved, is the genuine Christine: body and soul and blood and ouns. Slow music, please. Shut your eyes, gents. One moment. A little trouble about those white corpuscles. Silence, all.

He peered sideways up and gave a long low whistle of call then paused awhile in rapt attention, his even white teeth glistening here and there with gold points. Chrysostomos. Two strong shrill whistles answered through the calm.

- Thanks, old chap, he cried briskly. That will do nicely. Switch off the current, will you?
Filter Displayed Highlights

\begin{tabular}{|c|c|c|}
\hline Annotation & Filter & \\
\hline User & Man & 5(3) \\
\hline Tag & test & (x) \\
\hline Sort by & & \\
\hline Top-Rated & & $\checkmark$ \\
\hline
\end{tabular}

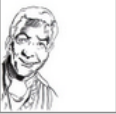

Annotation by: Amanda Visconti Date: January 29, 2015

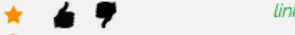

(c) $100 \% 0 \%$

Quote: Introibo ad altare Dei

Text: A line spoken by a priest during a Latin Catholic mass, meaning "I will go to the altar of God:

All tags language Latin

My tags

\section{add tags}

Your name Man in the Macintosh Comment 
3/7/2015:

\section{Come read Ulysses with us!}

We welcome readers of every background.

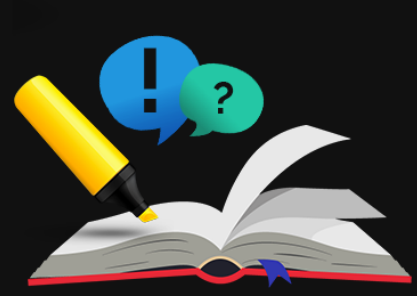

Highlight parts of the book and add your comments \& questions.

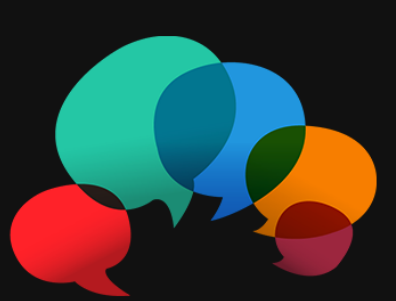

Read interpretations \& help left by other readers.

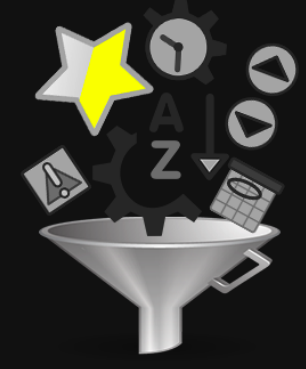

Customize the annotations you see to just the ones you need!
The Infinite Ulysses research project
A reading community

Join our 91 members in creating a site account for the best reading experience!

Where are people reading?

Today, the most popular pages in the book were 